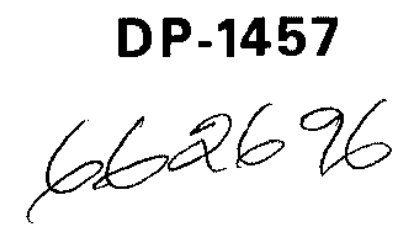

\title{
AUTOMATED ABSOLUTE ACTIVATION ANALYSIS WITH CALIFORNIUM-252 SOURCES
}

K. W. MacMURDO and W. W. BOWMAN

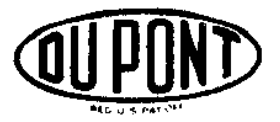

SAVANNAH RIVER LABORATORY AIKEN, SOUTH CAROLINA 29801 
This report was prepared as an account of work sponsored by the United States Government. Neither the United States nor the United States Department of Energy, nor any of their contractors, subcontractors, or their employees, makes any warranty, express or implied or assumes any legal lizbility or responsibility for the accuracy, completeness or usefulness of any information, apparatus, product or process disclosed, or represents that its use would not infringe privately owned rights.

Printed in the United States of America

Available from

National Technical Information Service

U.S. Department of Commerce

5285 Port Royal Road

Springfield, Virginis 22161

Price: Printed Copy \$6.00; Microfiche $\$ 3.00$ 


\section{AUTOMATED ABSOLUTE ACTIVATION ANALYSIS WITH CALIFORNIUM-252 SOURCES}

K. W. MacMURDO and W. W. BOWMAN

Approved by

E. I. Baucom, Research Manager

Analytical Chemistry Division

Publication Date: September 1978

\section{E. I. DU PONT DE NEMOURS AND COMPANY SAVANNAH RIVER LABORATORY AIKEN, SOUTH CAROLINA 29801}

PAEPARED FOR THE U. S. DEPARTMENT DF ENERGY UNDER CONTRACT AT(07-2)-1 


\section{ABSTRACT}

A $100-m g{ }^{252} \mathrm{Cf}$ neutron activation analysis facility is used routinely at the Savannah River Laboratory for multielement analysis of many solid and liquid samples. Applications include analysis of metal alloys, coal, fly ash, sediments, rocks, vegetation, inks, and many aqueous process solutions.

An absolute analysis technique converts counting data directly to elemental concentration without the use of classical comparative standards and flux monitors. This absolute technique predicts elemental neutron capture reaction rates from multienergy 2- and 84-group cross sections and calculated neutron fluxes for different source-moderator-sample arrangements.

With the totally automated pneumatic sample transfer system, cyclic irradiation-decay-count regimes can be pre-selected for up to 40 samples, and samples can be analyzed with the facility unattended. An automatic data control system starts and stops a high-resolution gamma-ray spectrometer and/or a delayed-neutron detector; the system also stores data and controls output modes.

Gamma ray data are reduced by three main programs in the IBM 360/195 computer. In the first program, the 4096-channel spectrum and pertinent experimental timing, counting, and sample data are stored on magnetic tape. In the second program, the spectrum is then reduced to a list of significant photopeak energies, integrated areas, and their associated statistical errors. The third program assigns gamma ray photopeaks to the appropriate neutron activation product(s) by comparing photopeak energies to tabulated gamma ray energies. Photopeak areas are then converted to elemental concentration by using experimental timing and sample data, calculated elemental neutron capture rates, absolute detector efficiencies, and absolute spectroscopic decay data.

Calculational procedures have been developed so that fissile material such as 1 ight water reactor plutonium and natural uranium can be analyzed by cyclic neutron activation and delayed-neutron counting procedures. These calculations are based on a 6 halflife group model of delayed neutron emission; calculations include corrections for delayed neutron interference from ${ }^{17} 0$. Detection sensitivities of $\leq 400 \mathrm{ppb}$ for natural uranium and $8 \mathrm{ppb}$ $[\leq 0.5(\mathrm{nCi} / \mathrm{g})]$ for ${ }^{239} \mathrm{Pu}$ were demonstrated with $15-\mathrm{g}$ samples at a throughput of up to 140 per day. 
Over 40 elements can be detected at the sub-ppm level in the 100 -mg ${ }^{252} \mathrm{Cf}$ facility. Precisions and accuracies of $\pm 10 \%$ for most elements were demonstrated in extensive multielement analyses of standards which include rock standards from the U.S. Geologic Survey, and coal and f1y ash standards from the Nationa1 Bureau of Standards. 


\section{CONTENTS}

Introduction 13

Description of Facility 17

Irradiation Tank Room 17

Counting Room 26

Rapid Sample Transport System 32

Detection Apparatus 37

Gamma Ray Detectors 37

Ge(Li) Detectors 37

NaI Detectors 39

Delayed Neutron Detector 39

Sample Preparation Facilities and Procedures 39

Basic Principles of ${ }^{252} \mathrm{Cf}$ Neutron Activation Analysis 41

Absolute Activation Analysis 41

Cyclic Activation and Counting 42

Cyclic Sensitivities 44

Master Equation 46

Specific Neutron Capture Reaction Rates 47

Multigroup (84-group) Summation 48

Analytical Function Approximations (2 Groups) 49

Neutron Flux Calculations 51

$17-\mathrm{mg}{ }^{252} \mathrm{Cf}$ Facility 51

ANISN Calculations 51

Comparison of Calculated and Experimental

Reaction Rates 58

100 -mg ${ }^{252}$ Cf Facility 59

ANISN Calculations 60

Comparison of Calculated and Measured Fluxes 72

Evaluation of the $\mathrm{H}_{2} \mathrm{O}-\mathrm{D}_{2} \mathrm{O}$ System 73 
Optimized Fissile Material Analysis with Cyclic Neutron Activation and Delayed Neutron Counting 74

Delayed Neutron Analysis 74

Optimization of Cyclic Analysis Procedures for Fissile Materials 75

Effect of Transit Time on Detector Response 78

Optimization Parameters 78

Comparison of Calculated and Measured Detector

Responses 84

Oxygen-17 Interference in Analysis of Low-Leve1

Aqueous Samples 85

Computer Data Processing 88

TRANSCRIBE 89

RAGS 89

SIFTER 89

EDIT Data Files 91

SIFTER Flow Diagram 91

Interpretation of SIFTER Output 94

Analysis of Test Mixture 96

Results and Applications 98

Solid Standards 98

Standard Coal (NBS Standard SRM-1632) 98

Standard Fly Ash (NBS Sample SRM-1633) 98

Rock Standards (USGS Samples GSP-1 and BCR-1) 101

Liquid Standards 101

Elemental Detection Limits 101

Summary of Routine Analyses 104

Appendix A: Data Reduction Tables 109

Appendix B: Calculation of Flux Depression Factors 111

Thermal Flux Depression 111

Resonance Flux Depression 112

References 115 
1 Timers in the Functional Control Unit 35

2 Sensitivity of Cyc1ic Activation with $17 \mathrm{mg}{ }^{252} \mathrm{Cf}$ Source 45

3 Calculated and Measured Neutron Capture Rates for the $17-\mathrm{mg}{ }^{252} \mathrm{Cf}$ Facility 58

4 Flux Ca1culations for Ideal Systems 66 5 Regions, Distances, and Materials in the 100-mg
${ }_{252}$ Cf Facility 66

6 F1ux Calculations that Include Effects of Stainless Stee1 70

7 Calculated Specific Fission Rates in the ${ }^{252} \mathrm{Cf}$ Facility 76

8 Delayed-Neutron Group Half-Lives and Yields for Therma1 Fission of ${ }^{23}{ }^{3} \mathrm{U},{ }^{235} \mathrm{U},{ }^{239} \mathrm{Pu}$, and ${ }^{241} \mathrm{Pu} 76$

9 Delayed-Neutron Group Half-Lives and Yields for Fast Neutron Fission of ${ }^{238} \mathrm{U}$ and ${ }^{240} \mathrm{Pu} 76$

10 Specific Saturated Delayed-Neutron Emission Rates Calculated for Fissile Isotopes 77

11 Changes in Calculated Detector-Response with Changes in Sample Transit Time for the Optimum Number of Cycles for Natural Uranium 82

12 Optimum Experimenta1 Conditions for Cyclic Analysis of Natural Uranium 83

13 Optimum Experimental Conditions for Cyclic Analysis of Common Fissile Materials 83

14 Delayed-Neutron Signa1-to-Noise Ratios for Cyclic Analysis of Natural Uranium in Aqueous Solution 87

15 Coding Format for Header Records 90

16 Analysis of Test Mixture 97 
17 Analysis of NBS Coal Standard SRM-1632 99

18 Analysis of NBS Fly Ash Standard SRM-1633 100

19 Analysis of USGS Rock Standard GSP-1 102

20 Analysis of USGS Rock Standard BCR-1 103

21 Absolute Ana1ysis of Atomic Absorption Liquid Standards 104

22 Interference-Free Elemental Detection Limits of the $100-\mathrm{mg}{ }^{252} \mathrm{Cf}$ Facility 105

23 Elemental Concentration Ranges Measured in Typical Samples 107 
$1 \quad{ }^{252}$ Cf Neutron Activation Analysis Facility 17

2 Source Tank 18

3 Primary Capsule for ${ }^{252} \mathrm{Cf}$ Source (Series SR-Cf-IX) 19

4 Secondary Capsule for ${ }^{252} \mathrm{Cf}$ Source (Series SR-Cf-100) 20

5 Typical Secondary Capsule for ${ }^{252} \mathrm{Cf}$ Source (Series 100) 21

6 Irradiation Tank Assembly 22

7 Neutron Activation Analysis Facility with ${ }^{252} \mathrm{Cf}$ Sources in Position 23

8 Annular Moderator Tank and Four-Position Source Holder 24

9 Polyethylene Sample Transfer Tubes 25

$10 \quad$ Filter Deionizer System 27

11 Sample Transfer Equipment 28

12 Sample Irradiation Container 28

$13 \quad$ Sample Sealer 29

14 Data Storage Facility 30

15 Shielded Dua1 Gamma-Ray/Delayed Neutron Detector 31

16 Schematic of Rabbit System 33

17 Sample Transport Contro1 Unit 34

18 Relative Detector Response for Cyclic Activation of Scandium 45

19 Neutron Energy Spectra at $3.81 \mathrm{~cm}$ and $10.61 \mathrm{~cm}$ as Calculated by ANISN 53

20 Change in Thermal Flux with Distance from Source 53 
21 Change in Epithermal Flux with Distance from Source 54

22 Epithermal-to-Thermal Flux Ratio with Distance from Source $\quad 54$

23 Change in Thermal Flux with Distance from Source to Centers of $\mathrm{H}_{2} \mathrm{O}, \mathrm{D}_{2} \mathrm{O}$, and Air Moderated Central Regions 55

24 Change in Epithermal-to-Thermal F1ux Ratio with Distance from Source to Centers of $\mathrm{H}_{2} \mathrm{O}, \mathrm{D}_{2} \mathrm{O}$, and Air Moderated Central Regions 56

25 Changes in Calculated and Measured Thermal Fluxes with Distance from Source 57

26 Arrangement of Irradiation Tubes and Sources in $100-\mathrm{mg}{ }^{252}$ Cf Facility 60

27 Calculated Therma1 Flux for Ideal System with $\mathrm{H}_{2} \mathrm{O}$ Moderator (Case 1) 62

28 Calculated Thermal Flux for Ideal System with $\mathrm{H}_{2} \mathrm{O}-\mathrm{D}_{2} \mathrm{O}$ Moderator (Case 2) 63

29 Calculated Thermal Flux for Ideal Case, $\mathrm{H}_{2} \mathrm{O}-\mathrm{D}_{2} \mathrm{O}$ Moderator with Sample in Outer Ring (Case 3) 64

30 Thermal F1ux Ratio for Ideal System (Case 2/Case 1) 65

31 Thermal Flux Ratio for Idea1 System (Case 3/Case 1) 65

32 Schematic of Regions Surrounding ${ }^{252} \mathrm{Cf}$ Sources Used in ANISN Calculations 67

33 Calculated Thermal Flux for Inner Ring in NonIdeal System with $\mathrm{H}_{2} \mathrm{O}$ Moderator (Case 4) 68

34 Calculated Thermal Flux for Inner Ring in Non-Ideal System with $\mathrm{H}_{2} \mathrm{O}-\mathrm{D}_{2} \mathrm{O}$ Moderator (Case 5) 69

35 Calculated Therma1 Flux Ratio for Inner Ring in Non-Ideal System with $\mathrm{H}_{2} \mathrm{O}-\mathrm{D}_{2} \mathrm{O}$ Moderator (Case 5/Case 4) 69

36 Calculated Thermal Flux for Outer Ring in Non-Ideal System with $\mathrm{H}_{2} \mathrm{O}$ Moderator (Case 6) 70

37 Calculated Thermal Flux for Outer Ring in Non-Ideal System with $\mathrm{H}_{2} \mathrm{O}-\mathrm{D}_{2} \mathrm{O}$ Moderator (Case 7) 71 
38 Calculated Therma1 Flux Ratio in Outer Ring in NonIdeal System with $\mathrm{H}_{2} \mathrm{O}$ Moderator (Case 7/Case 6) 72

39 Calculated Group Response and Detector Response for Natural Uranium for Transit Time of $0.25 \mathrm{sec} 79$

40 Calculated Group Response and Detector Response for Natural Uranium for Transit Time of $1.0 \mathrm{sec} 80$

41 Effect of Sample Transit Time on Detector Response for Natura1 Uranium 81

42 Relative Detector Response for Fissile Isotopes 84

43 Comparison of Calculated and Measured Detector Responses for Cyclic Analysis of ${ }^{235} \mathrm{U} \quad 85$

44 Calculated Detector Response for Aqueous Samples Containing $10 \mathrm{ppm}$ Natural Uranium 86

45 Data Reduction Flowsheet 90

46 SIFTER Program Flowsheet 92 


\section{INTRODUCTION}

The usefulness of neutron activation analysis (NAA) as a multielement analytical tool has been demonstrated over the past thirty years. During 1950-1970, many publications described successful use of NAA in the trace analysis of samples for geology, biology, archeology, chemistry, and criminology application. For multielement activation analysis, either complete exhaustive chemical separation and counting of products or some type of gamma ray spectroscopy is used. With the earliest spectroscopic technique of gamma ray absorption, resolution was extremely poor. In 1948, Hofstader ${ }^{1}$ pioneered the development of NaI (T1) scintillation crystals; this development opened a new dimension in gamma ray spectrometxy. Further improvements in the early 1960's included Ge(Li) detectors which made highresolution gamma ray spectrometry possible. ${ }^{2}$ With $\mathrm{NaI}$ detectors and early Ge(Li) detectors, energy resolution was very poor compared to today's standards, and elements were separated by chemical group before counting. By the early 1970's, the technique of NAA, once regarded as the ultimate method of trace analysis, was in a recognized decline. ${ }^{3}$ This decline was caused by development of better instrumental techniques and by a limited understanding of basic NAA principles. The users of activation analysis assumed that NAA was basically a chemical technique, and therefore its development was hindered because advances in the basic physics of the technique were ignored. Neutron activation analysis is a nuclear technique, not a chemical technique. In fact, the most serious limitation has been the low sample throughput of NAA because chemical separations were required.

The basic physical principles of NAA, though understood for 30 years, have been used mainly for teaching purposes and have not been incorporated into routine analytical procedures. Most activation analysts use the standard comparative technique basic to all analysis techniques. In these techniques, a standard of almost identical matrix and similar trace constituents is analyzed simultaneously with the sample. The comparative technique requires estimates of sample composition, preparation, packaging, irradiation, and counting of both samples and standards; sample throughput is necessarily reduced. With the standard comparative technique, the analysis procedure is reduced to a determination of counting ratios because the following basic factors are eliminated: 
- Uncertainties in radioactive decay parameters such as halflife and absolute decay abundance.

- Variations in effective element response to the particular irradiation conditions and sample matrix.

- Changes in neutron flux and energy distribution which accompany changes in reactor power level and fuel burnup.

In recent years, major advances have been made by nuclear chemists and physicists in the measurement of multigroup cross sections and in the development of neutron shielding and neutron transport codes used to calculate isotope production in reactors. Significant advances have been made in the measurement of spectroscopic decay data and in the determination of decay schemes for most isotopes. Because of improvements in the efficiency and resolution of $\mathrm{Ge}(\mathrm{Li})$ detectors and associated electronics, separations can be done electronically rather than chemically.

The sensitivity and multielement capabilities of neutron activation analysis made it a highly desirable technique for use at Savannah River Laboratory. Because production reactors were not a convenient source of neutrons for activation, large ${ }^{252} \mathrm{Cf}$ sources available in the laboratory were used to develop neutron activation analysis. However, the relatively low thermal neutron flux (a factor of $\sim 1000$ below that available from a sma11 reactor) limited elemental sensitivities and hampered diversified applications because of low sample throughput.

A facility at the Savannah River Laboratory was first designed for a $17-\mathrm{mg}{ }^{252} \mathrm{Cf}$ source. Analysis capabilities of this facility were later expanded when this source was replaced by four $25-\mathrm{mg}{ }^{252} \mathrm{Cf}$ sources. An absolute technique (eliminating comparative standards) was also developed which uses accurately known neutron capture cross sections ${ }^{4}$ and the constant spectral and spatial distributions of ${ }^{252} \mathrm{Cf}$ neutrons calculated from neutron transport codes. Sample throughput was further increased by using automated sample handling and data reduction procedures and tabulated spectrometric data. The rapid sample transport system also improved detection sensitivities of certain elements by using cyclic activation and counting regimes. These regimes were designed for analysis of elements with neutron capture products with half-1ives $\leq 60 \mathrm{sec}$. Other design features were included in the facility to increase sample throughput and to compensate for the relatively low flux of isotopic neutron sources. These features include 18 irradiation tubes in two concentric rings around the source, a $\mathrm{D}_{2} \mathrm{O}$ moderator annulus to increase the thermal flux in 9 of the irradiation tubes, provision for irradiating sample volumes up to $11 \mathrm{~cm}^{3}$, a shielded counting room, and high-efficiency detectors. 
This report is written in four main parts: 1) a complete description of the facility; 2) a discussion of the principles and techniques developed for the facility; 3) a section describing practical application of these principles and techniques, and 4) appendices describing the computer programs developed and currently used in the ${ }^{252} \mathrm{Cf}$ facility. 


\section{IRRADIATION TANK ROOM}

The current neutron activation analysis facility (Figure 1) contains four nominal $25-\mathrm{mg}{ }^{252} \mathrm{Cf}$ sources near the bottom of a $1 / 4$-inch stainless stee 1 tank which is $12-1 / 2 \mathrm{ft}$ deep and 4-ft in diameter. The tank (Figure 2) was constructed from two cylindrical sections and a hemispherical bottom section sealwelded together. A 1 -ft-thick concrete shell surrounding the tank supports the tank and prevents loss of tank water to the ground in the unlikely event of tank rupture. The interior of the tank is painted with white epoxy for improved visibility. The doubly encapsulated ${ }^{252} \mathrm{Cf}$ sources are attached to a fourposition zircaloy source holder assembly extending approximately two feet up from the tank bottom. Figures 3-5 show the primary (inner) and secondary (outer) zircaloy source capsules. Figure 6 shows the irradiation tank assembly.

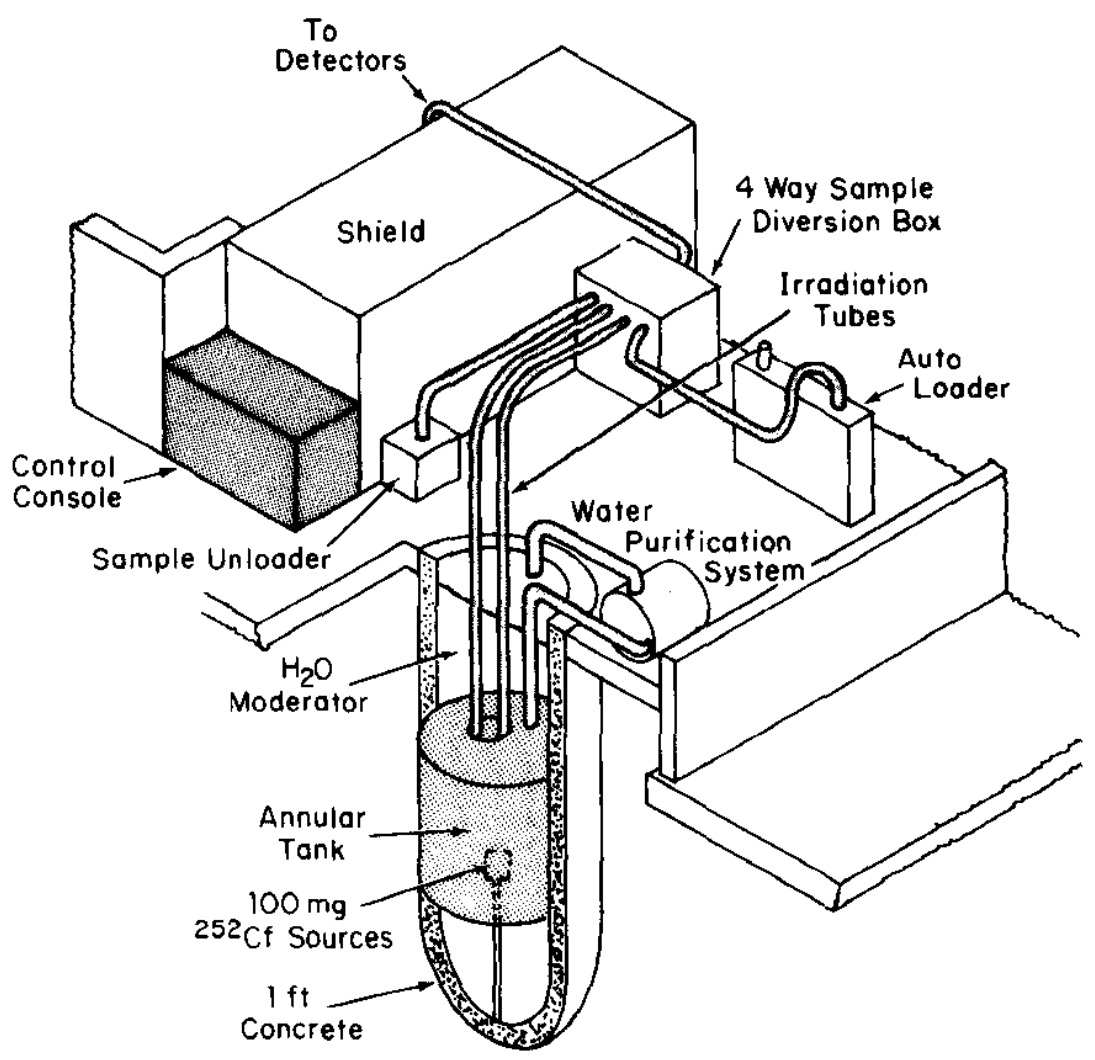

FIGURE 1. ${ }^{252} \mathrm{Cf}$ Neutron Activation Analysis Facility 


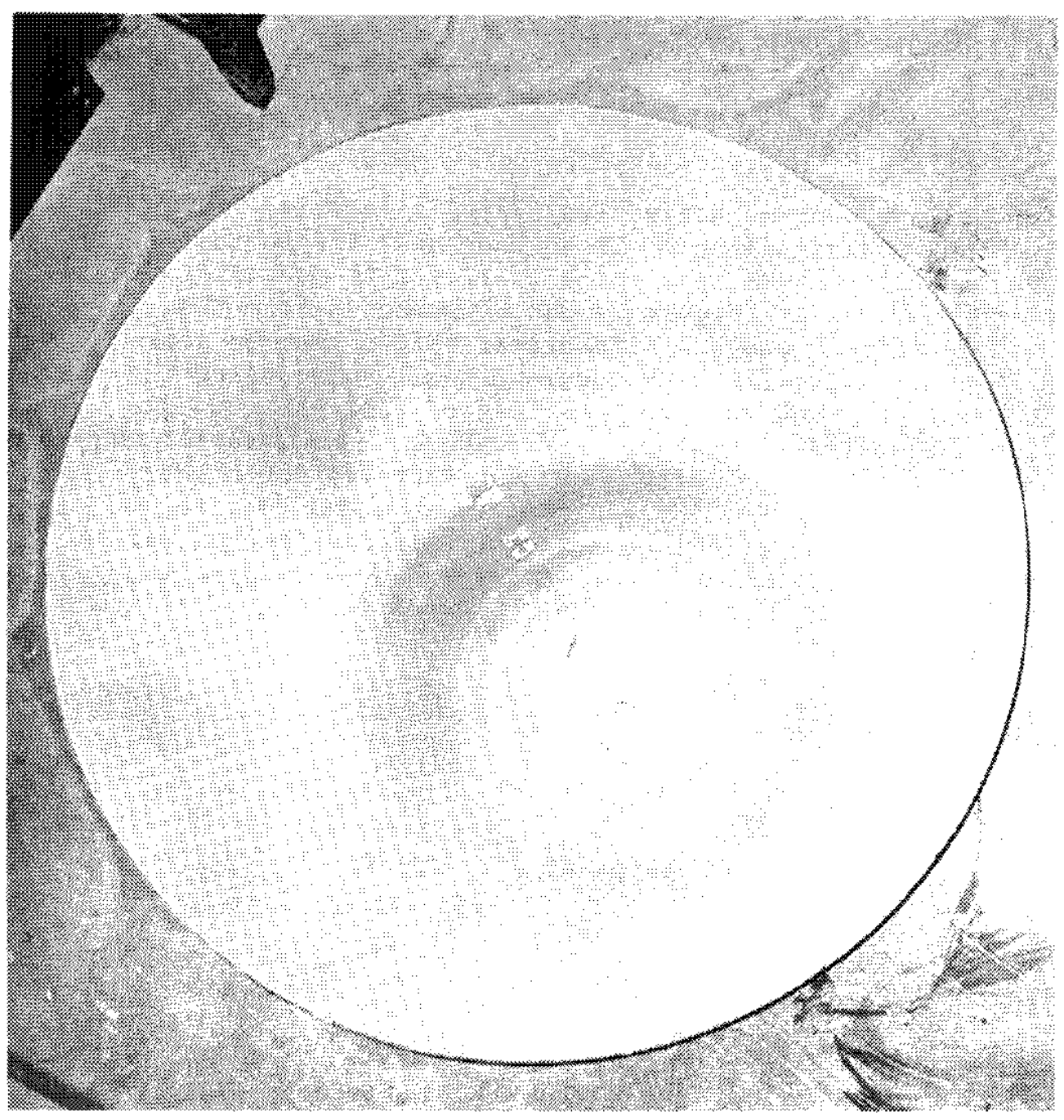

FIGURE 2. Source Tank 


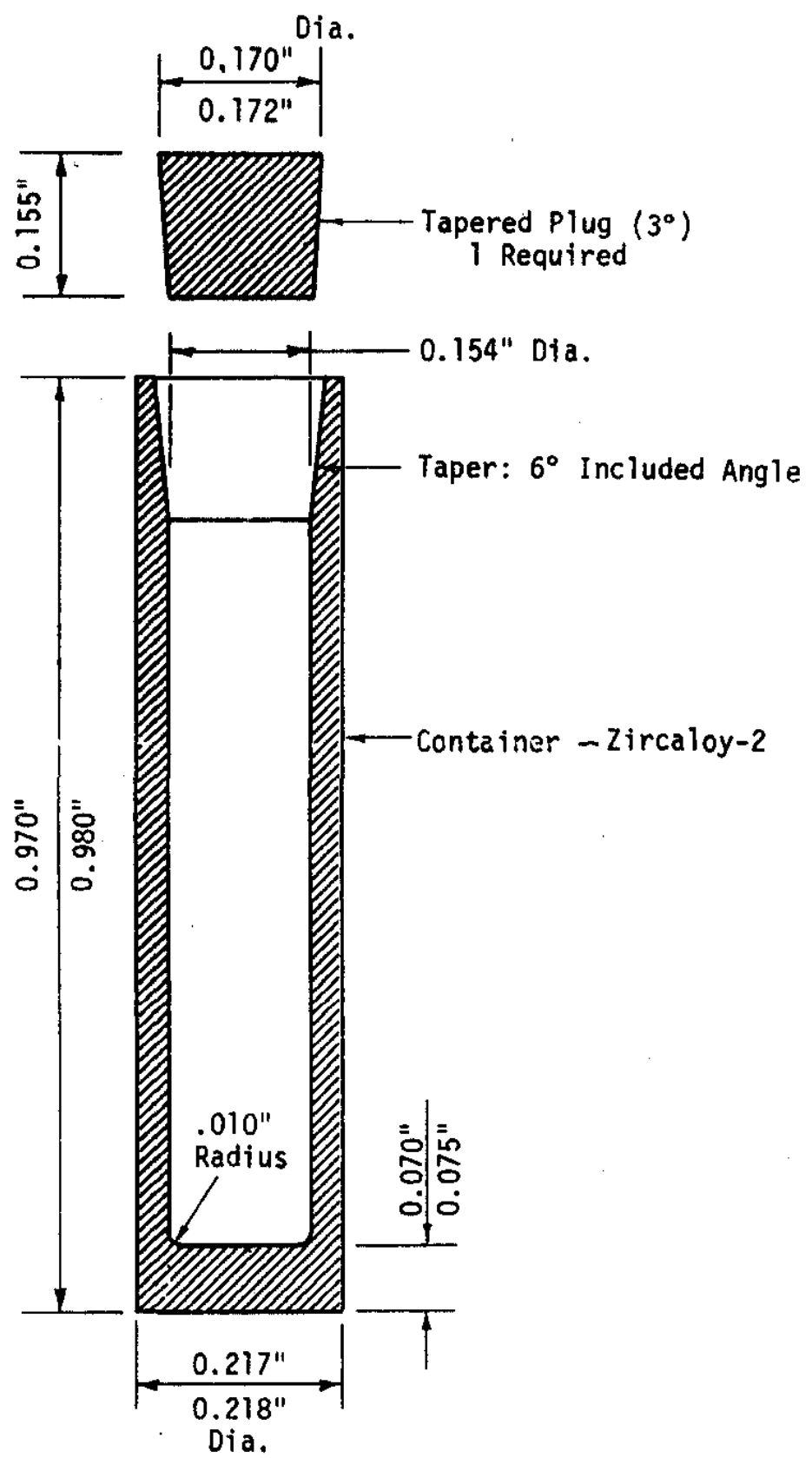

FIGURE 3. Primary Capsule for ${ }^{252} \mathrm{Cf}$ Source (Series SR-CF-IX) 

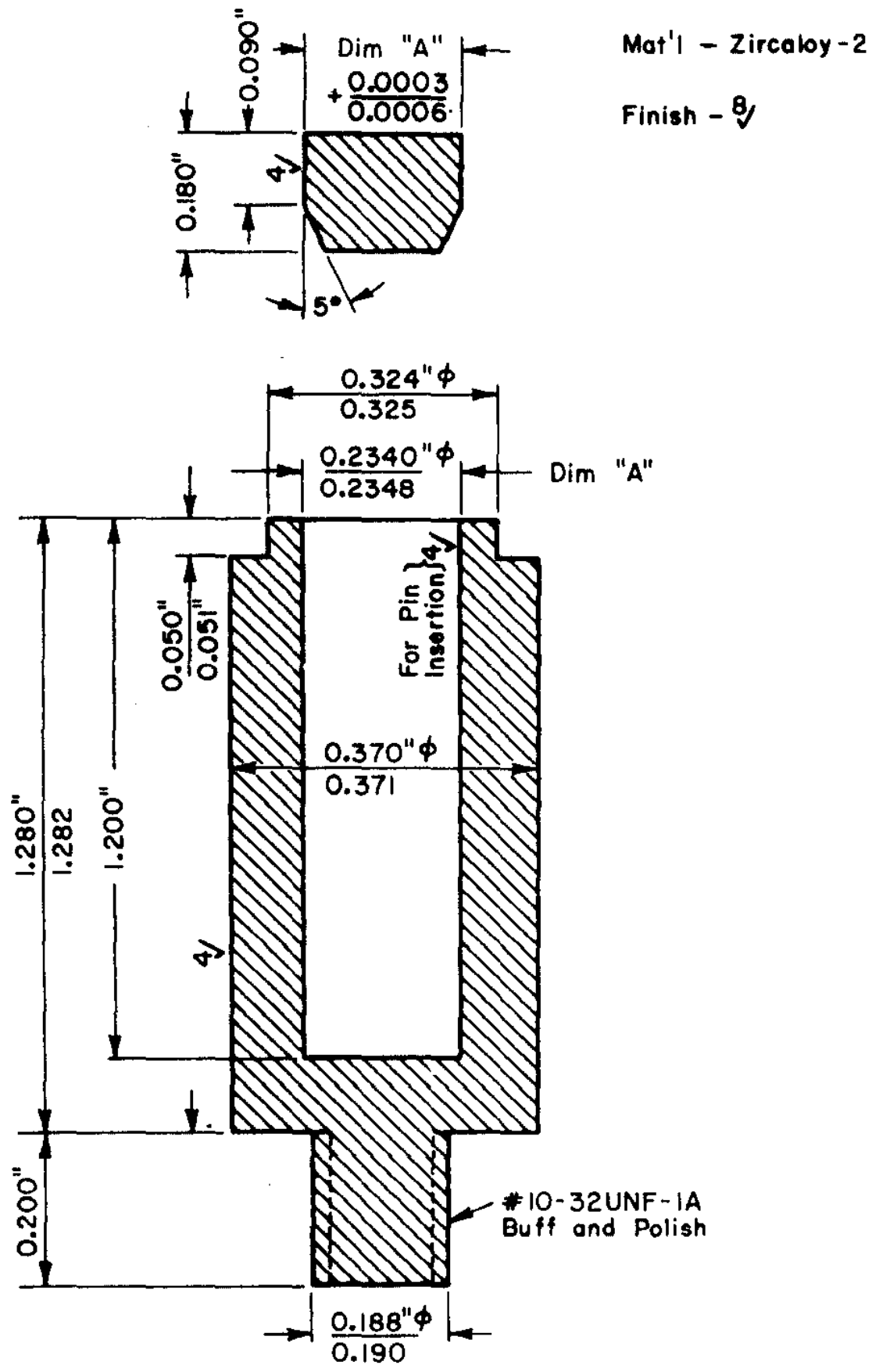

FIGURE 4. Secondary Capsule for ${ }^{252} \mathrm{Cf}$ Source (Series SR-CF-100) 


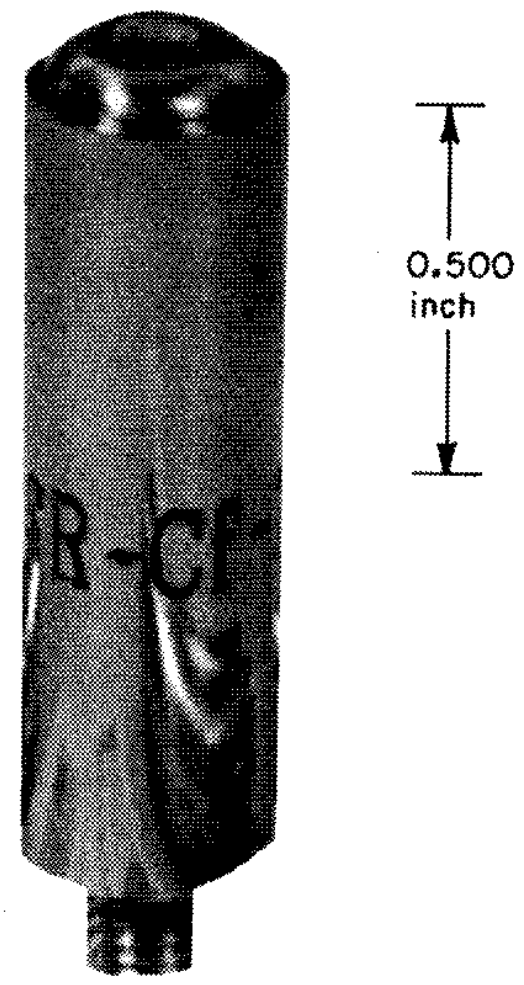

FlGuRE 5. Typical Secondary Capsule for ${ }^{252} \mathrm{Cf}$ Source (Series 100) 


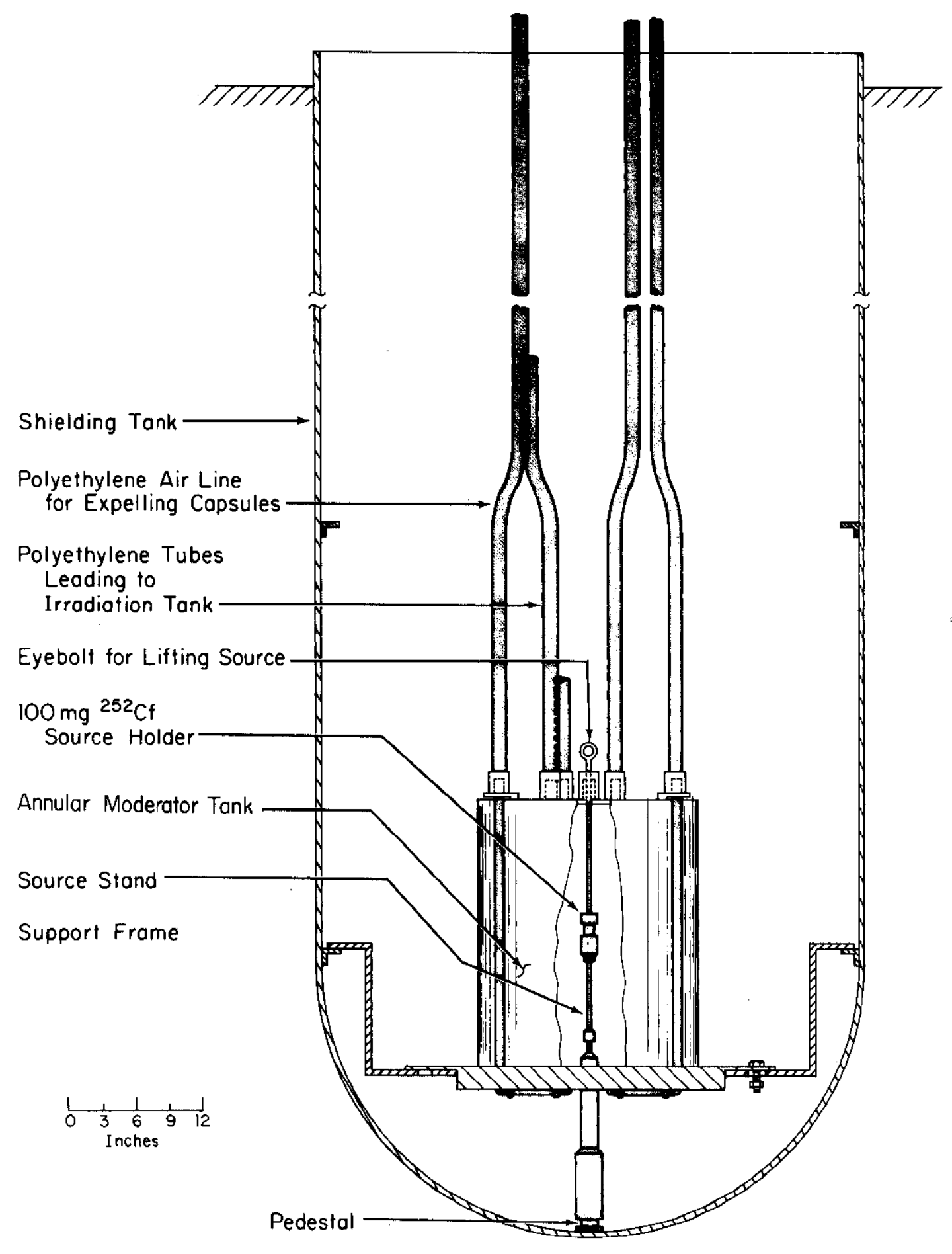

FIGURE 6. Irradiation Tank Assembly 
A cylindrical region of deionized light water of $4.68-\mathrm{cm}$ radius surrounds the source (Figure 7). A seal-welded stainless steel annular tank containing $\mathrm{D}_{2} \mathrm{O}$ surrounds the $\mathrm{H}_{2} \mathrm{O}$ region. The outer diameter of the $\mathrm{D}_{2} \mathrm{O}$ annulus is $22.77 \mathrm{~cm}$, and the wall thickness of the tank is $0.1588 \mathrm{~cm}$. Fittings on the tank permit addition and removal of $\mathrm{D}_{2} \mathrm{O}, \mathrm{H}_{2} \mathrm{O}$, or air for adjustment of the neutron energy spectrum. Figure 8 shows the annular tank and the four-position source holder. Nine stainless steel sample irradiation tubes are located within the $\mathrm{H}_{2} \mathrm{O}$-moderated region. Three of these sites are connected to a pneumatic, rapid sample transfer system designed for short half-life studies and cyclic irradiation and counting procedures. Nine additional drop tube irradiation sites are within the annular $\mathrm{D}_{2} \mathrm{O}$ tank. All irradiation sites are stainless steel tubes of $2.54-\mathrm{cm}$ outer diameter and $0.0089-\mathrm{cm}$ wal1 thickness.

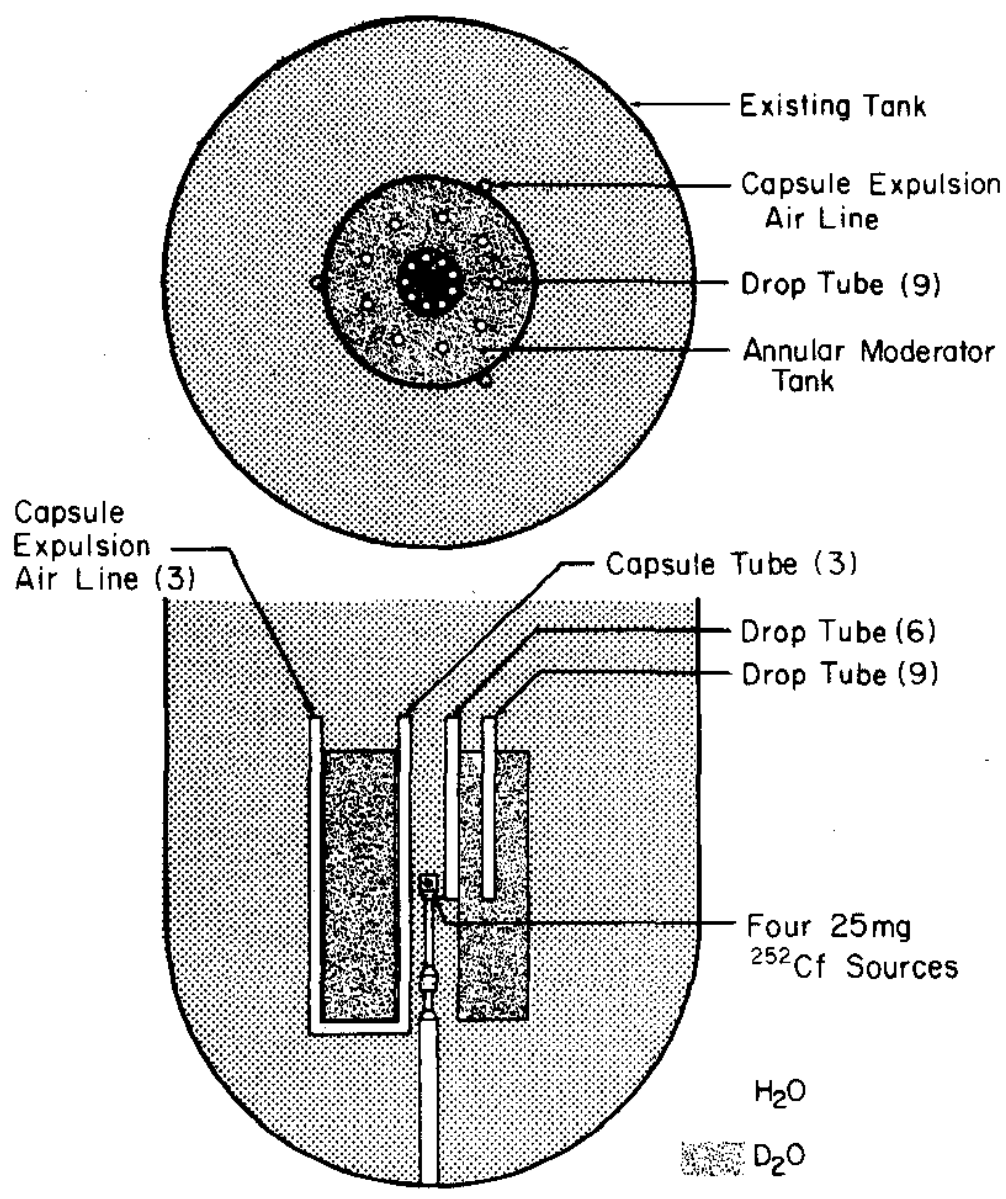

FIGURE 7. Neutron Activation Analysis Facility with ${ }^{252} \mathrm{Cf}$ Sources in Position 


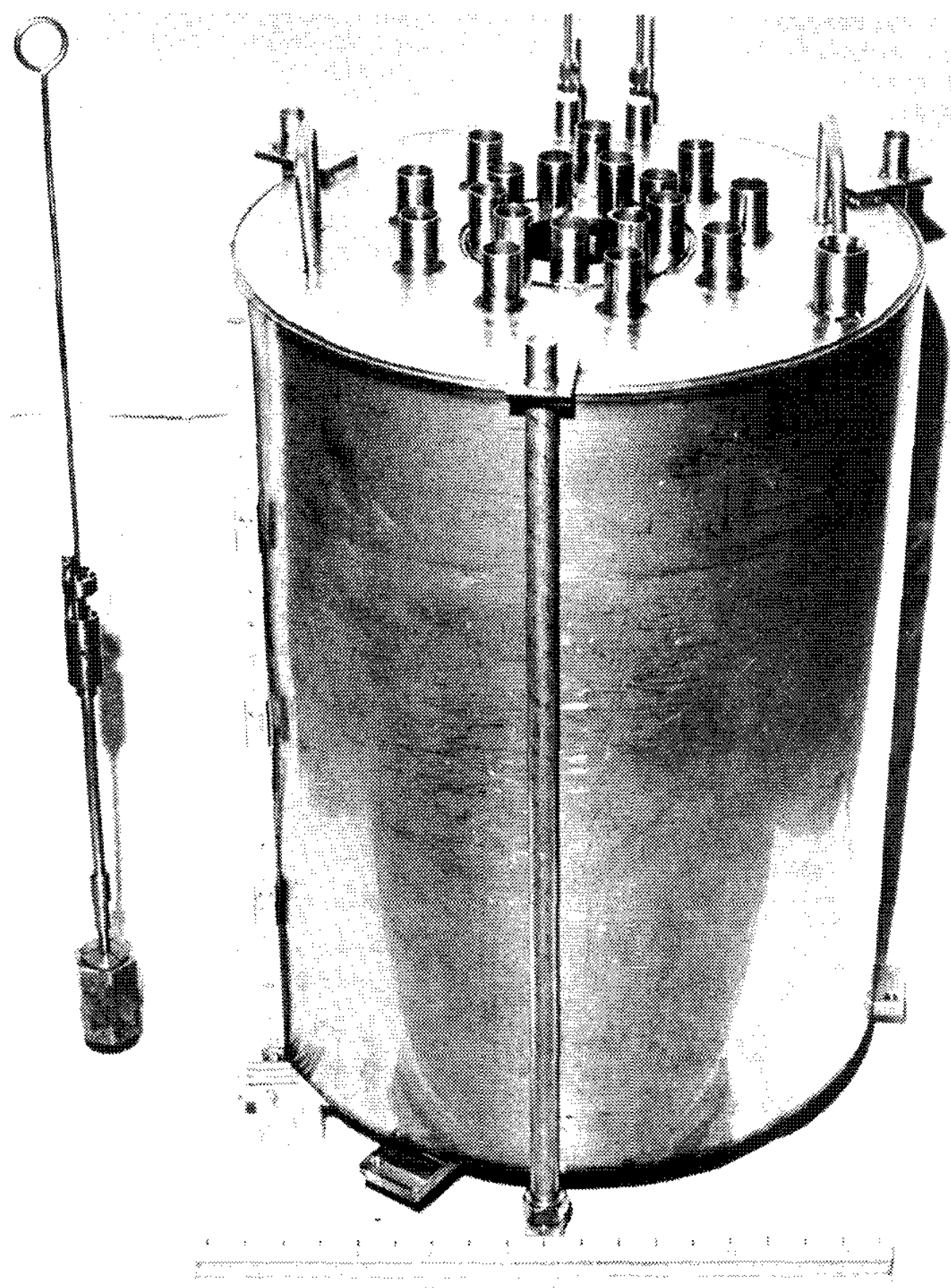

FIGURE 8. Annular Moderator Tank and Fourmpostiton Source Holder 
Samples to be irradited are heat-sealed within high density polyethylene containers called rabbits of wll $\mathrm{cm}^{3}$ internal volume. Samples are introduced to the irradiation site e ther manually or autonatically from the pneumatic sample transter system through 2.85-crmoxter diameter polyerhylene transfer tubes. These tubes spiral downard from the working level to the stanless steel irratiation tubes (Figure 9). The polyethylene transfer tubes are anmed to the stainless steel jradiaton tubes at about $40 \mathrm{~cm}$ trom the sources to prevent radiation damage to the polyctirylene.

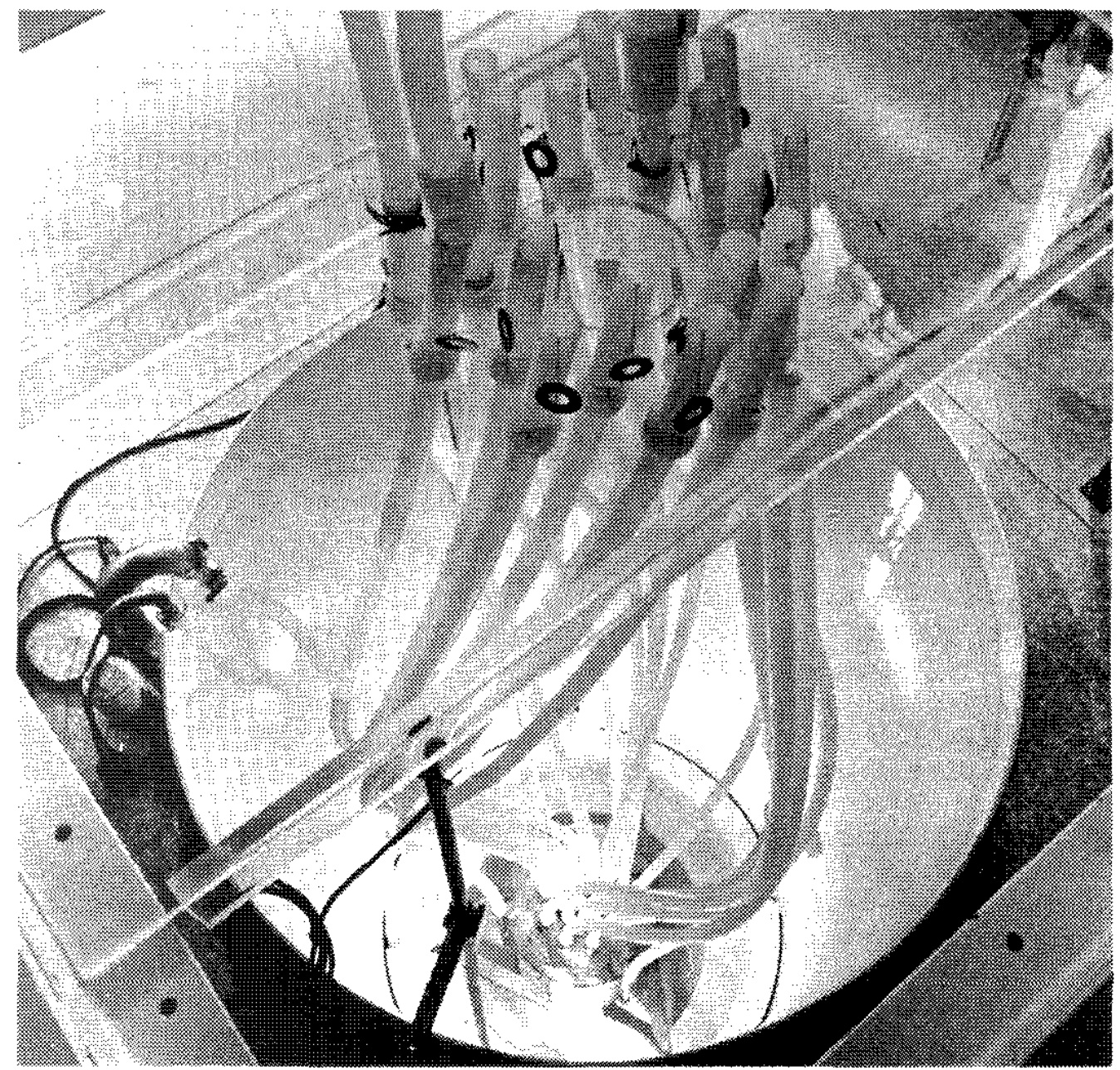

FGCURE 9. Polyethylene Sample Transfer Tubes 
The source tank is filled with 1100 gallons of distilled water for moderation and radiation shielding. This water is circulated continuously through a mixed-bed cation-anion demineralizer and filtration system (Figure 10) to prevent buildup of radioactive activation products within the moderator. The ion exchange bed is monitored continuously for gamma and neutron radioactivity which would result from a breached source or sample. The neutron monitor alarm automatically shuts off the moderator circulation pump. The neutron monitor and a beta-gamma air activity monitor are connected to the building alarm panel.

A four-foot square table with a stainless steel framework and acrylic sides and top covers the tank. The tank cover is vented to the laboratory exhaust system. Shielded floodlamps with a 12-V DC power supply provide underwater lighting in the source tank.

The source tank room contains a sample transfer control unit, an automatic sample loader, an unloader, a four-way sample diversion unit, and sample preparation equipment (Figure 11). Sample preparation equipment includes a Class $100 \mathrm{clean}$ bench and a Class 100 fume hood. Polyethylene irradiation containers (Figure 12) are heat-sealed with a pneumatically operated sealer (Figure 13) which moves a resistance-heated wire coil over the threaded end of the rabbit. Then the containers are automatically pressed into an aluminum cooling block.

\section{COUNTING ROOM}

Irradiated samples are counted in a concrete-shielded vault of 4-ft wall thickness. Within this vault, secondary lead shields of minimum 2-inch thickness surround the two Ge(Li) gamma ray spectrometers, a $\mathrm{NaI}$ detector, and a $\mathrm{BF}_{3}$ delayed neutron detector. The dual $\mathrm{BF}_{3}-\mathrm{Ge}(\mathrm{Li})$ spectrometer system within the vault is shown in Figure 15. The dual counting system is part of the automated sample transfer system and is activated automatically through the data storage control module.

Instruments for data acquisition are adjacent to the shielded counting vault (Figure 14). A Canberra Model 8100 multichannel analyzer receives gamma ray spectra from irradiated samples. Accumulated spectra are transferred to nine-track magnetic tape with a Canberra Mode1 8531 magnetic tape controller and a Wang Mode1 7 tape transport. 


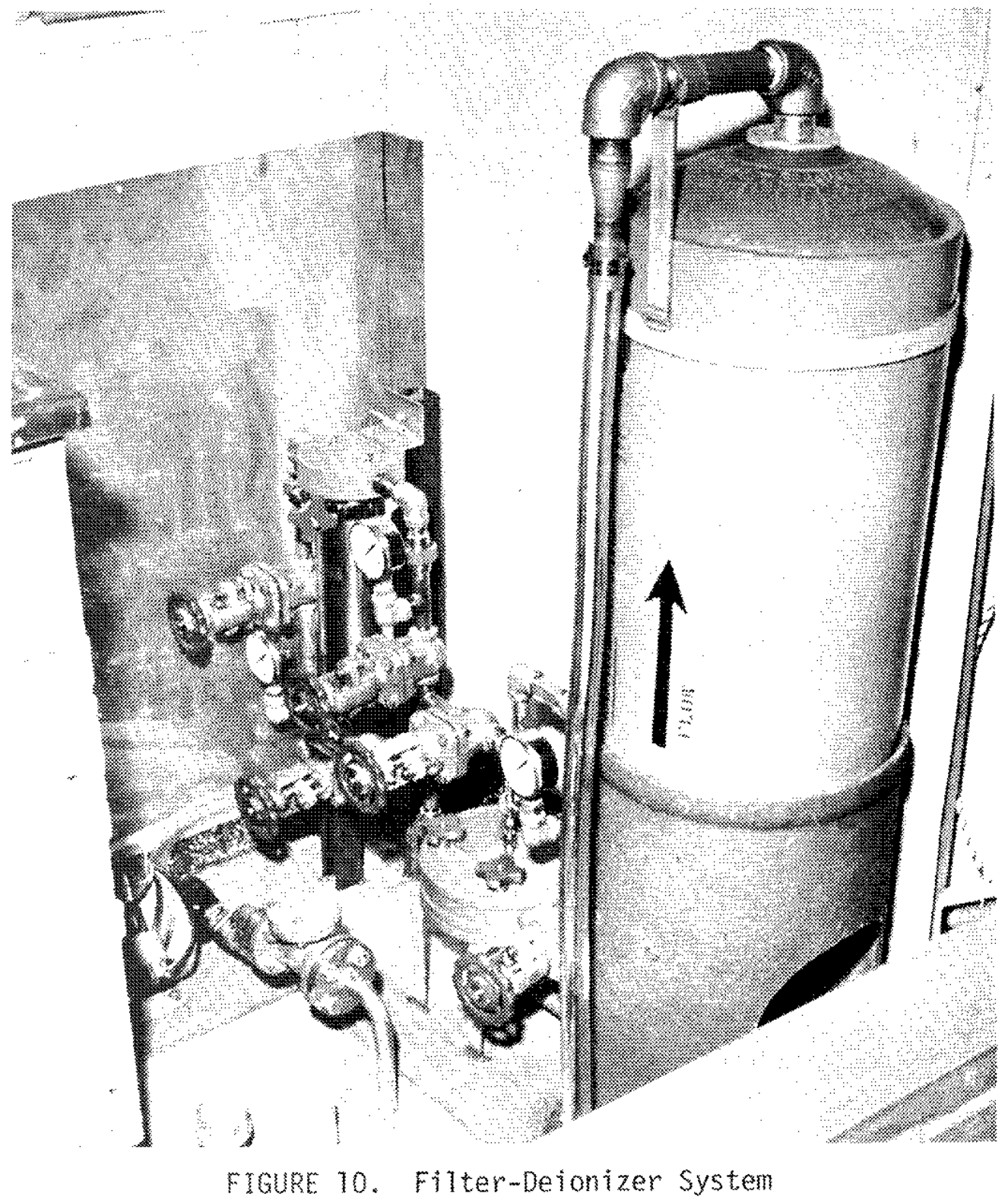




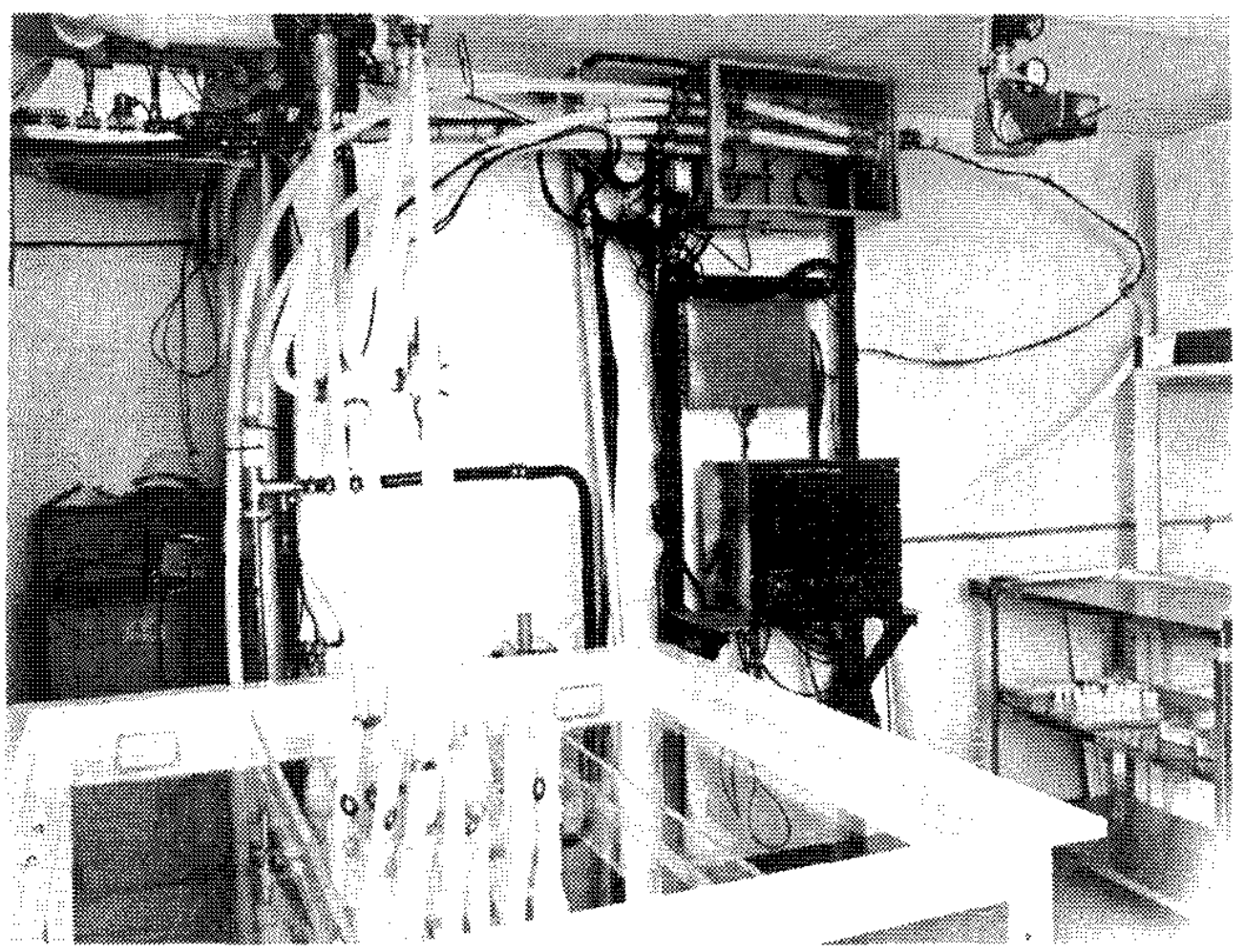

FIGURE 11. Sample Transfer EquTiment
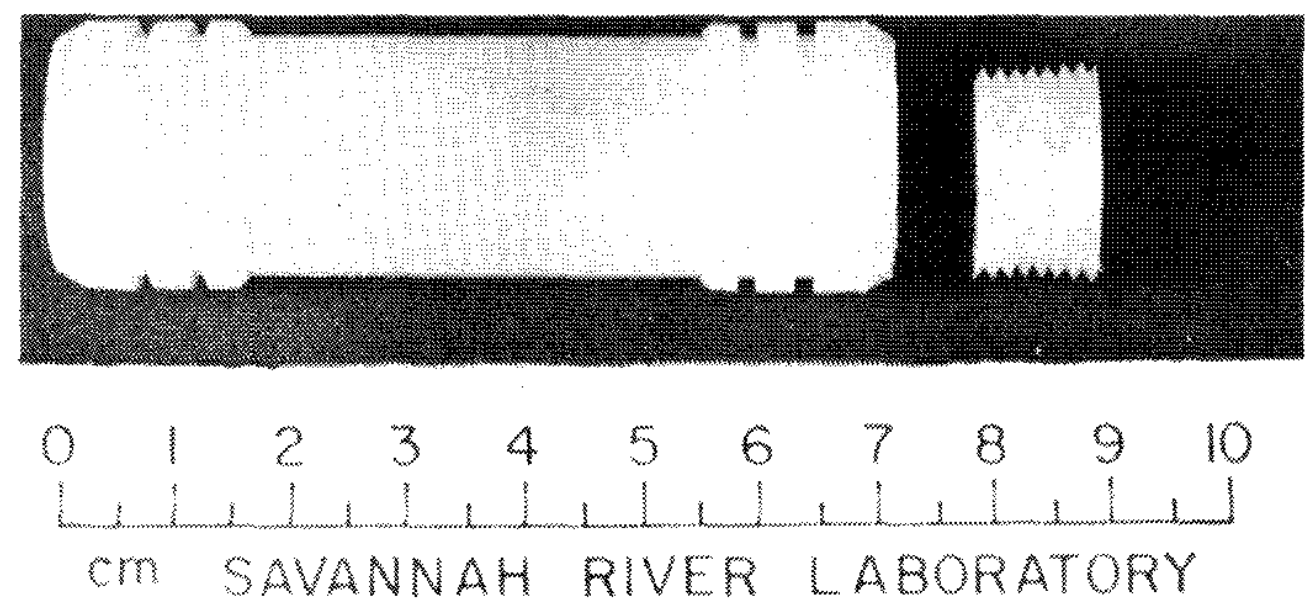

FICURE 12. Sample Irradiation Container 


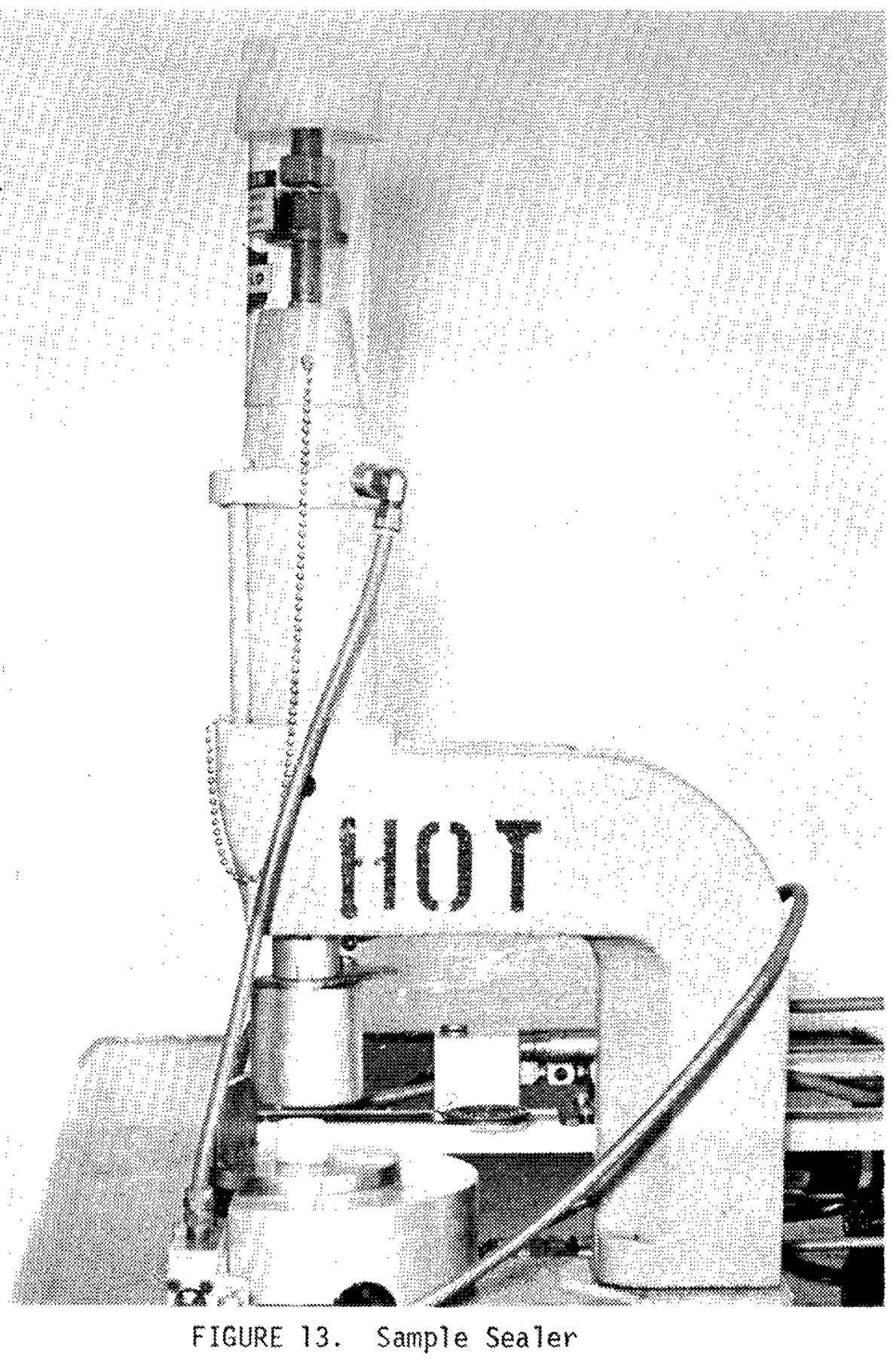

$-29=$ 


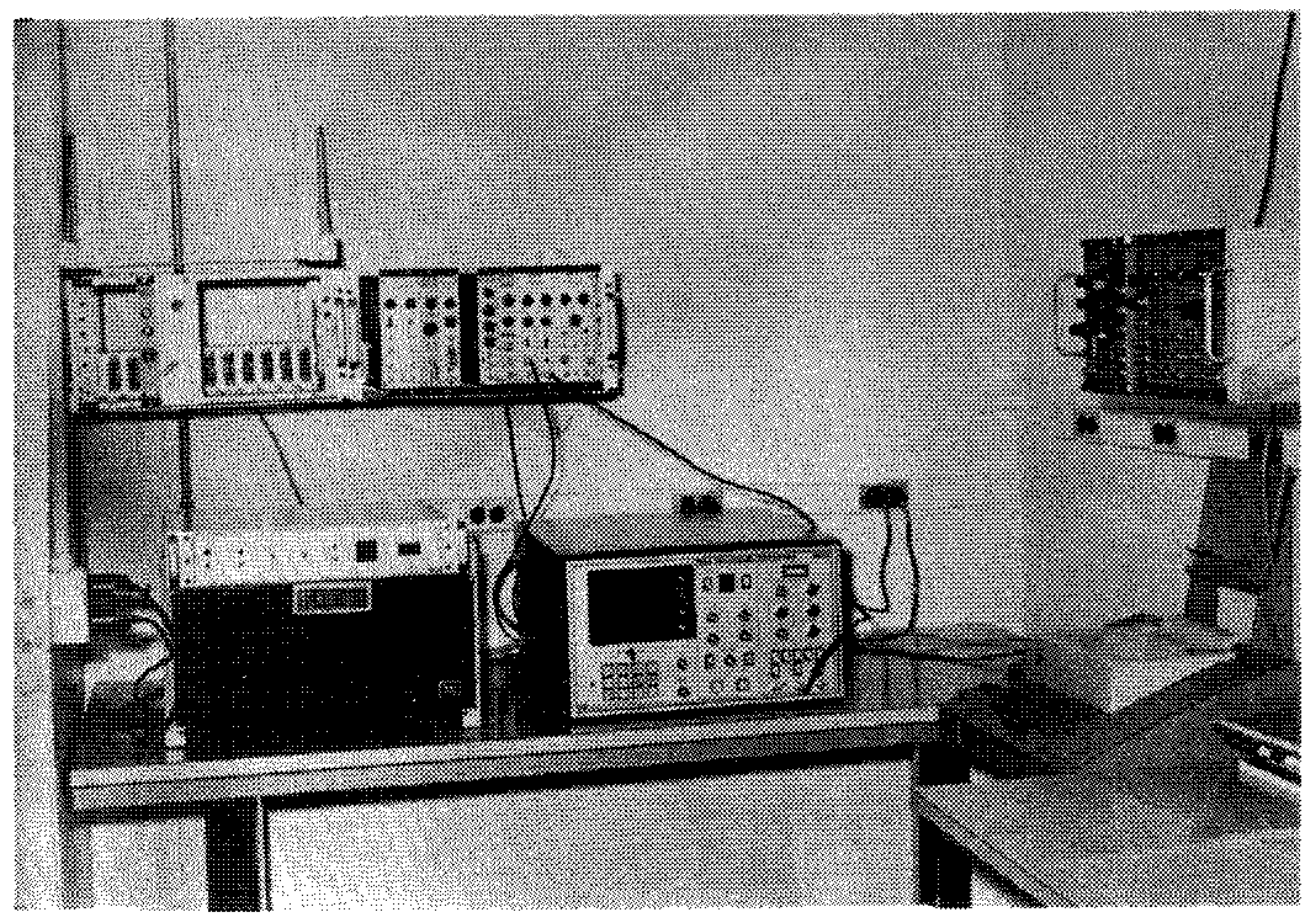

Froure 14. Data Storage Facility 


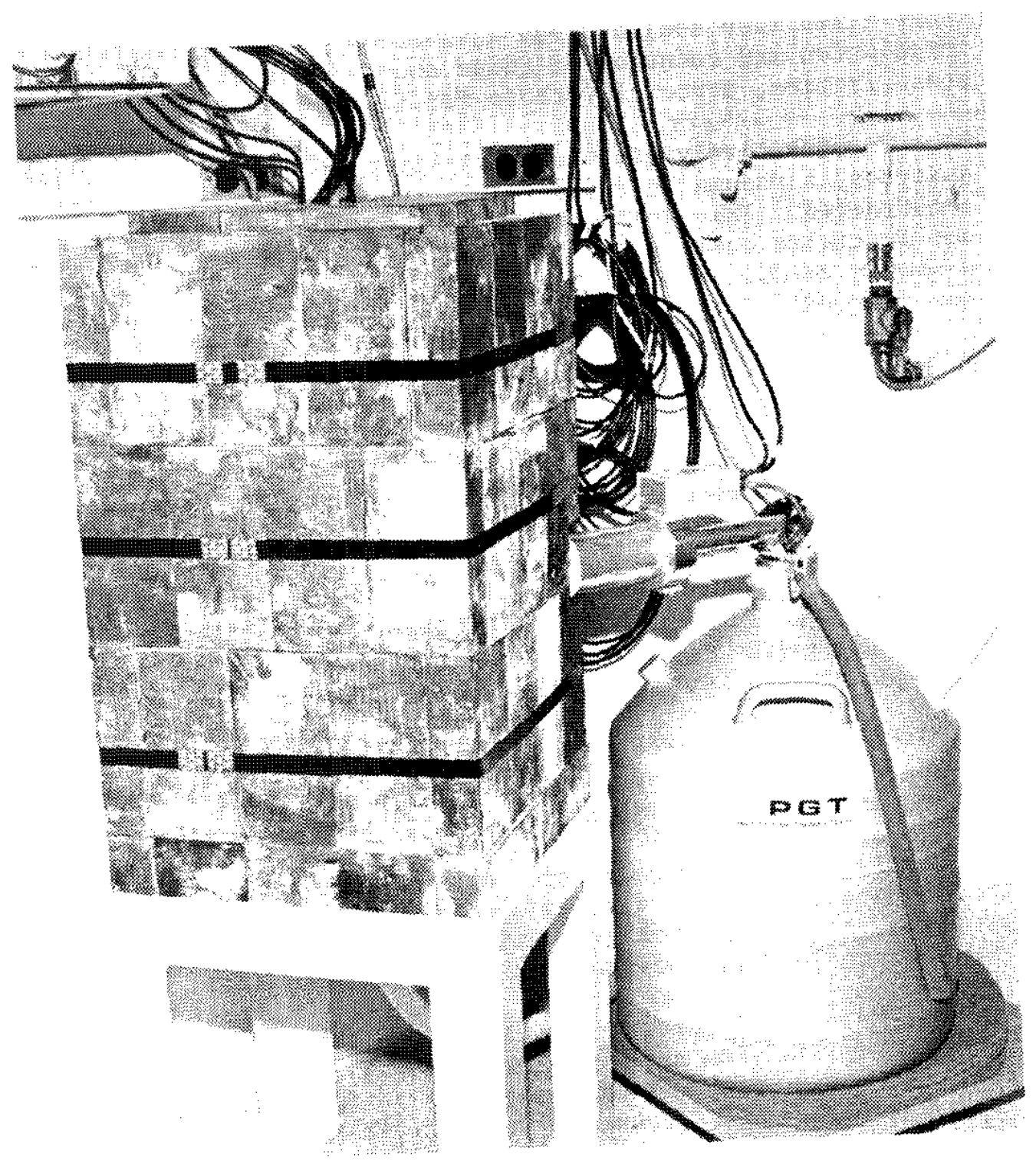

FICURE 15. Shielded Dual Gamma Ray, Delayed Neutron Detector 


\section{RAPID SAMPLE TRANSPORT SYSTEM}

Analysis times can be decreased for many elements by detecting short-1ived ( $\leq 60 \mathrm{sec})$ neutron activation products. Cyclic neutron irradiation and counting of these short-lived products also improves sensitivities, especially those for fissile materials.

To effectively use the short-1ived products for activation analyses, a pneumatic rapid sample transfer system (rabbit) was constructed. This system includes several features which were not available commercially. Main system specifications assumed a sample volume of $10 \mathrm{ml}$ and a transit time of $\leq 1.5 \mathrm{sec}$. The key features of this system are:

- Completely automatic sequencing of each rabbit throughout the system.

- Automatic self-loading and unloading of samples without operator attention.

- Accurate preselection of irradiation, decay, and counting intervals.

- Recycle capabilities (up to 100 times) for identical irradiation, decay, and counting regimes.

- Simultaneous sequencing of two samples (dual mode) through identical regimes by using two sample irradiation positions and one counting position.

- Completely automatic control of the multichannel analyzer for accumulating gamma ray spectra, storing data on magnetic tape, and automatically routing spectra into the appropriate analyzer memory location for dual mode operation.

- A data control interface which allows the counting mode (delayed neutron and/or gamma counting) to be preselected and allows delayed neutron data to be automatically routed to a scaler and gamma data to a multichannel analyzer.

- An automatic system abort mode (with audio and visual a1arms and system depressurization if a rabbit should fail to complete a selected path).

- Visua1 display of the next function to be undertaken by the control unit and current location of all rabbits in the system. 
- A disp1ay indicating the number of cycles completed for each rabbit being irradiated and digital readout of the irradiation, decay, and counting times.

- Air-cushioning of samples upon arrival at all locations within the systen.

- Exhaust of all air used within the system to 1aboratory exhaust system.

The transport system is shown schematically in Figure 16.

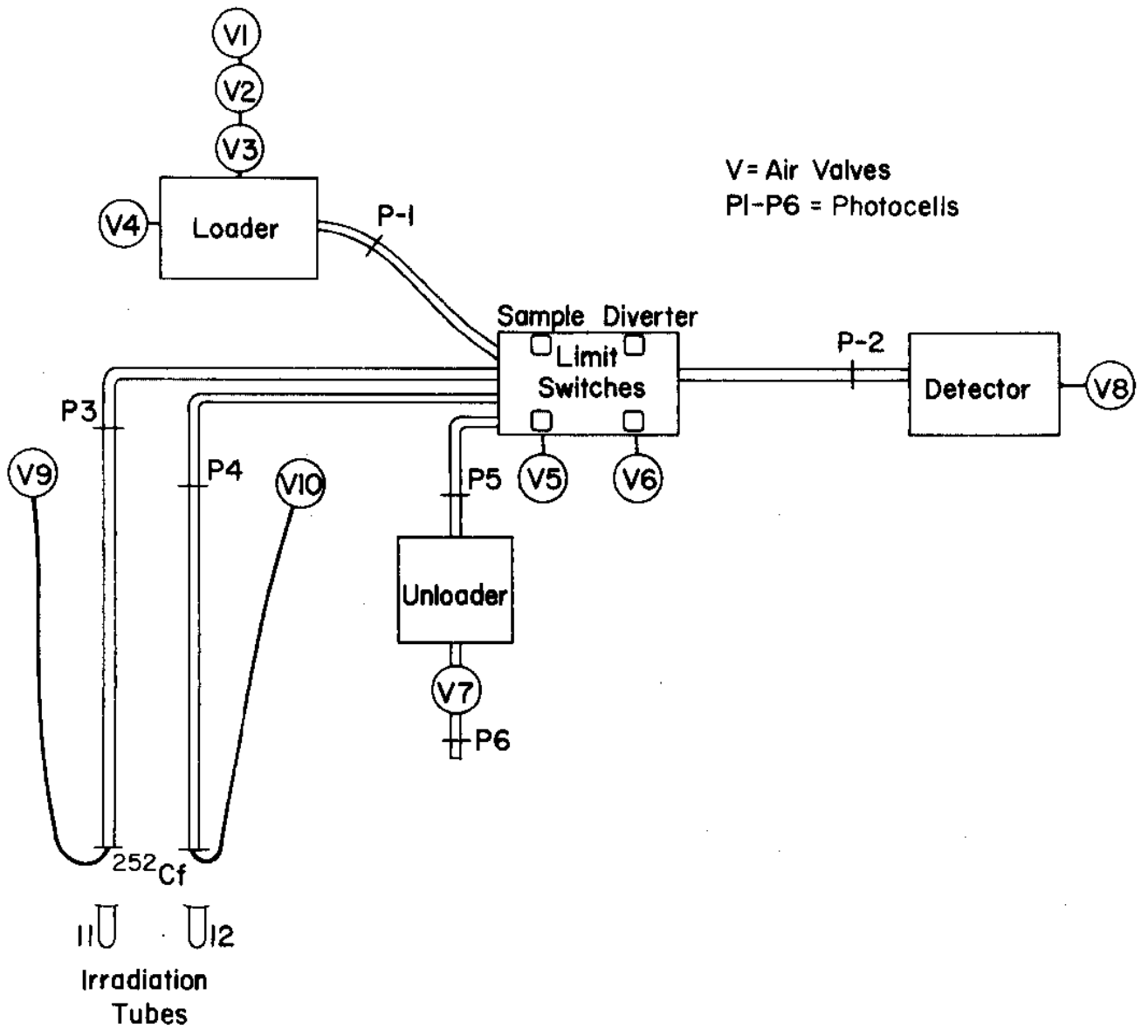

FIGURE 16. Schematic of Rabbit System 


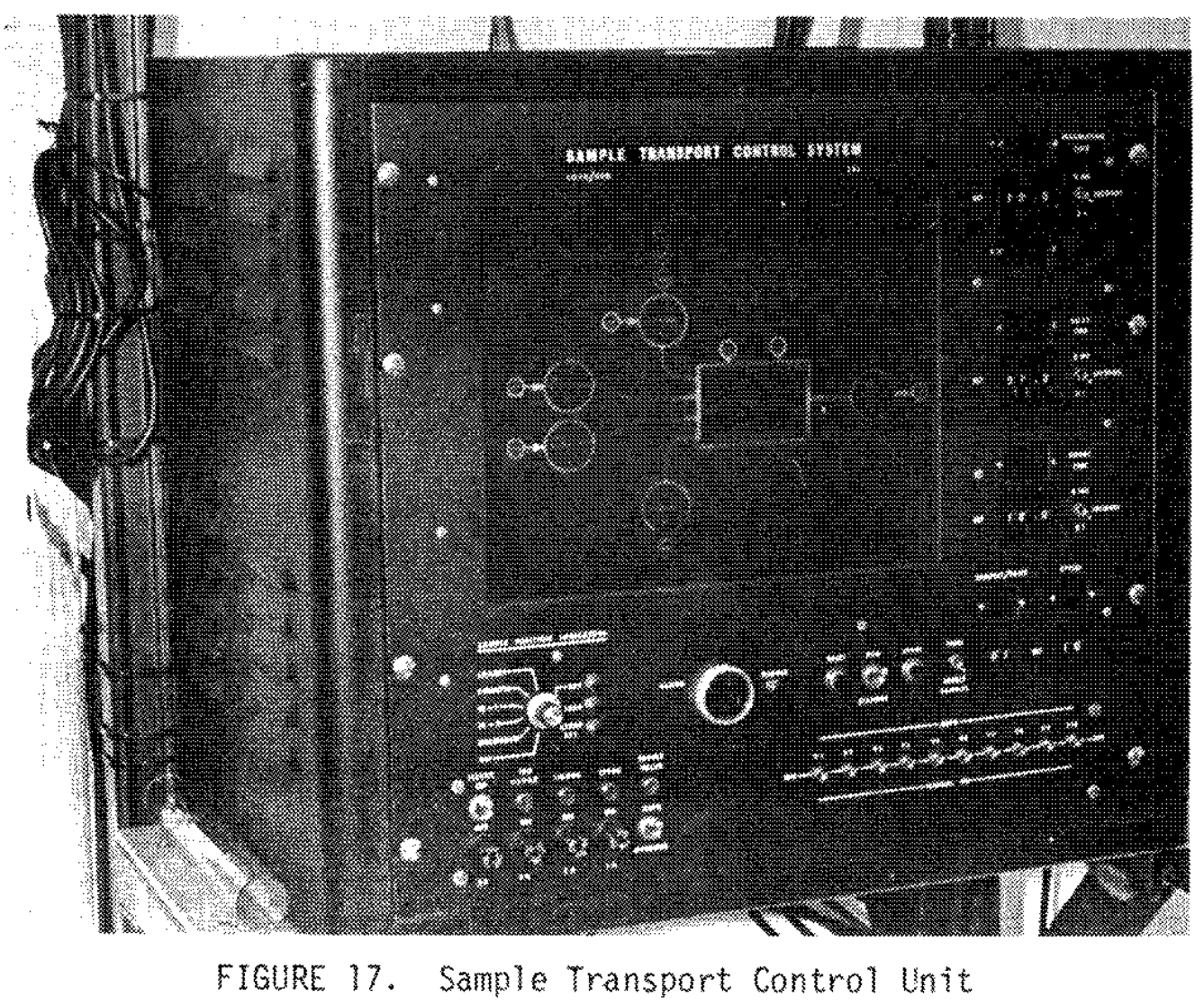

Figure 17 is a photograph of the sample transport control wht. The transport system consists of the following harbare in addition to the control unit:

- Two ixwadition tubes when are assd to transport and position the samples near the four sources.

- An automatic rabbit loader.

- Ar automatic rabbit unloador.

- A detection cnd observed by a sw(is) detector andor a delayed neutron detector.

- A fourway sample diverter which comects the detector site to the other portions of the system.

- Two atr valves, VS and V6, which actuate the swiching in the fourway diverter.

- Four init switches which verity the state of the coumway diverter. 
- Four ais valves, V4, V8, V9, and V10, which propel the rabbits from location to location.

- Three loading valves, V1, V2, and V3, which load samples into the system one at a time; and a ball valve, $V 7$, which unloads samples after sequencing at the unloader.

- Six photocells P1-P6, which signal rabbit passage at key locations.

Sequencing is accomplished with stepping relays. Table 1 lists timers in the functional control unit. All timers are crystal-controlled oscillators, which provide both high accuracy and stabilta in the timing of analysis regimes. A single-cycle regime (load, irradiate, count, and unload), proceeds as follows:

\section{TABLE I}

Timers in the Functional Control Unit

Therer Function

Tr Tradiation timex for Tube II

T2 Delay timer for Tubes $I 1$ and 12

T3 Counter timer

T4 Irradiation time for Tube 12

- Vaves 1 and 2 (V1 and V2) sequence, one rabbit is dropped beyond opening of $V 4$ verified by a signal from photocell 1 (P1), and analyzer menory is cleared.

- Vy seals the loader end of the transport line and pemits 44 to be activated. The rabbit is then propelled through the previously positioned fourway divertex box (VS and V6 off verified by $(L-L A)$ to the detector site.

- Astgna from 2 confirms passage of the rabbit, actuates V5 (which selects irradiation tube 11 for next path), and permits actuation of V8 (which fires the rabbit toward the 28 at source through irradiation tube Ml).

- A P3 signa closes V8 and starts the irradiation timer (T1).

- At end of Th, V9 is actuated, p3 starts decay timer T2, and 22 closes $V 9$ and opens VS and V6 (which selects unloader for noxt path. 
- At end of T2, the analyzer or the scaler-timer and counttimer T3 are activated by the Data Control Module.

- At end of T3, the analyzer or scaler-timer records or prints out counting data. V8 is actuated (P5 signals closure of V8 and opens V7; 26 signals closing of V7).

- At the end of the analyzer or printer readout, the control unit is automatically reset to the beginning of the next cycle.

- After the next rabbit is loaded, V4 clears the analyzer memory.

If a rabbit should get stuck in the system, no signal will be received by the photocell at the destination. If this signal is not received within $15 \mathrm{sec}$ after valve firing, the control unit alarms (audibly and $v i$ sually) and shuts off the main air supply. No additional action can be taken by the system without operator intervention.

As described above, a single rabbit irradiation uses only one function at a time, i.e., one irradiation tube (and timer), decay timer, or detector (count timer). In the dual mode of operation, two rabbits may be analyzed concurrently, if the sum of the times on $\mathrm{T} 2$ and $\mathrm{T} 3 \mathrm{is}$ less than the time on TI. In concurrent analyses:

- Rabbit 1 is loaded into the system and moved to irradiation in irradiation tube $I 1$ (and starts TI), and Rabbit 2 is immediately loaded into the detector site.

- Just before $T$ counts down, Rabbit 2 is moved to irradiation tube 12, and the irradiation timex (T4) for tube T2 is started.

- When Tl counts down, Rabbit 1 is transferred to the detector, and $\mathrm{T} 2$ and $\mathrm{T} 3$ are started.

- When T3 counts down, Rabbit 1 stays at the detector until just before T4 counts down. Then Rabbit 1 is transferred back to irradiation tube 11 for its second irradiation (or to unload at the end of the regime).

- When T4 counts down, Rabbit 2 is transferred to the detector, and $T_{2}$ and $T 3$ are started.

- The system is now in the same configuration as in Step 1, and both rabbits can now be recycled. 
The data are routed into the appropriate location in the analyzer menory depending on the status of Tl. If Th is counting, kabbit 2 is at the detector, and the spectrum is stored in one part of menory. If 1 is not counting, Rabbit 1 is at the detector axd the spectrum is stored in another part of menory. Both spectra are retaned in nenory until Rabbit 2 is unloaded. When Rabbit 2 is moloaded, the analyzer output mode begins.

\section{DETECTION APPARATUS}

\section{Cammanray Detectors}

Most activation products are gamanay emiters; therefore, waphasis is placed on detecting these gamanays with efficiency and wh hishest resolution. Two practical detector types cur rembly available commercially are Nal and Ge(Li). Nal detectors have higher effictency and lower resolution than Ge(ti) detectors. ce(ti) detectors are nomally used except when the gamma-ray exergy is very high (>A MeV) or when only one elenent with a simple (1 or 2 steps) gamam ray decay schene is only weakly activate

\section{Geris) Deteotors}

Many laboratories use Ge(Li) detectors for activation analysis; however, the comparative techique uses only the ratio ot detector responses. With the absolute technique used at SRL'S Metron activation analysis facility, the detector must be acourately calibrated for detector efficiency vs energy for each sianeledetector arrangenent ased (such as samplendetector distance and sample size).

Two Ge(t) detectors are currently used in the ${ }^{252}$ (t) neutror actuation analysis facility. One detector is a Canberra Indusm twes detector of $15 \%$ efficiency relative to a $3 \times 3-$ inch Nal desector and of $2.04 \mathrm{keV}$ FWH (full width at half-maximum) resolution at $1332.495 \mathrm{keV}$. This detector is used exclusively tor drop tube sample counting, and it has three detector-sample arrangements for which absolute efficiency vs. energy calibrations have been performed (identified as positions 01,04 , and 05 ). The otuer detector is a princeton Gama Tech detector of $16 \%$ efterency and a resolution of $1.88 \mathrm{keV}$ FWM at $1332.495 \mathrm{keV}$. Ths deretor is used exclusively in the rabbit system, and it has two detector sample arrangements for which absolute officiency vs. energy calibrations have been made (positions 03 and 06 ).

* Canberra Industries, Meriden, on

** prineston Gama Tech, Ine., princeton, N3 
These absolute efficiency curves are stored as EFFCAL data files on disk with the IBM 360/195 computer. The EFFCAL data files are 1 isted in Appendix, Table A-6.

The absolute efficiency vs. energy curve for each detectorsample axrangement is determined in a two-step process. First, the general shape of the curve (log efficiency vs. $\log$ energy) is determined by counting nuclides such as ${ }^{182} \mathrm{Ta},{ }^{169} \mathrm{Yb},{ }^{125} \mathrm{Sb}$, ${ }^{3}{ }^{3} \mathrm{Ba}$, and $165 \mathrm{mHo}$. These isotopes have complex decay schemes which yield a distribution of abundant gamma rays with well known energies and relative intensities. Second, National Bureau of Standards Reference Materials (absolute gamma ray standards) are counted to determine several absolute log energy vs. log efficiency points. The relative and absolute data are combined to produce an efficiency curve for each counting arrangement.

When one of these nuclides is used as a calibration source, the efficiency calibration curve is determined as follows: 1) spectra are accumulated with at least 10,000 net counts in the photopeaks, 2) the photopeak areas are determined in the same manner that any sample spectrum is analyzed, 3) the relative detector efficiency is calculated by dividing the relative gamna ray intensity by the photopeak area, 4) for each source, the logarithm of the relative efficiency is plotted against the logarithm of the ganma-ray energy, 5) these plots are superimposed and the best single relative curve is constructed, 6) because no single theoretical function adequately describes the data, the curve is drawn by hand and not determined by computer least squares analysis.

A certified calibration source converts the relative efficiency curve to an absolute curve. One of the best sources is available from the National Bureau of Standards (NBS 4243E). It consists of a solution containing accurately known quantities of ${ }^{103} \mathrm{Cd},{ }^{57} \mathrm{Co},{ }^{139} \mathrm{Ce},{ }^{20} \mathrm{Hg},{ }^{11{ }^{3}} \mathrm{Sn},{ }^{85} \mathrm{Sr},{ }^{1{ }^{7} 7} \mathrm{Cs},{ }^{60} \mathrm{Co}$, and ${ }^{88} \mathrm{Y}$. This solution is packaged in a container identical to those used for samples, and spectra are collected. Absolute detector efficiencies are determined for these ganma rays. The relative curve is then scaled so that it best intersects with these absolute points.

For computerized data reduction, these efficiencies are listed for selected energies. The computer interpolates the efficiency for a desixed energy by using a second-order least. squares fit to the four nearest log efficiency log energy points.

Table Am6 lists the absolute efficiencies used in the ${ }^{252} \mathrm{Cf}$ facility. The fixst block contains the selected energies, and the second block contains the corresponding reciprocal of the absolute counting efficiency. 


\section{Me.. Detector}

A Nal detector is also used for gama-ray detection for specific analyses. For oxygen malysis, the 6.2 MeV gammanay frow the ${ }^{16} \mathrm{o}(\mathrm{n}, \mathrm{n}){ }^{16} \mathrm{~N}\left(\mathrm{~T}_{1} / 2 \ldots 7.1 \mathrm{~s}\right.$ sec) activation reaction product is the most sensitive indicator. for such analyses, a $3 \times 3$ inch Nal detector* with $6.5 \%$ resolution at $662 \mathrm{keV}$ is used with the rabbit system. For analyses where only one element is activated and a product emits only one gamma ray, the Nal detector in the secondary shielded vaut provides maximum gama-ray detection sensitivity and lowest possible detection limit. No absolute activation analyses are performed routinely with the Nar detector.

\section{Delayed Neutron Detector}

Many samples from plant processes require analysis for fissile isotopes such as $2350,239 \mathrm{pu}$, and natural uramium. The most specific and sensitive method for such analyses is to hetect beta-delayed neutron decay. A high-eficiency (12\% absom lute) assembly was designed and constructed to detect neutrons with energy distributions chaxacteristic of betandelayed neutron

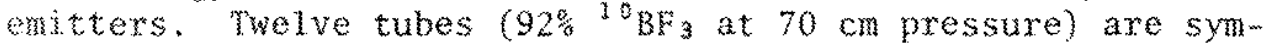
merticaly arranged around the sample. High density polyethylene is used to themalize the neutrons for most efficient detection. The average delayed neutron has an energy of $4500 \mathrm{keV}$; thus, only 4. $12 \mathrm{~cm}$ of moderator is required between source and detectors. in the shiclded facility, the neutron detector background averages ony 4 councs/min. cyclic inradiation and delayed neutron counthum are optimized for analysis of different fissile materials.

\section{SAMPLE PREPARATYON FACLLITIES AND PROCEDURES}

Because of the sensitivity of activation analysis, samples are prepared for irradiation in a clean environment. A clean berch and a clean fume hood (Agnew Higgins) provide a Class 100 envisonment for sample preparation.

Samples are weighed on an automtaring, rapid-readout Mettar Model 4 m 64 balance with a sensitivity of 10 Hg over a $160 \mathrm{~m}$ range. Sold samples are weighed into premcleaned poly ethylene rabbits; linud samples are pippetted.

Woquenty, the physical forms of samples are changed before irradiation. These changes include:

\footnotetext{
* Bicron, moorpoxated, Cleveland, OH.
} 
- Grinding of samples to reduce particle sizes.

- Blending of small samples.

- Freeze drying of biological samples.

- Compaction of samples into pellets (especially freeze-dried samples).

- Motstening of all powdered samples with enough water to comm plete the $10-c c$ volume followed by vortexing to ensure complete mixing.

All of the above are done in a clean environment.

Ion exchange concentration procedures were developed especially for analysis of very dilute solutions. These procedures involve batchmcontacting of 1 liter of the dilute aqueous solution with equal equivalent amounts of mixed cationanion exchange resins. Detection sensitivities are improved 100-fold for almost every element dissolved in the water by direct activation analysis of the resin. With this technique, 5 ppb of natural uranium in water can be detected. The resin was specially purified by BioRad Laboratories, Richmond, CA. 


\section{BASIC PRINCIPLES OF ${ }^{252}$ CI NEUTRON ACTIVATION ANALYSES}

\section{ABSOLUTE ACTVATION ANALYSIS}

One of the unique features of the ${ }^{252}$ cf neutron activation analysis facility is that it can perform rapid multielenent malyses whout the routine use of comparative standards. In the absolute technique, the naster equation of activation analysis is used to relate a measured detector response to the nultielement concentration of the sample. Many factors enter into the absolute calculation of detector response. These factors include absolute decay data, sample weight, experimental irradiation, decay, and counting thmes; absolute detection efficiency; and, most important, elemental heutron capture reaction rates, which are calculated from measured flux and cross section data.

During irradiation of a sample, the instantaneous change in the number of atoms of some activated product species (N) present in the sample is:

$$
\frac{d N}{d t}=\text { (xate of production) - (rate of decay) }=x-\lambda N
$$

where

$$
\begin{aligned}
& \lambda=\text { decay constant of the product, } s \in \mathrm{e}^{-1} \\
& x=\text { production } \text { xate, atoms/sec }
\end{aligned}
$$

mermating this equation over the irradiation time from 0 to (1) yieds

$$
N_{1}=\frac{x}{x}\left(1-\exp \left(-\lambda \mathrm{r}_{y}\right)\right)=\frac{x}{\lambda}
$$

Wherestar

$$
\begin{aligned}
& r_{i}=\text { Sradiation time, sec } \\
& N_{3}=\text { number of product atons present at ri } \\
& s=\left[3-\exp \left(-\lambda T_{1}\right)\right] \text {; the irradiation saturation factor }
\end{aligned}
$$

If the sample is removed from the neutron flux at $T_{1}$ and then allowed to acay during the, $T_{z}$, the number of atoms renaining at the end of $\mathrm{T}_{2}$ is 


$$
N_{2}=N_{1} \exp \left(-\lambda T_{2}\right)=\frac{r S D}{\lambda}
$$

where

$D=\exp \left(-\lambda T_{2}\right) ;$ the decay factor.

At the end of $\mathrm{T}_{2}$, the sample is counted for a time, $\mathrm{T}_{3}$. At the end of $r$, , the number of product atoms remaining is

$$
N_{3}=N_{2} \exp \left(m \lambda T_{3}\right)
$$

The number of atoms which decayed during the counting period is given by

$$
\Delta N=N_{2}-N_{3}=N_{2}\left[1-\exp \left(-\lambda T_{3}\right)\right]=\frac{r S D C}{\lambda}
$$

where

$$
C=\left[1-\exp \left(-\lambda T_{3}\right)\right] \text {, the counting factor. }
$$

The number of counts $G$ observed by the detector is

$$
G=E I \Delta N
$$

where

$$
\begin{aligned}
E= & \text { the absolute detector efficiency for the gamma } \\
& \text { ray counted } \\
I= & \text { the absolute decay abundance of the radiation, } \\
& \text { number of gamma rays emitted per decay. }
\end{aligned}
$$

Thus, the number of counts observed for an activated species found in a single irradiation-decaymcount cycle is given by

$$
G=\frac{\operatorname{EIrSDC}}{\lambda}
$$

\section{CYCLIC ACTIVATION AND COUNTING}

Cyclic activation and counting is used to enhance the sensitivity of analyses of short-lived species. Because the production and decay rates are the same at saturation, and because saturation is achieved quickly for short-lived product species, detection sensitivity does not increase when the irradiation and counting intervals are increased beyond a few half-lives. In fact, for analysis times which are much largex than the product half-life, a significant gain in detection sersitivity is achieved by cyclically activating and counting a sample several times during the analysis. 
As in Equations $2-4, T_{1}, T_{2}$, and $T_{3}$ are the irradiation, becay, and counting intervals, respectively. If $\mathrm{T}_{4}$ is defined at the time required to transport the sample from the counter back into the neutron flux, then the total time required for each cycle is

$$
\mathrm{T}_{\mathrm{C}}=\mathrm{T}_{1}+\mathrm{T}_{2}+\mathrm{T}_{3}+\mathrm{T}_{4}
$$

For the first cycle, $\mathrm{G}$ counts are recorded. For the second cycle, 6 counts are accumulated from the second irradiation, ard $G \exp \left(-\lambda \mathrm{T}_{\mathrm{C}}\right)$ counts are accumulated from the activity remain ing from the first irradiation. For the third cycle, $G$ counts axe accumulated from Irradiation $3, \operatorname{Gexp}\left(-\lambda \mathrm{T}_{\mathrm{C}}\right)$ counts are accumulated from Trxadiation 2 , and $G \exp \left(-\lambda \mathrm{T}_{\mathrm{C}}\right) \exp \left(-\lambda \mathrm{T}_{\mathrm{C}}\right)$ counts are accumulated from the activity remaining from the first irradiation. whe number of counts accumulated during the counting time fox wach cycle is

$\begin{array}{ll}\text { Cucle } & \text { Counto } \\ 1 & 6 \\ 2 & G+6 Q \\ 3 & G+6 Q+6 Q^{2} \\ 4 & G+6 Q+6 Q^{2}+6 Q^{3} \\ : & : \\ & = \\ M & G+G Q+\ldots G Q^{M-1}\end{array}$

whexe

$$
Q=\exp \left(n \lambda \mathrm{T}_{\omega}\right)
$$

The total the required for the cyclic analysis is

$$
\mathrm{T}_{\mathrm{A}}=\mathrm{MT}_{\mathrm{C}}
$$

Thus, afer $M$ cycles, the total number of counts $K$ collected is the sum of the counts for each cycle, or

$$
\begin{aligned}
K & =M C+(M-1) G Q+(M-2) Q_{Q}^{2}+\ldots G Q^{M-1} \\
& =G\left[M+(M-1) Q+(M-2) Q^{2}+\ldots Q^{M-1}\right]
\end{aligned}
$$

The firlte series in brackets may be expressed as the difference betwen two infinde series (which are each expansions of anam lytual expressions as follows: 


$$
M+(M-1) Q+(M-2) Q^{2}+\ldots Q^{M-1}=\frac{M}{1-Q}-\frac{Q(1-Q M)}{(1-Q)^{2}}=F
$$

Replacing this series by fyelds

$$
K=G F
$$

By substitution, the number of counts recorded during a cyclic irradiation and counting regime is

$$
K=\frac{E I S D C F}{\lambda}
$$

For a fixed total analysis time $T_{A}, k$ would be maximized when the irradiation and counting times are equal $\left(T_{1} \approx T_{3}\right)$ and when the transit times $\mathrm{T}_{2}$ and $\mathrm{T}_{\mathrm{z}}$ are zero. For a given total analysis time $\mathrm{T}_{\mathrm{A}}$ and finite values for $\mathrm{T}_{2}$ and $\mathrm{T}_{4}$, there is a particular number of cycles for which $k$ is a maximum. The analysis procedure is optimized with this equation for a given isotope.

A maximum total analysis time is usually determined by the number of samples to be analyzed within a certain time period. ${ }^{46 \mathrm{M}} \mathrm{Sc}$, with an 18.7 -second neutron capture product, is a good example to demonstrate the effect of optimized cyclic activation and counting regimes. The rnaximum analysis time is assumed to be 200 seconds, the ixradiation and counting intervals are assumed to be equal, and the sample transfer times are assumed to be 1.0 second. The curve in Figure 18 shows the relative number of ${ }_{4}{ }^{6} \mathrm{Sc}$ counts as a function of the number of cycles calculated from Equation 11. The experimental response was determined with a scandium standard; the response is normalized to the calculated curve. The optimum number of cycles is about 4 ; thus, the ixradiation and counting intervals for maximum sensitivity is 24 seconds for the assumed analysis conditions.

\section{Cyclic Sensitivities}

Table 2 compares interferencemfee detection limits calcum lated for elements which yield short half-1ife neutron activation products suitable for analysis when irradiated. For single cycle manual irradiation, the calculation was based on the most sensitive isotope that can be produced by activating that element regardless of half-life. The maximum analysis time allowed was 190 hours. For 100 mcycle autonatic irradiation, the calculation was based on the cyclic activation product indicated. The maximum analysis time allowed was 16 hours. For the elements fluorine through cobalt, the advantages of cyclic activation are that both analysis time and detection limits are greatly improved. For other elements, 


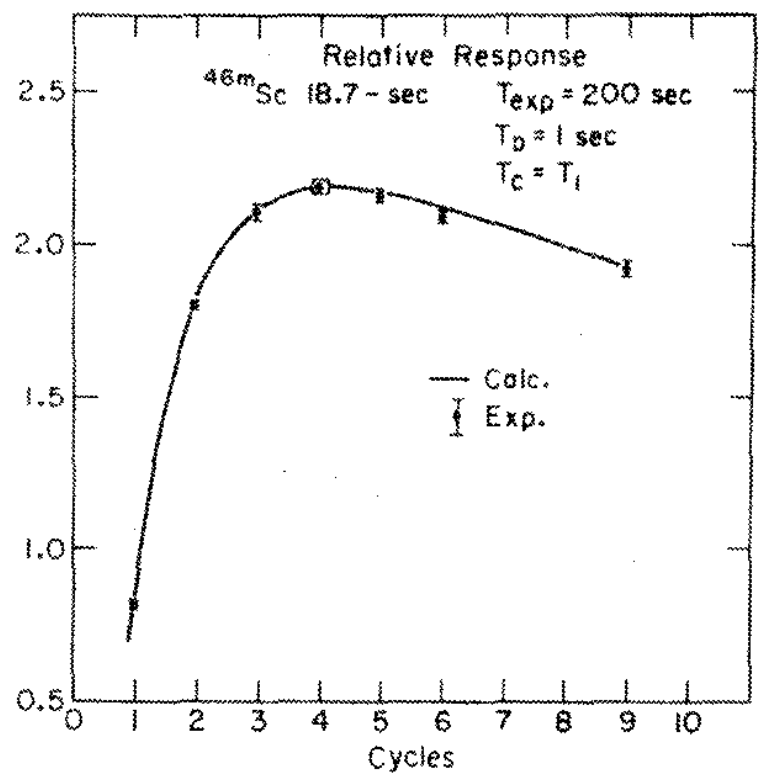

FlGue 18. Relative Detector Response for Cyclic Activation of Scandium

TXLL 2

Sensitivity of Cyclic Activation with 17 mg asc source

\begin{tabular}{|c|c|c|c|c|c|}
\hline & byolio Aotivation & simgle cyez & Maniat & 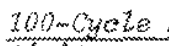 & itomatio \\
\hline Kroment & procket & tamets $t_{s}$ & Thme, $h p^{2}$ & limits, $1 \mathrm{~g}$ & Thnes, $k y$ \\
\hline s & $\left\{1, l-s^{20} x\right.$ & & & 800 & 0.7 \\
\hline in & $34.2-5 \times 16 n$ & & & 20 & 0.8 \\
\hline 88 & $17.5-5{ }^{7 m_{S e}}$ & 0.9 & 190 & 0.6 & 1.1 \\
\hline by & $1.24-m s s m_{0 y}$ & 3 & 26 & 0.2 & 4.2 \\
\hline 好 & $3.67 \cdots \mathrm{m}{ }^{163} \mathrm{gd}$ & 10 & 26 & 3 & 32 \\
\hline w & $5.3 m m{ }^{65} \mathrm{Cu}$ & 80 & 26 & 5 & 36 \\
\hline$\infty$ & $10.5-50 \mathrm{mog}_{\mathrm{Co}}$ & 0.6 & 190 & 0.3 & 16 \\
\hline 80 & $38.7-5{ }^{403} 50$ & 0.02 & 190 & 0.3 & 1.1 \\
\hline S3: & $37,4-5 m^{80} 8 x$ & 0.2 & 53 & 0.4 & 3.6 \\
\hline $235_{4}$ & Bes & 1.3 & 0.1 & 0.03 & 1,2 \\
\hline $\mathrm{Ag}$ & $24.6 \mathrm{~m}=120 \mathrm{Ag}$ & 60 & 0.6 & 1.0 & 3.4 \\
\hline 以ू & $42 \sim 5{ }^{100^{3}} 2 h$ & 600 & 0.2 & 20 & $2 \cdot 4$ \\
\hline Al & $2.24 m 38{ }^{20} \mathrm{NI}$ & 60 & 0.5 & 2 & 7.5 \\
\hline$y$ & $3.76-32 y$ & 3 & 0.9 & 0.09 & 13 \\
\hline $\mathrm{T}$ & $5, y+\ldots$ m & 250 & 1,3 & 10 & 16 \\
\hline Ny & $6.27-3 \mathrm{ma} \quad 54 \mathrm{mb}$ & 3400 & 1.5 & 3.30 & 16 \\
\hline Cas & $8.3-m+3 \mathrm{ca}$ & 5000 & 2.0 & 290 & $\xi 6$ \\
\hline My & $9.4-m 23 k g$ & 1700 & 2.2 & 100 & 16 \\
\hline
\end{tabular}


the particular experimental requirement on analysis time or detection limit will determine whether cyclic activation is used. For both scandium and bromine, the analysis time is greatly reduced, but the detection limit is somewhat higher. For silver through magnesium, the analysis times are increased, but the detection limits are improved. All calculations in Table 2 assume a $17 \mathrm{mg}{ }^{252} \mathrm{Cf}$ source and a flux of $3.5 \times 10^{8}$ $\mathrm{n} /\left(\mathrm{cm}^{2} \mathrm{sec}\right)$.

\section{MASTER EQUATION}

A master activation analysis equation can be derived from the rate of production shown in Equation 11, $x$, which may also be expressed as

$$
\mathrm{r}=\mathrm{nR}
$$

where

$$
\begin{aligned}
& \mathrm{n}=\text { number of parent (target) atoms present in the sample, } \\
& \text { and } \\
& \mathrm{R}=\text { specific neutron capture reaction rate leading to the } \\
& \text { product [captures/(sec-atom) }{ }^{*}
\end{aligned}
$$

The number of target atoms in the sample of weight, $W$ in grams, containing $\mathrm{P}$ parts per million of that element is

$$
n=\frac{P B N_{O}}{10^{6} A}
$$

where

$B=i$ isotopic abundance of parent nuclide

$A=$ atomic weight of parent nuclide

$N_{0}=$ Avagadro's number

Substituting Equations 12 and 13 into Equation 11 gives

$$
K=\frac{N_{0} \text { PWBEISCDFR }}{10^{6} \mathrm{A \lambda}}
$$

* The ability to predict the specific neutron capture reaction rate by calculation is the basis of the absolute technique and is discussed in later sections. 
solving for $p$

$$
P=\frac{k A \times 10^{6}}{N B E+N_{O}} \cdot \frac{1}{S D C D} \cdot \frac{1}{R}
$$

Equation 15 is the master activation analysis equation. As with most squatons which are derived for molear processes. simplifying assumptions have been made to reduce the complexity of the expresson. The assumptions implied in the preceding aerivation and the range of applicability of this master equation are as follows:

- The fraction of target molei activated during the rotal irxarator is very small, i.e., target burnup is neglected. This assumbton is realistio if $n R T<<1$ (which is true exm cept sor very high neutron fluxes, very large cross sections, and/or very long irradiations).

- Maltiple neutron captures are neglected, i.e., product burnup is neglected.

* R is constan over the total irradiation time. This assumption may rot be valia for reactor activation becuse both the neutron flux magnitude and energy distribution charge as a furction of power level and fuel burnup. For isotopic neutron sources, this condition is met if the total irradition time is a small fracm

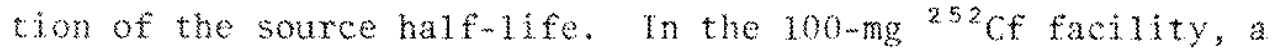
maximu iradiation time of 14 days 5 nomal; therefore, the acorease in flux is $4 \%$ during irradiation.

* The detector and associated electronics have negligible dead thene. This condition can be met by asing small samples or by compling the sample at bov detection etticiency. If these steps are undesinabe, there are electronic procedures which allow ton dead time compensation.

- The the of tranest of samples into and out of the fux is very short compared to the ixrabiation time. Mhis condition is generaly met with manual inradation becase only long-lived species are heing considered. Using the rabbit system, transit theses are keduced by increasing the transport velocity.

In practice, quation is is solved by computer. As disw cussed aribe, specific neutron capture teaction rates, R, are caloulated from the molerated 252 Cf tission nevtron spectrum, an imporant forture in the absolute technique.

\section{SPECIFIC NEUTRON CAPTURE REACTION RATES}

Wach maleas has a neutron capture cross section, o, which is an effective area of interaction with a point neutron moving 
at some speed $s$. The number of neutrons passing through (into and out of) an area per unit time is the flux $\phi$. The specific neutron capture reaction rate can be expressed as the product

$$
R=\varnothing \phi
$$

Both $\sigma$ and $\phi$ are functions of the neutron speed, such that

$$
R=\int[\sigma(s) \phi(s)] d s
$$

The flux may be expressed as a speed distribution

$$
\phi(s)=n(s) s
$$

Where $n(s)$ is the number of neutrons per unit volume having speed $s$.

Thus

$$
\mathrm{R}=f[\sigma(\mathrm{s}) \mathrm{n}(\mathrm{s}) \mathrm{s}] \mathrm{ds}
$$

To date no analytical functions accurately describe either $o(s)$ or $\mathrm{n}(\mathrm{s})$ for any real experiment. Two approaches to approximating $R$ have developed: 1) multigroup sumations, and 2) anam lytical function approximations.

\section{Multigroup (84-group) Sumation}

Equation 19 may be expressed by a sum of many integrals over sma11 regions of $s$ by

$$
R=\sum R_{i}=\sum_{i=1}^{M} \int_{s_{i}}^{s+1}[o(s) n(s) s] d s \quad\left(s_{1}=0 ; s_{m+1}=\infty\right]
$$

If $M$ is large and the neutron distribution is smooth between $s_{i}$ and $s_{i+1}$, each rate may be expressed by

$$
R_{i}=\phi_{i} \tilde{\sigma}_{i}
$$

where

$$
\begin{aligned}
& \phi_{i}=\begin{array}{l}
\text { the flux in group } i \text { (number of neutrons } /\left(\mathrm{cm}^{2} m \mathrm{sec}\right) \text { with } \\
\text { speeds between } s_{i} \text { and } s_{i+1} \text {, and }
\end{array} \\
& \bar{\sigma}_{i}=\text { the average cross section over the neutron speed range. }
\end{aligned}
$$

Each $\tilde{\sigma}_{j}$ is obtained by weighting $\sigma(s)$ by some function of $s$ for each speed group. In practice, $\sigma(s)$ is calculated from a measured smooth cross section component and the measured resonance parameters superimposed on this smooth componert; $\sigma(s)$ is then weighted by the 
wicroscopically smooth flux distribution (in 84 speed groups) supplied for the rate calculation. The 84 group approximation assumes that the flux distribution within a speed group is microm scopically smooth and that the cross section retains its resonance fluctuations. The description of the microscopic cross section requares a large number of parameters for each nuclide. Unfortunately, only a limited number of nuclides has been studied in detail sufficient to provide all these data; even more unfortunate is the fact that, of the well-studied nuclides, only a few of interest to activation analysis have their parameters coded into the computer data libraries. The multigroup description of the neutron fux distribution will be discussed later.

\section{Analytical Function Approximations (2-Group)}

The second approach to calculating the specific neutron capture rates is to divide $R$ into two components, $i, e$.

$$
R=R_{\mathrm{T}}+\mathrm{R}_{\mathrm{E}}=f_{0}^{\mathrm{s}}\left[\sigma(s) n_{\mathrm{T}}(s) s\right] \mathrm{d} s+\int_{\mathrm{o}}^{s_{1}}\left[\sigma(s) \mathrm{n}_{\mathrm{E}}(s) \mathrm{d}(\mathrm{s})\right.
$$

Where $R_{Y}$ and $R_{E}$ are the thermal and epithermal components to the rate, and $s_{0}$ is the speed of the neutrons at the thermal/ epithermal boundary (called the cadmin cutoff energy).

By approximating the themal and epithermal fluxes and the cross section by analytical expression, $R$ can be expressed as,

$$
R=a_{\mathrm{T}} \cdot \phi_{\mathrm{T}}+b * \sigma_{\mathrm{E}} \cdot \phi_{\mathrm{E}}
$$

Which contains only two parameters for the cross section, or and ए; two parameters for the flux distribution, to and $\phi \mathrm{E}$, and two constants a and $b$. The analytical functions which are normally assumed are isted below:

- The thermal fux $n_{\mathrm{T}}(\mathrm{s})$ is Maxwellian, i.e.

$$
n_{\mathrm{rq}}(s)=\frac{4 m}{\sqrt{\mathrm{T}}} \frac{\mathrm{s}^{2}}{s_{\mathrm{r}} \mathrm{w}^{3}} \exp \left(-\mathrm{s}^{2} / \mathrm{s}_{\mathrm{T}}{ }^{2}\right)
$$

where

$$
\begin{aligned}
& s^{2}=2 k T / m \\
& T=\text { moderator temperature, }{ }^{\circ} K \\
& \text { m }=\text { nemtron mass, g } \\
& k=\text { Boltzmann constant } \\
& s_{\mathrm{T}}=\text { the most probable thermal speed } \\
& \text { (whexe dnof(s)/ds = 0) }
\end{aligned}
$$



- The cross section is proportional to $\frac{1}{\mathrm{~s}}$, (usually expressed as
$l / v)$

$$
\sigma(s)=\sigma_{0} s_{0} / s
$$

where

$\mathrm{s}_{\mathrm{o}}$ is some standard speed, usually $2200 \mathrm{~m} / \mathrm{s}\left(\mathrm{s}_{\mathrm{T}}\right.$ at $\left.293^{\circ} \mathrm{K}\right)$

$\sigma_{0}$ is the $\frac{1}{s}$ cross section at $s_{0}$ (usually $\sigma_{2200}$ )

- The epithermal flux is proportional to $\frac{1}{\mathrm{~s}^{2}}$ (usually expressed as $\frac{1}{\mathrm{E}}$ such that

$$
\int_{s_{0}}^{s_{1}}[\sigma(s) n(s) s] d s=k \int_{s_{0}}^{s_{1}} \frac{\sigma(s) d s}{s}=k r
$$

where

$I$ is the so-called resonance integral, which is the average epithermal cross section weighted by the $\frac{1}{s^{2}}$ flux spectrum,

$$
\begin{aligned}
K & =\beta \phi_{\mathrm{E}} \\
\phi_{\mathrm{E}} & =\text { the epithermal flux }\left(s>s_{0}\right), \text { and } \\
\beta & =\ln \frac{E_{1}}{E_{O}}\left(\text { if } \phi \propto \frac{1}{s^{2}} \text { and } \sigma(s) \propto \frac{1}{s}\right)
\end{aligned}
$$

With these assumed functions, the two group specific neutron capture reaction rate $R$ is

$$
R=\alpha \sigma_{2200} \phi_{\eta}+\beta T \phi_{E}
$$

where

$$
\begin{aligned}
& \alpha=\left(\frac{\pi}{4} \frac{T_{O}}{T}\right)^{1 / 2}=0.886 \text { if } T=T_{O}=293^{\circ} \mathrm{K} \\
& B=0.0603 \text { if } E_{O}=0.625 \mathrm{eV} ; E_{1}=10 \mathrm{MeV}, \text { or } \\
& B=0.0597 \text { if } E_{O}=0.4 \mathrm{eV} ; \mathrm{E}_{1}=10 \mathrm{MeV}
\end{aligned}
$$

(chotce of $E_{O}$ depends on the values used to determine $\phi \mathrm{z}_{\mathrm{s}}$ and $\left.\mathrm{I}\right)$ 
The applicability of the two group technique to calculations

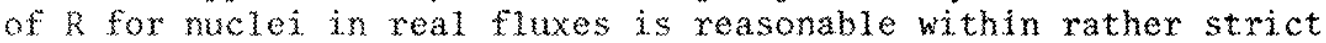
limitations:

- Epithermal resonances should be small and evenly spaced (in $\frac{1}{E}$ ) for maximum ky accuracy.

- Nuclides with resonances below $\mathrm{E}_{0}$ (subcadmium resonances) will not be properly calculated, i.e., 239 p.

- The epithermal flux must be proportional to $\frac{1}{E}$ to properly account fox the epithemal contribution to $R$. (An additional approximation which treats 8 as a variable may be used for non $\frac{3}{1}$ fruxes.)

- Reactions which have thresholds [most neutronminduced reactions except $(n, y)$ reactions $)$ cannot be treated by the twomgroup approximation.

\section{NEUTRON FLUX CALCULATIONS}

To accurately predict absolute neutron capture reaction rates, the moderated neutron energy spectrum and flux at the sample irradiation site must be calculated. As described earliex, these fyux and spectrum calculations and the multigroup (2 or 84$)$ cross section data form the basis of the absolute technique used in the 252 ct activation analysis facility. The results of the neutron anergy spectral calculations will first be discussed for the original $17-m g{ }^{252} \mathrm{Cf}$ facility with all $\mathrm{H}_{2} \mathrm{O}$ moderator and then for the moremcomplex $100 \mathrm{mg}{ }^{252} \mathrm{Cf}$ facility with $\mathrm{H}_{2} \mathrm{O} / \mathrm{D}_{2} \mathrm{O}$ moderator.

The 37 ming $252 \mathrm{Cf}$ Facility

\section{AnTSD Catoulations}

The mevtron transport code ANISN was used to calculate the neutron spectrum in 84 energy groups for the 17 mg ${ }^{252} \mathrm{Cr}$ facility. Modification of this calculation provided the thermal and epi. themal flax in the 2-group reaction rate method. ANISN assunes one-dimensional spherical geonetry in calculating neutron transport into and out of moderator and tank material zones (distances) surrounding the source. ANISN also accounts for scattering and absorption in each energy group in these zones. The details of ANISN are outside the scope of this report; however, the results consist of tables of unit neutron fluxes at each zone for each of the 84 energy subgroups. In the design of the source tank hardm ware, care was taken to approxinate the spatial geonetry assumption in ANISN: a point source surrounded as nearly as possible with a sphere of moderator. Samples contained in the hexagonal 
array of polyethylene irradiation tubes were fixed between solid polyethylene rods to displace air. The source-tomsample distances (center-to-center) for the two concentric rings were $3.81 \mathrm{~cm}$ and $10.16 \mathrm{~cm}$. The results of the $84-$ group neutron spectrum calculation for a single source surrounded by a sphere of water at $298^{\circ} \mathrm{K}$ is shown in Figure 19. Key features are:

- The Iarge thermal Maxwel1ian centered at 0.0525 ev $(0.0263 \mathrm{ev}$ if plotted $\phi$ vs $\mathrm{E}$ ).

- The unmoderated fission spectrum centered at about $2.3 \mathrm{MeV}$.

- The slightly nonm $1 / \mathrm{E}$ epithermal distribution cespecially for the $3.81 \mathrm{~cm}$ distance.

For the twomgroup approximation, which assumes a cadmium cutoff energy of $0.632 \mathrm{eV}$ and a maximum fission neutron energy of $10 \mathrm{MeV}$, the themal flux is obtained by suming fluxes $\phi_{i}$ in the energy groups below the cadmium cutoff energy. The epithernal flux is obtained by suming fluxes $\phi_{i}$ in the energy groups above the cadmium cutoff energy. plots of $\phi \mathrm{T}$ and $\phi \mathrm{E}$ and the ratios of $\phi E / \phi T$ for an all $\mathrm{H}_{2} \mathrm{O}$ moderated systen are illustrated in Figures $20 \mathrm{22}$ for the $17 \mathrm{mg}{ }^{252} \mathrm{Cf}$ facility. For these calculations, a total source emission rate of $3.51 \times 10^{\text {in }}$ neutrons/sec (15 $\mathrm{mg}$ of ${ }^{252} \mathrm{C}$ ) was used. Note the steep decline in the epithermal-tom themal Elux ratio with a minimum of 0.24 at about $15 \mathrm{~cm}$. The steep decline in flux with distance results in a thermal flux dropoff of $225 \%$ and an epithemal flux dropoff of $33 \%$ across an aqueous sample $(2.5 \mathrm{~cm}$ diameter $)$.

ANISN calculations were also performed for hypothetical cases in which the $\mathrm{H}_{2} \mathrm{O}$ moderator was replaced with spherical regions (30 cm radius) of $\mathrm{D}_{2} \mathrm{O}$ and $\mathrm{H}_{2} \mathrm{O}$. The calculated changes in $\phi_{\mathrm{T}}$ and $\phi_{\mathrm{E}} / \phi_{\mathrm{r}}$ with distance for $\mathrm{D}_{2} \mathrm{O}$ and air are show in Figures 23 and 24. $\mathrm{H}_{2} \mathrm{O}$ is the most efficient moderator; however, it has a larger absorption cross section than does $\mathrm{D}_{2} \mathrm{O}$; therefore, a higher thermal flux is observed at distances close to the ${ }^{252} \mathrm{Cf}$ source $(0$ to $10 \mathrm{~cm})$ for an all $\mathrm{H}_{2}$ Ommoderated system. Because the absorption cross section is lower for $\mathrm{B}_{2} \mathrm{O}$, the decrease in thermal flux with distance is 1ess, and useful sample irradiation region around the source is greater. Figure 24 shows the softex (lower $\phi_{\mathrm{E}} / \phi_{\mathrm{T}}$ ratio) spectmu achievable with the $D_{2} 0$ moderated system at greater distances from the sources. For example, for $\mathrm{H}_{2} \mathrm{O}$, the minimum ratio is 0.24 at $215 \mathrm{~cm}$ where $\phi_{\mathrm{T}} 02.5 \times 10^{7}$ $\mathrm{n} /\left(\mathrm{cm}^{2}-\mathrm{sec}^{2}\right)$. For $\mathrm{D}_{2} \mathrm{O}$, at $30 \mathrm{~cm}$ from the source, the flux ratio is 0.08 ; however, the thermal flux is still $0.3 \times 10^{7} \mathrm{n} /\left(\mathrm{cm}^{2}-\mathrm{sec}\right)$.

In the $17-m g{ }^{252} \mathrm{Cf}$ facility, absolute thermal neutron flux was detemined by irradiating gold wires. Measurements were made across the first irradiation position at distances of $2.72,3.18$, 


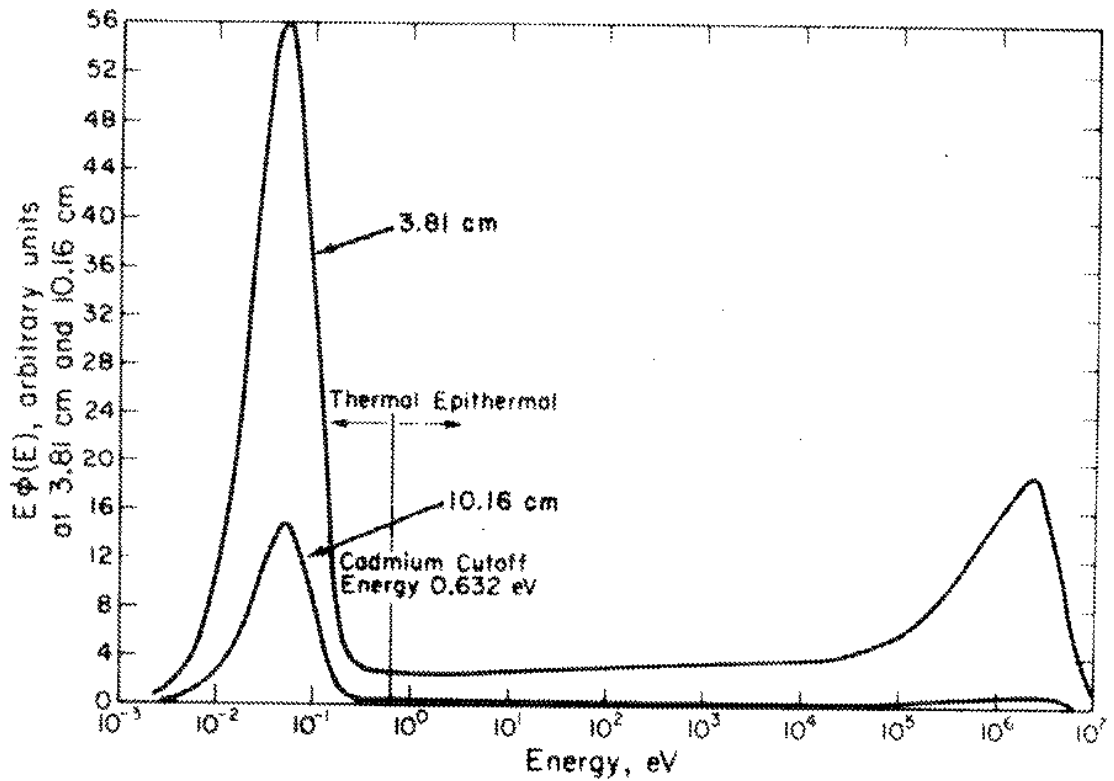

FloURE 19. Neutron Energy Spectra at $3.81 \mathrm{~cm}$ and $10.16 \mathrm{~cm}$ as Calculated by ANISN

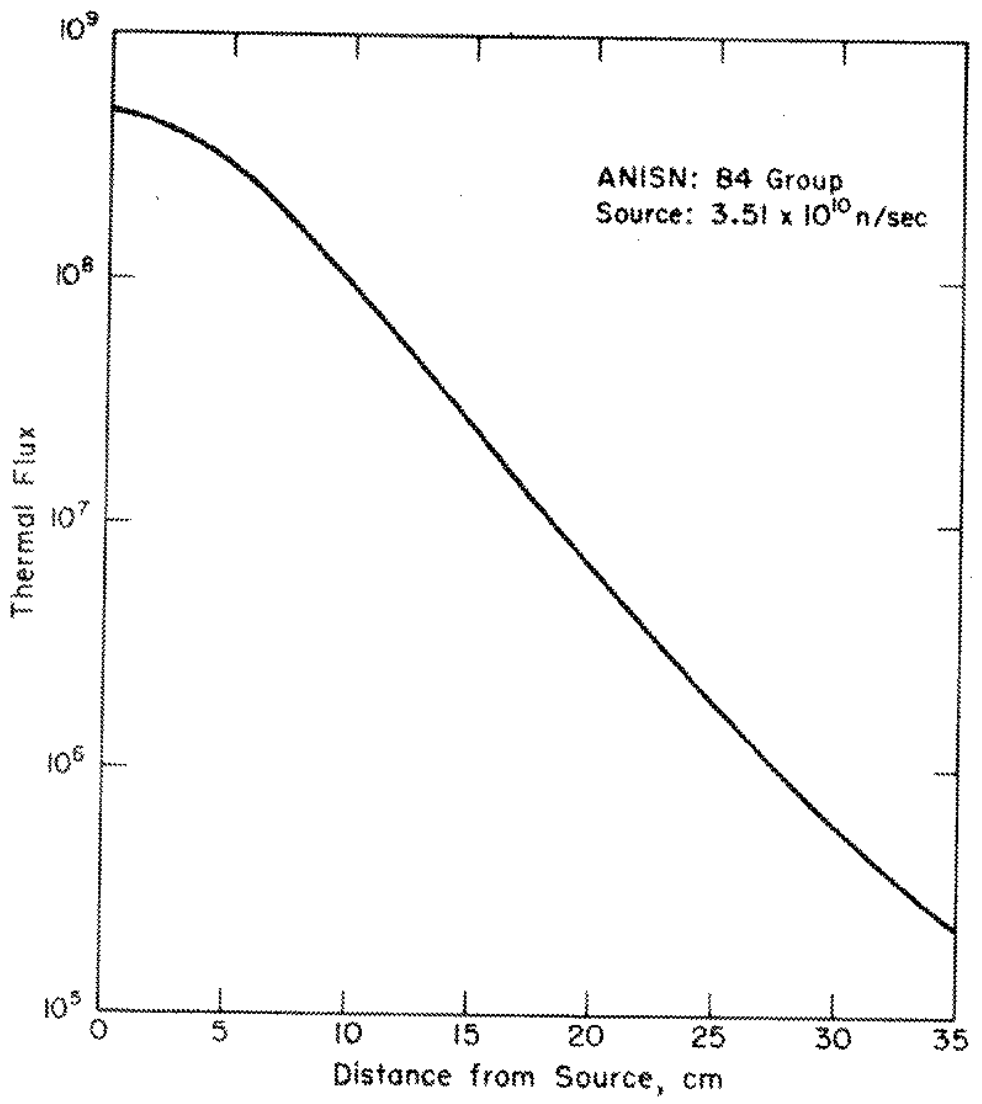

FGURE 20. Change in Thermal Flux with Distance from source 


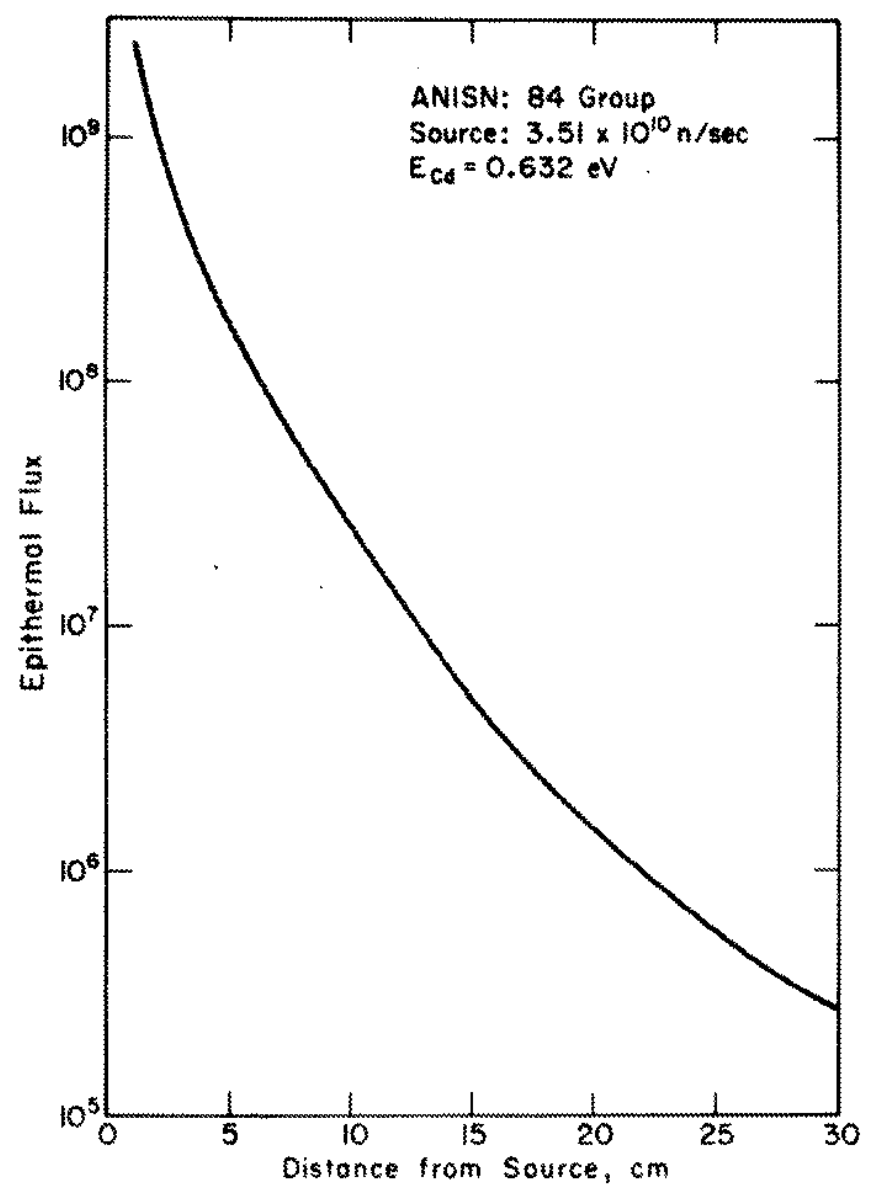

FIGURE 21. Change in Epithermal Flux with Distance from Source

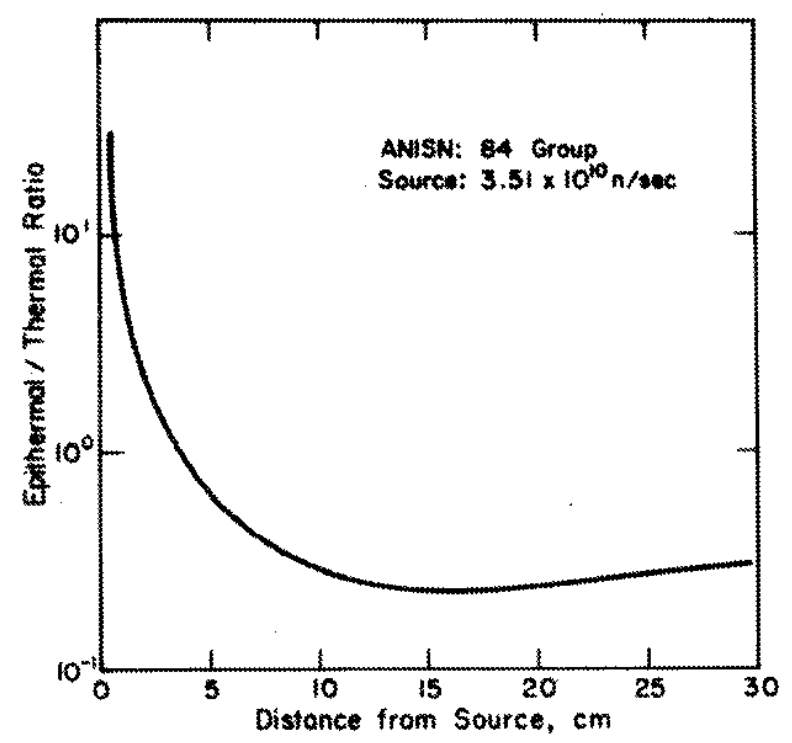

FIGURE 22. Change in Epithermal-to-Thermal Flux Ratio with Distance from source 


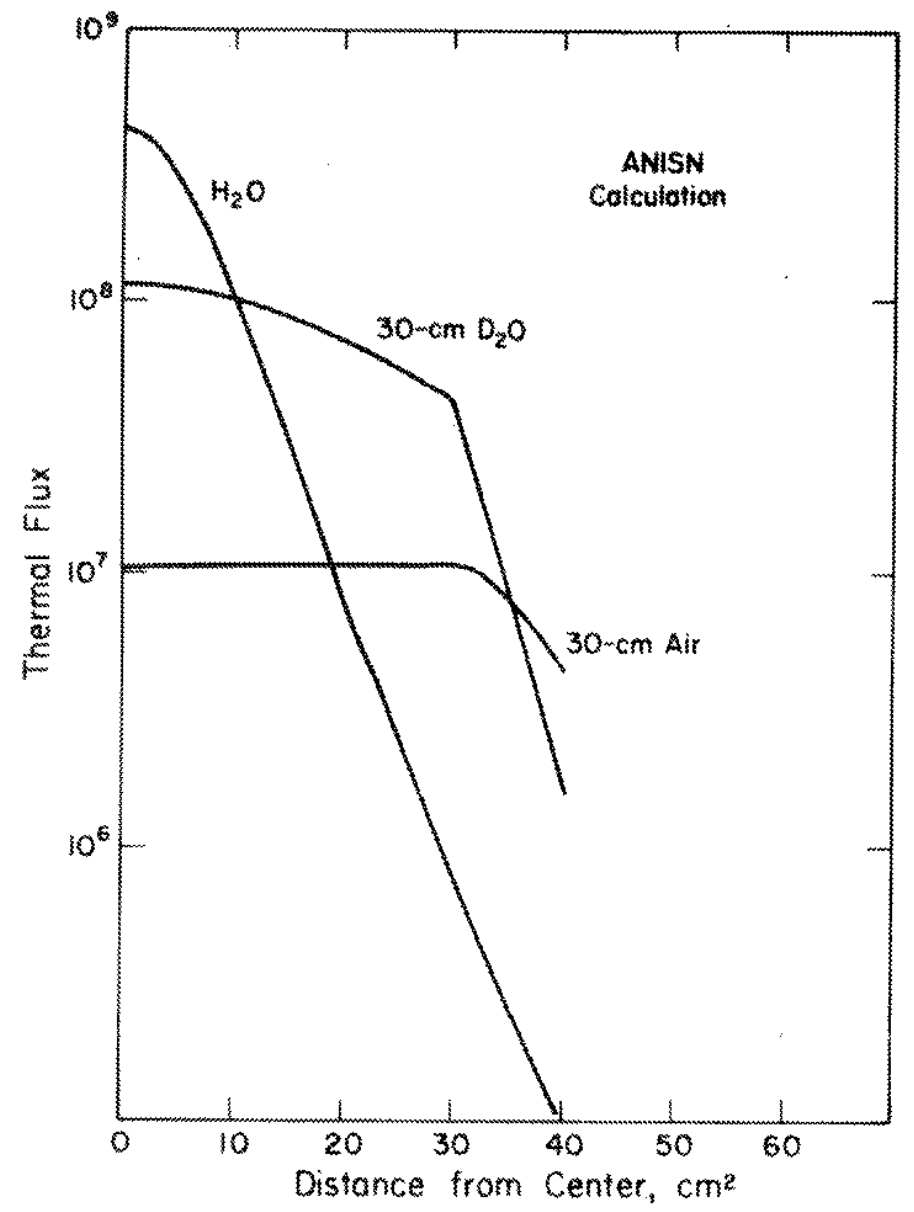

FlGuRE 23. Change in Themal Flux with Distance from Source to Centers of $\mathrm{H}_{2} \mathrm{O}, \mathrm{D}_{2} \mathrm{O}$, and Airmoderated Central Regions 


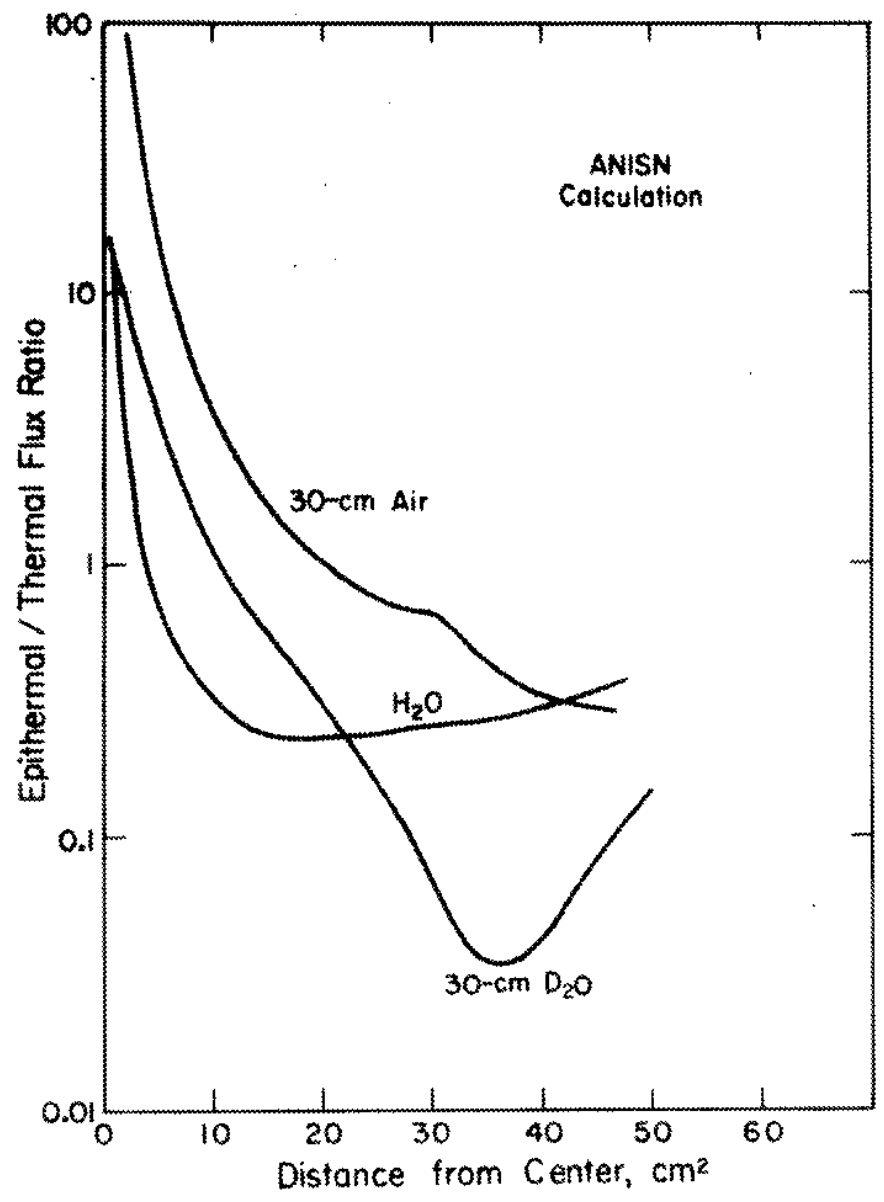

FIGURE 24. Change in Epithermal/Thermal Flux Ratio with Distance from Source for $\mathrm{H}_{2} \mathrm{O}, \mathrm{D}_{2} \mathrm{O}$, and Air Moderated Central Regions 
$3.81,4.45$, and $4.90 \mathrm{~cm}$ and at the center of the second and third irradiation tubes at 10.16 and $20.32 \mathrm{~cm}$. Results of these measurements and of integral measurements for standard gold solutions agreed within $43 \%$ of those calculated by ANISN at the $3.81 \mathrm{~cm}$ invadiation position. Agreenent was $10 \%$ at the seldomused irradiation distances of 10.16 and $20.32 \mathrm{~cm}$. Appendix $B$ summarizes the calculation of flux depression factors for the gold wres used in these experiments. Figuxe 25 sumarizes results of the thermal flux measurements.

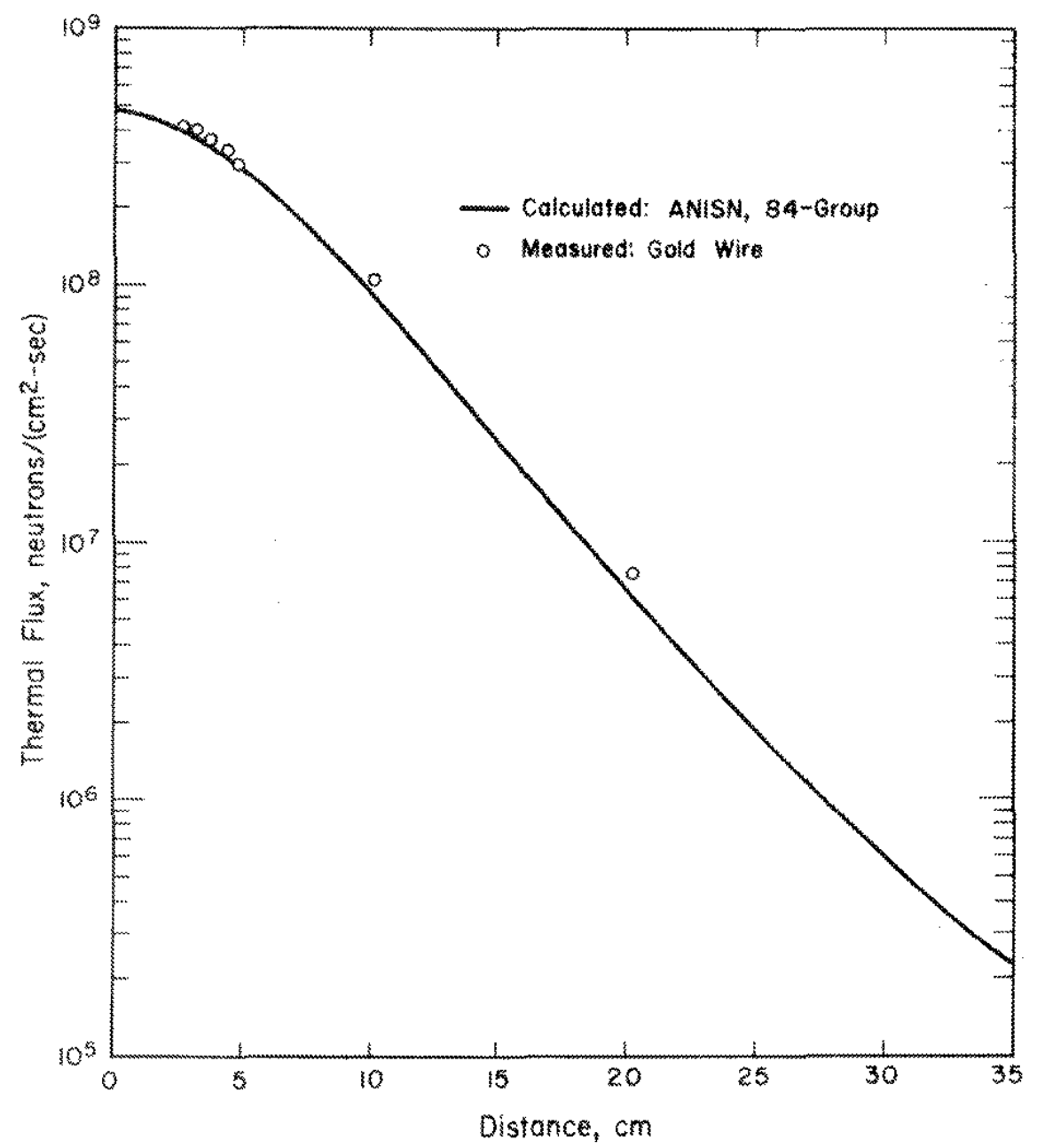

Flcukn 25. Changes in Calculated and Measured Themal Fluxes with Distance from Source 
Comparison of Caloulated and Expeximental Reaction Rates

Two-group reaction rates were calculated fxom Equation 28

for 17 elements (Tab1e 3).

$$
\begin{aligned}
\text { with } \alpha= & 0.886 \text { (using } \mathrm{T}=293^{\circ} \mathrm{K} \text { ) and } \\
\beta= & 0.023 \text { (as experimentally determined using Au and } \mathrm{Co} \\
& \text { standard solutions to account for the non- } \frac{1}{\mathrm{E}} \text { epithermal } \\
& \text { spectrum and the unmoderated neutron peak at } 2.1 \mathrm{MeV} \text { ) }
\end{aligned}
$$

As described earlier, the 84 mgroup reaction rates were calculated for nine elements from

$$
R=\sum_{i=1}^{84} \sigma_{i}(\mathrm{E}) \phi_{i}(\mathrm{E}) \quad \text { (84-group) }
$$

TABE 3

Calculated and Measured keutron Capture Rates for the $17 \mathrm{mg}$ 25acf Facility

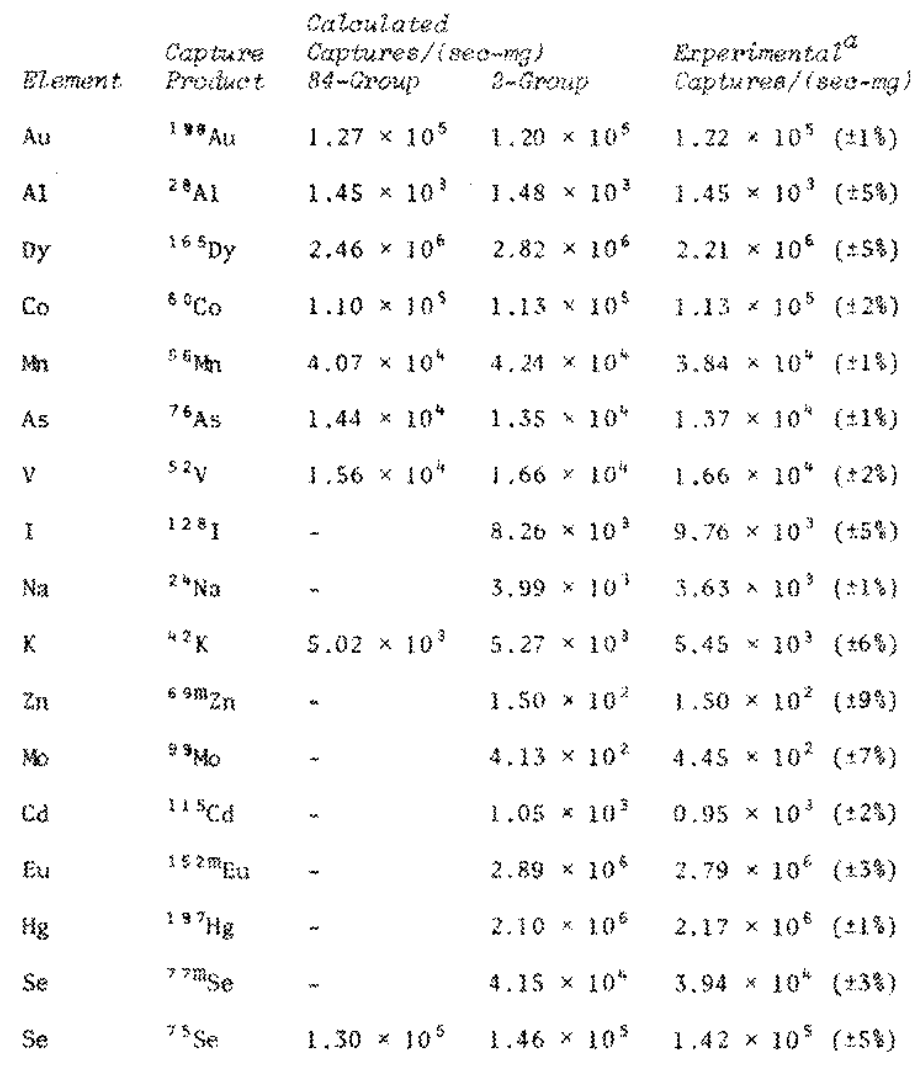

a. Uncertainties represent ondy counting statistics. 
The $\sigma_{2200}$ values and resonance integrals $I$ were taken from the recommended values of the chart of the Wolidea, 1972 edition. $^{7}$ The multigroup cross section data, $\sigma_{i}(\mathrm{E})$, were taken from the ENDF $-B$ cross section libraxy.

For experimental measurements, 17 elemental standard solutions were prepared. During sequential irradiations, all other irradiation tubes were removed to approxinate more closely the assumption of spherical moderator arrangenent. Sample irradiation, decay, and counting intervals were carefully timed, and a callbrated detector was used fox absolute counting. Results are shown in Table 3 . Eighty four group reaction rates were calculated for those nine isotopes for which multigroup cross sections are available. In general, the results of the 2 -group method are as reliable as those of the moremsophisticated 84 -group technique. However, the limitations of the twomgroup approach listed earlier must be conm sidered. Except in the cases of gold and arsenic, $>90 \%$ of the total reaction rate is the result of thermal neutron capture. The simple two-group approach to the calculation of neutron capture reaction rates appeared adequate for the particular experimental conditions within the $17 \mathrm{mg}{ }^{252} \mathrm{Cf}$ facility in which $\phi \mathrm{E} / \phi \mathrm{T}$ is about 1.0. Thus, only twomgroup reaction rates are used in the $100-\mathrm{mg}$ 252 Cf facility.

In the $17 \mathrm{mg}{ }^{25 /} \mathrm{Cf}$ facility, six irradiation tubes in a hexagonal axray were located axound the ${ }^{252} \mathrm{Cf}$ source. The presence of these tubes and of samples located within them reduce the thermal flux somewhat by displacing noderator. Quantitative measurements were performed to detemine and to correct for this effect. The net effect of the presence of the othex five irram diation tubes containing aqueous samples was to reduce the calculated thermal flux by $11 \%$ and the epithermal flux by $3 \%$. These flux reduction factors were used in the data reduction programs used for routine analysis in the $17 \mathrm{mg}{ }^{252} \mathrm{Cf}$ facility.

The $100 \mathrm{mg}{ }^{252} \mathrm{Cf}$ facility

To take advantage of the rapid modexation of $\mathrm{H}_{2} \mathrm{O}$ and the Low absorption cross section of $\mathrm{D}_{2} \mathrm{O}$, an $\mathrm{H}_{2} \mathrm{O}_{-} \mathrm{D}_{2} \mathrm{O}$ moderated system was installed in the $100 \mathrm{mg}{ }^{252} \mathrm{Cf}$ facility. As shown in Figures 6 through 8 , the first concentric ring of 9 irradiation tubes is located in the $\mathrm{H}_{2} \mathrm{O}$-moderated region, and the second ring of tubes is in the $D_{2} 0$ region. This arrangement was based on ANISN calculations in an attempt to increase the thermal flux at the second ring of irradiation sites over an all- $\mathrm{H}_{2} \mathrm{O}$-moderated system. However, because stainless steel is used in the moderator tank, the expected increase was only partly realized. 


\section{ANISN CaZoulations}

The one-dimensional ANISN code again was used to calculate the thermal and epithermal neutron fluxes and the neutron energy distribution in 13 energy groups at the sample irradiation sites. Figure 26 is a scaled drawing of the $\mathrm{H}_{2} \mathrm{O}-\mathrm{D}_{2} \mathrm{O}$ moderated system showing the locations of the rotating four-source holder $(2 \mathrm{ircaloy}-2)$, the $\mathrm{H}_{2} \mathrm{Om}$ moderated region containing the first ring of irradiation sites, and the annulax $D_{2} \mathrm{O}$ tank containing the second ring of irradiation tubes. For one-dimensional ANISN calculations, the distance zones of the different construction, moderator, and sample materials are assumed to be concentric spheres. Thus these calculations only approximate the complex three-dimensional array.

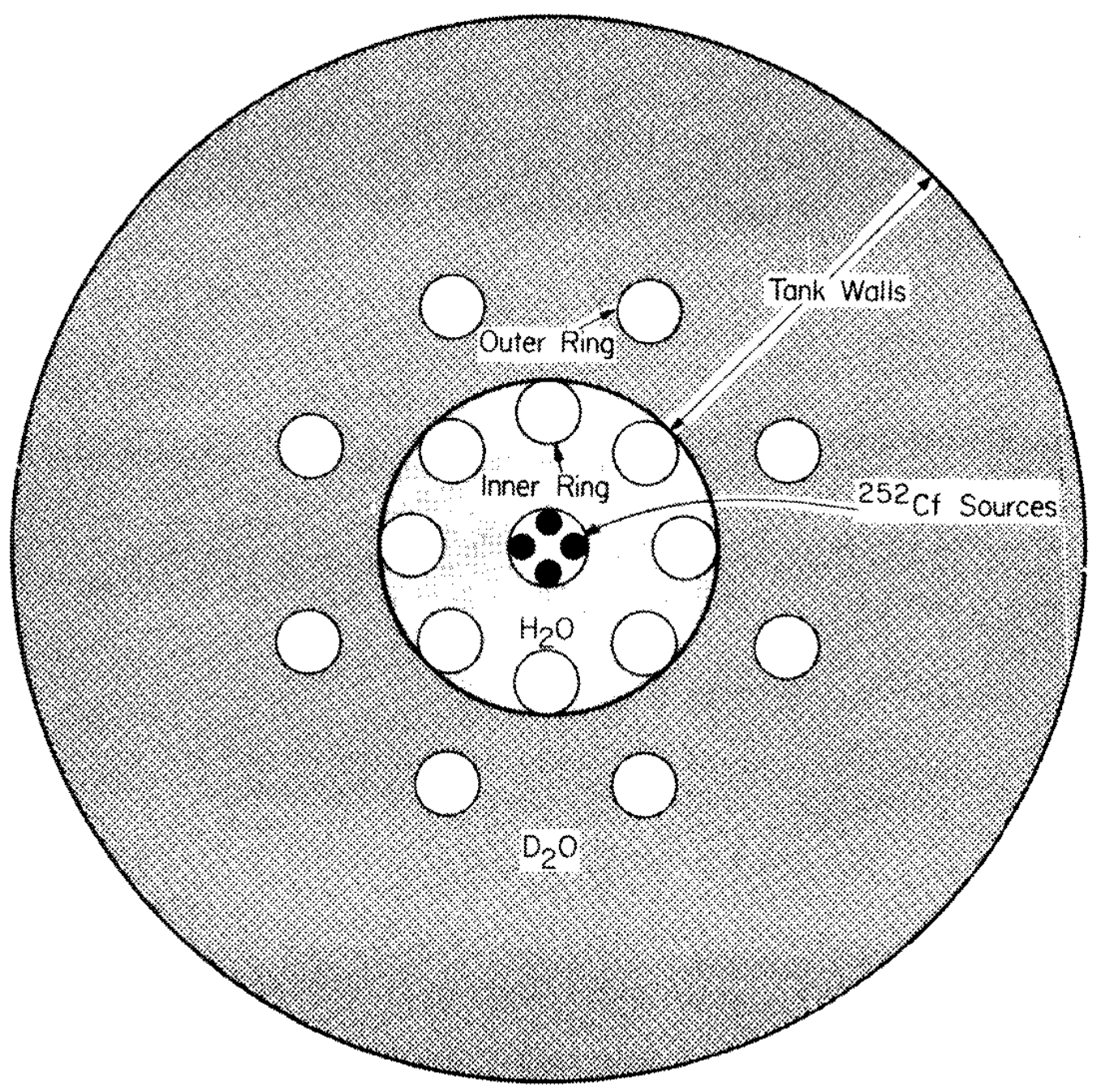

FIGURE 26. Arrangement of Irradiation Tubes and Sources in $100 \mathrm{mg}{ }^{252} \mathrm{Cf}$ Facility 
Two basic sets of calculations were performed. The first set of calculations assumed ideal systems; a spherical source and spherical regions of moderator were assumed. The stainless steel in both the moderator tank and the sample irradiation tubes were not included in the calculations. The second more realistic set of calculations included the effects of stainless steel. In all calculations, the actual source neutron emission rate $\left(2.53 \times 10^{11}\right)$ neutrons/sec) was used.

Figure 27 shows the calculated change in thermal flux with distance for an ideal all- $\mathrm{H}_{2} \mathrm{O}$-moderated system surrounding the zircaloy ${ }^{252}$ Cf source holder (Case 1). This curve is superimposed on several other curves for reference puxposes.

Figure 28 shows the results of ANISN for an ideal $\mathrm{H}_{2} \mathrm{O}-\mathrm{D}_{2} \mathrm{O}$ moderator system (Case 2). Actual $D_{2} O$ tank dimensions and the $0.692 \mathrm{~cm}$ radius of the zircaloy source holder axe shown. The effects of stainless steel and of an aqueous sample in the outer ring are not included. As expected, the flux is increased by (20\% in the $\mathrm{D}_{2} \mathrm{O}$ moderated region (outer ring sample irradiation site) over that expected from an all $\mathrm{mH}_{2} \mathrm{O}$ moderated system.

Figure 29 shows ANISN results for an ideal $\mathrm{H}_{2} \mathrm{O}_{-1} \mathrm{D}_{2} \mathrm{O}$ moderator system using actual tank and source dimensions. The effect of an aqueous sample located in the second ring irradiation site is included (Case 3). The thermal neutron absorption within the aqueous sample itself (outer ring sample region of 10.01 to $12.32 \mathrm{~cm}$ ) reduces the net increase in thermal flux at the center of the sample $(11.19 \mathrm{~cm})$ to $260 \%$ over the all $1 \mathrm{H}_{2} \mathrm{O}$ moderated system.

Figures 30 and 31 show the calculated ratios of thermal fluxes for Case $2 /$ Case 1 and for Case $3 /$ Case 1; shaded areas indicate the locations of the two irradiation rings. Flux ratio values greater than one indicate a thermal flux enhancement relative to the all$\mathrm{H}_{2} \mathrm{Om}$ moderated system. Averaged over the entire inner sample irradiation region $(4.69$ to $7.05 \mathrm{~cm})$, the effect of adding $D_{2} O$ to the inner ring is negligible because neutrons from the $D_{2} O$ region do not reflect back into the $\mathrm{H}_{2} \mathrm{O}$ region. However, the net flux gain in the outer ring is significant even when the absorbing effect of the aqueous sample is included (Case 3/Case 1). Table 4 summarizes these calculated results at the center of two rings of irradiation sites for the ideal systems.

The second, more realistic, set of calculations include the effect of the stainless steel irradiation tubes and annular tank walls. Again, because of the one-dimensional limitation of the ANISN flux calculations, simplifying assumptions were nade. Because of the staggered arrangement (Figure 26) of inner and outer rings of irradiation tubes, flux ratios for inner and outer 
irradiation tubes were calculated separately. In all calculations, however, the steel walls of the $0_{2} 0$ tank were included. Table 5 lists the regions, distance intervals, materials, and explanations of these regions shown schematically in figure 32. Regions 4 and 9 are the innex and outer ring sample irradiation positions.

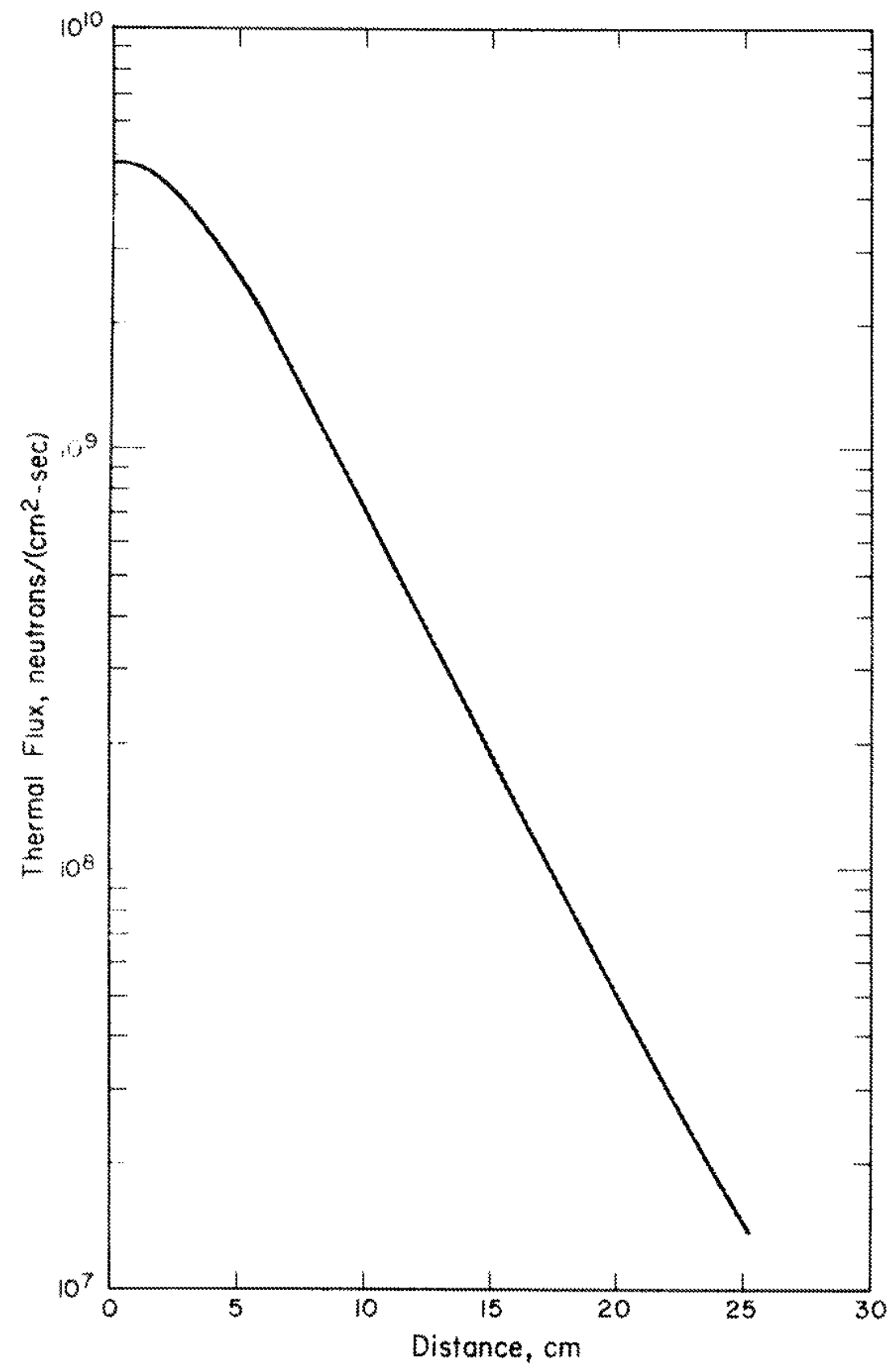

FlGURE 27. Calculated Thermal Flux for Ideal System with $\mathrm{H}_{2} \mathrm{O}$ Moderator (Case 1) 


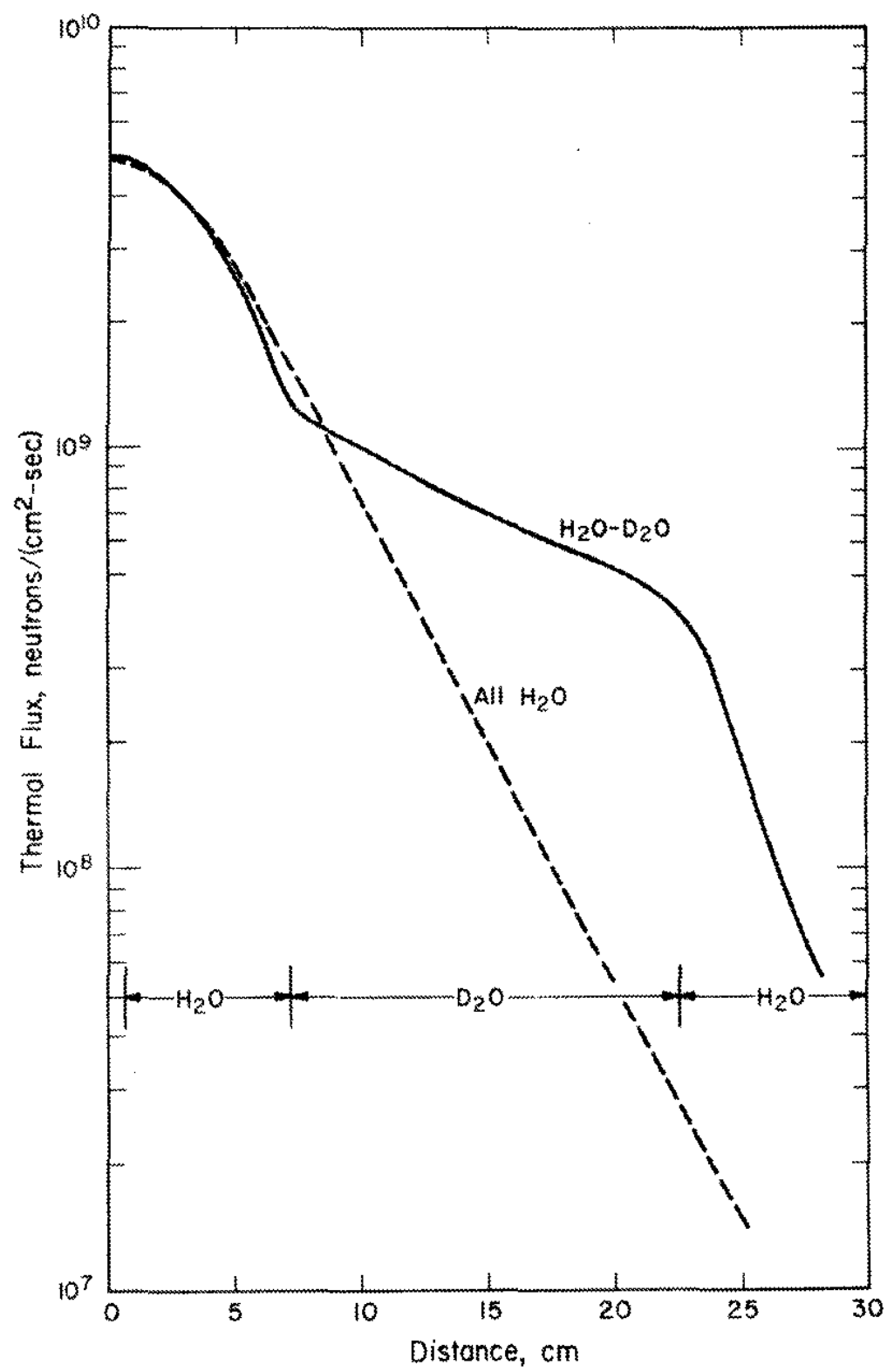

FIGURE 28. Calculated Thermal Flux for Ideal System with $\mathrm{H}_{2} \mathrm{O}-\mathrm{D}_{2} \mathrm{O}$ Moderator (Case 2) 


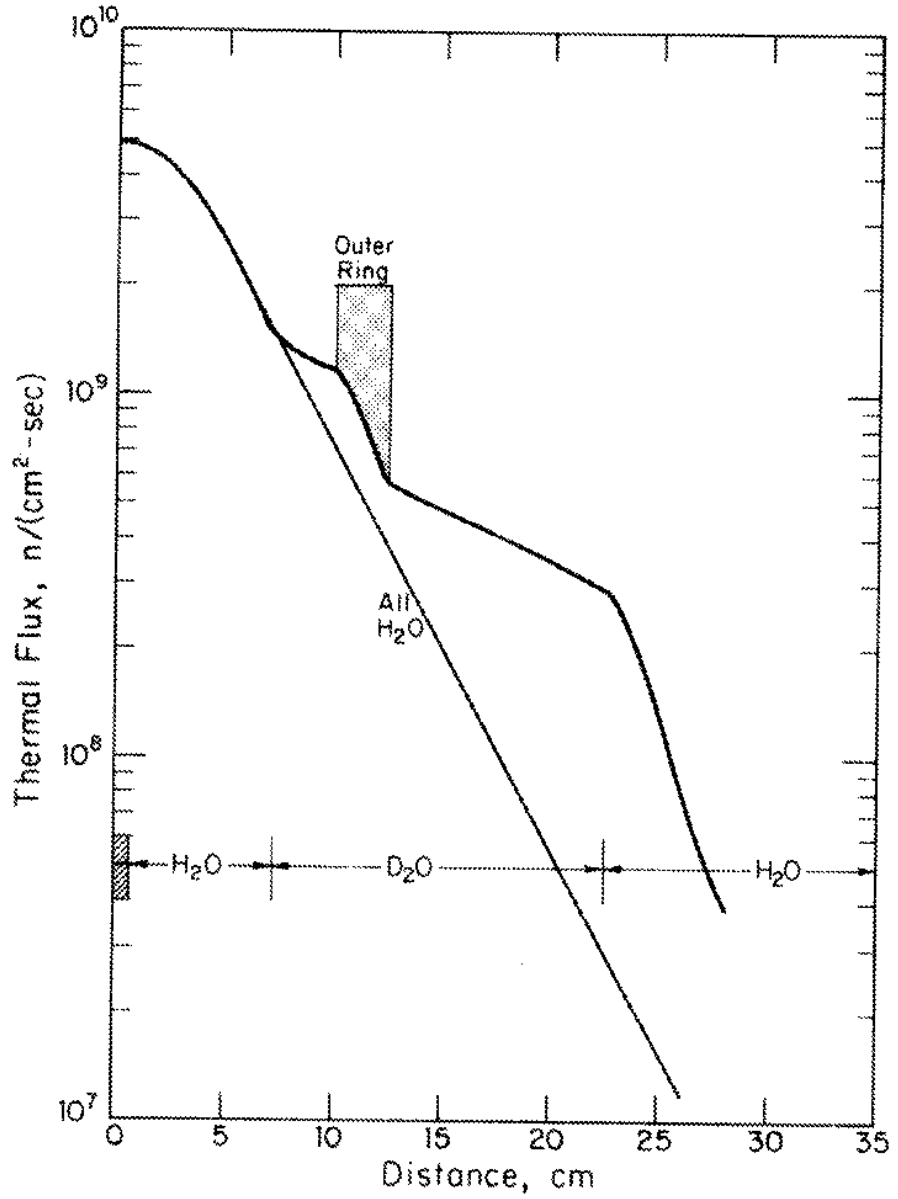

FIGURE 29. Thermal Flux for Ideal Case, $\mathrm{H}_{2} \mathrm{O}-\mathrm{D}_{2} \mathrm{O}$ Moderator with Samples in Outer Ring (Case 3) 


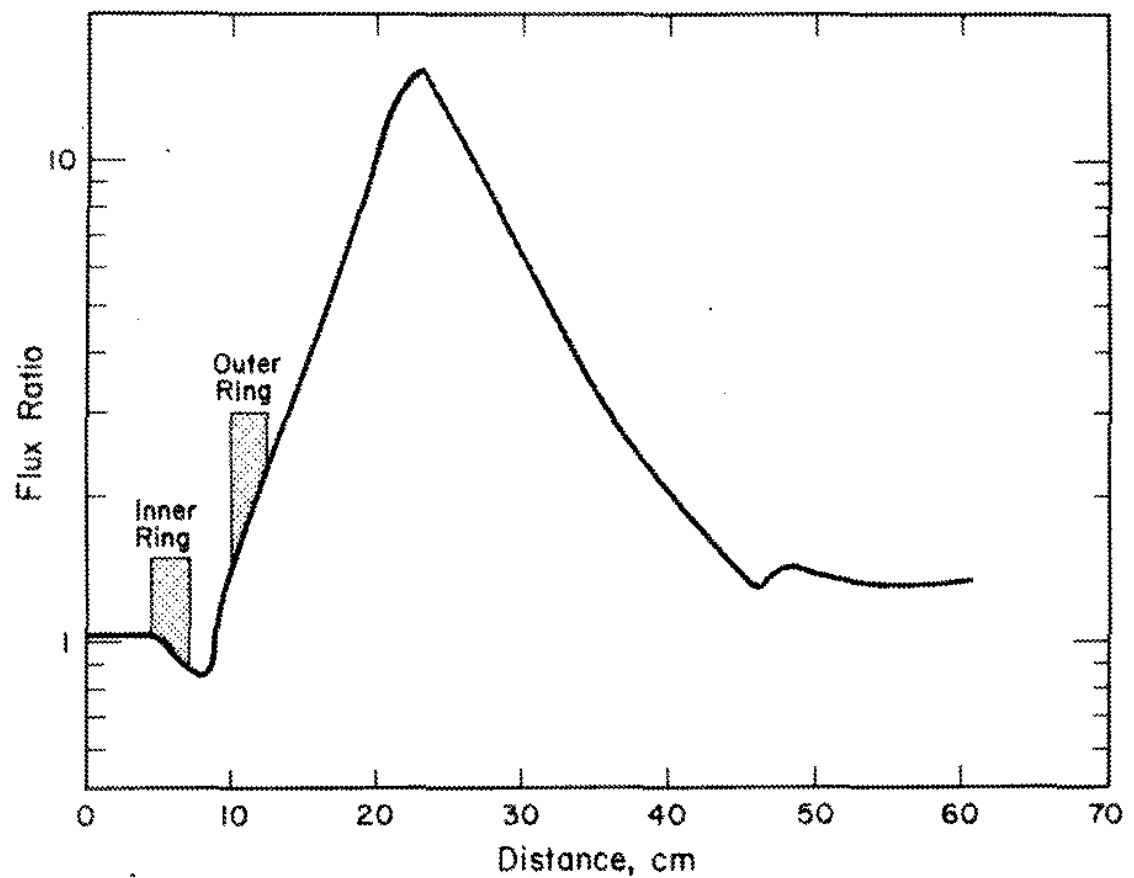

FIGuRE 30. Thernal Flux Ratio for Ideal System (Case 2/Case 1)

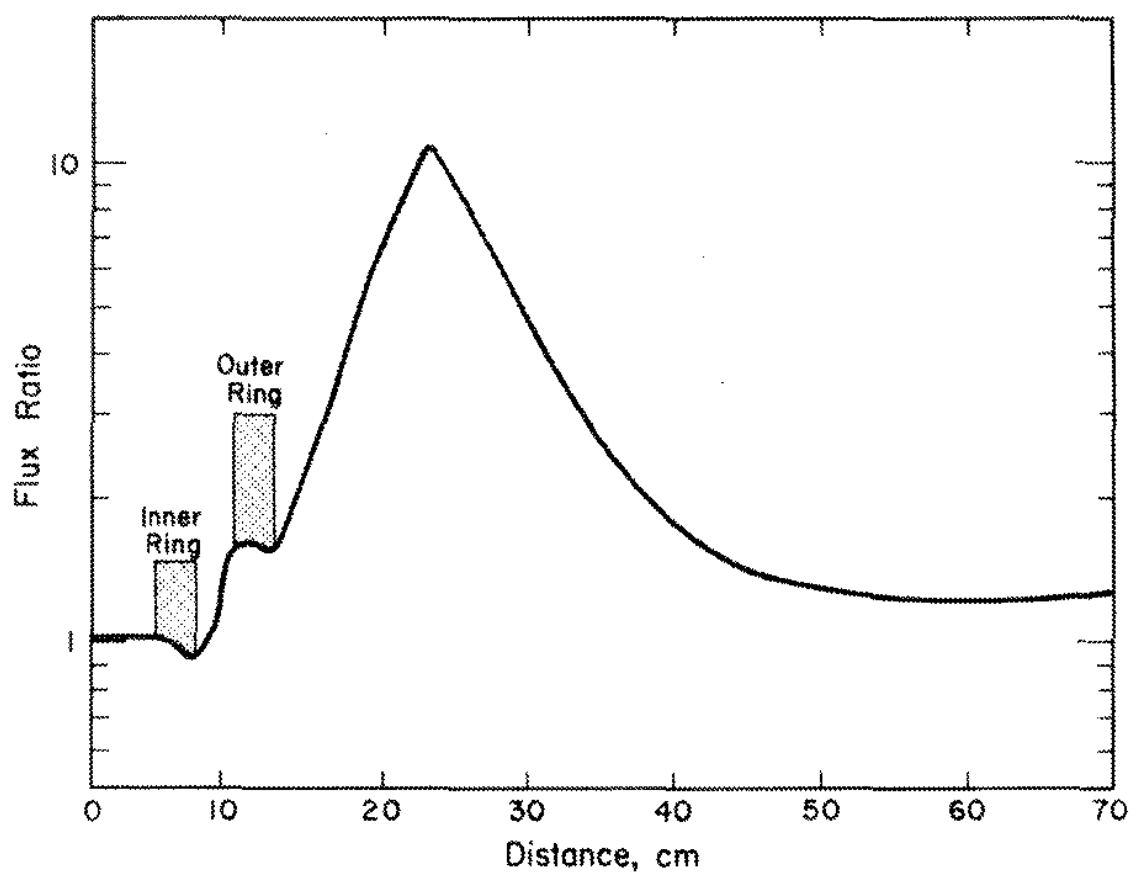

FIGURE 31. Thermal Flux Ratio for Ideal System (Case 3/Case 1) 
TABLE 4

Flux Calculations for Ideal Systems ${ }^{2}$

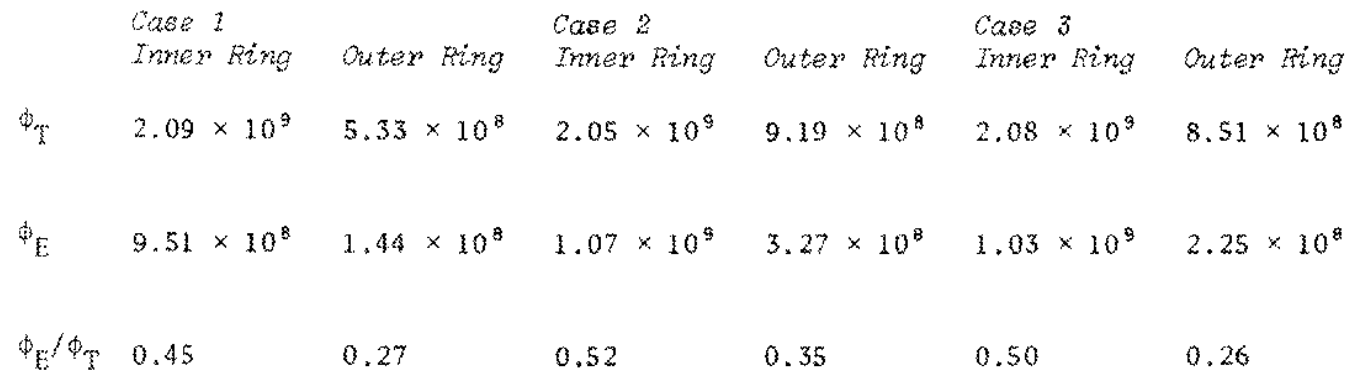

a. Case 1 , all $\mathrm{K}_{2} \mathrm{O}$ moderator;

Case $\left.2, \mathrm{H}_{2} \mathrm{O}-1\right)_{2} \mathrm{O}$ moderators; and

Case $3, \mathrm{H}_{2} \mathrm{O}-\mathrm{D}_{2} \mathrm{O}$ moderator and outer ring aqueous sample.

The effects of stamless steel were not included in these calculations.

TABLE 5

Regions, Distances and Materials

in the $100-\mathrm{mg}{ }^{252} \mathrm{Cf}$ Facility (see Figure 32)

\begin{tabular}{|c|c|c|c|}
\hline Region? & Imiermal, om & Matiertiaz & smplanation \\
\hline 1 & $0-0.6922$ & zirealoy & ${ }^{252} \mathrm{Cf}$ source holder \\
\hline 2 & $0.6922-4.602$ & $\mathrm{H}_{2} \mathrm{O}$ & $\mathrm{H}_{2} \mathrm{O}$ Soderator Around ${ }^{252} \mathrm{CE}$ Source \\
\hline 3 & $4.602-4.691$ & Stainless Steel & Near-Wall Inner Irradiation Bing \\
\hline 4 & $4.691 \times 7.054$ & $\mathrm{H}_{2} \mathrm{O}$ & Aqueous Sample Innex Ring \\
\hline 5 & $7.054-7.143$ & Stainless Steel & Fax-Wals Inner Irradiation Ring \\
\hline 6 & $7.143-7.301$ & Stainless Steel & Near Wall of Annulax Modexator Tank \\
\hline$\gamma$ & $7.301-9.921$ & $\mathrm{D}_{2} \mathrm{O}$ & $\mathrm{D}_{2} \mathrm{O}$ Moderator \\
\hline 8 & $9.921-10.010$ & Stainless Steel & Nearwall Outer Irradiation Ring \\
\hline 9 & $10.010-12,372$ & $\mathrm{n}_{2} \mathrm{O}$ & Aque ous Sample Outer Ring \\
\hline 10 & $12.372-12.461$ & Stainless steel & Far-Wall Outer Irradiaton Ring \\
\hline 13 & $\{2.461-22.460$ & $0_{2} 0$ & $\mathrm{~B}_{2} \mathrm{O}$ Moderator \\
\hline 32 & $22.460-22.619$ & Stainless Steel & Fax-Wall Anmalar Maderator Tank \\
\hline 3 & $22.619 \%$ & $\mathrm{H}_{2} \mathrm{O}$ & $\mathrm{H}_{2} \mathrm{O}$ Shielaing and Moderator \\
\hline
\end{tabular}




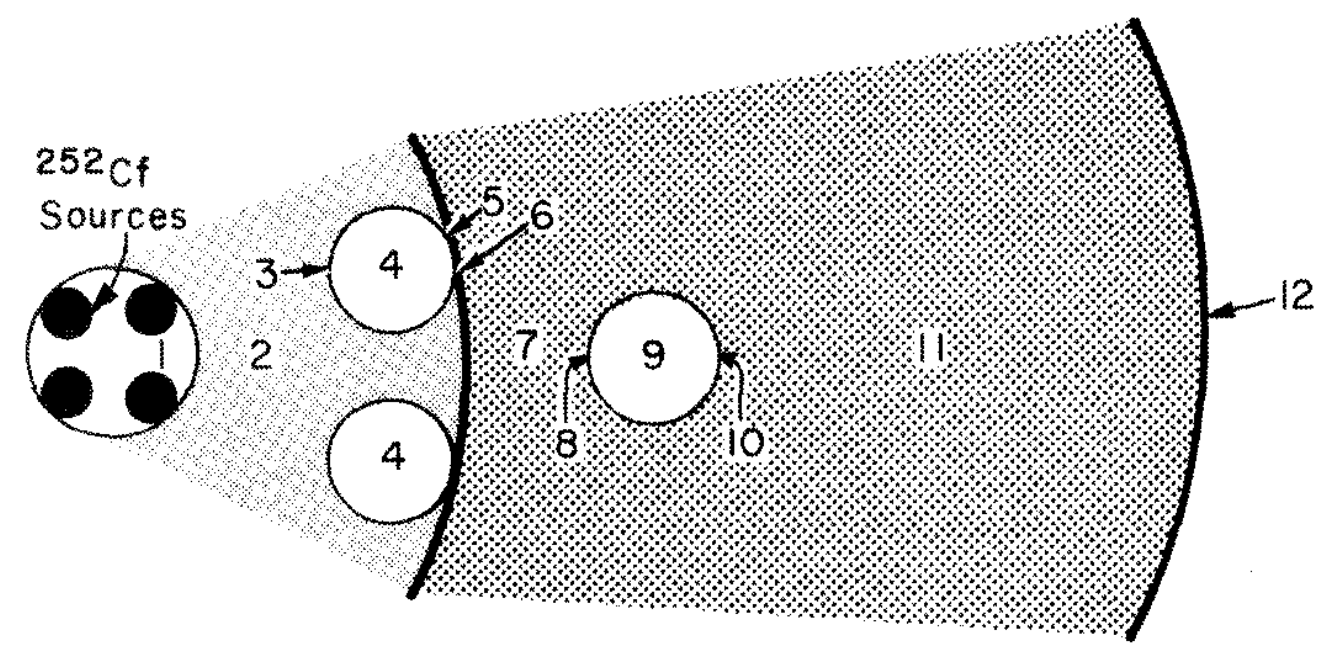

FIGURE 32. Schematic of Regions Surrounding 252 Cf Sources Used in ANISN Calculations (see Table 5)

Figure 33 (Case 4) shows the change in calculated thermal flux with distance for the inner irradiation ring for an all $\mathrm{H}, \mathrm{O}$-moderated system. (Regions 1 through 6 are as indicated in Table 5; however, the outer ring is not considered and regions 7 through 11 are assumed to be $\mathrm{H}_{2} \mathrm{O}$ ). Flux depressions are seen in Figure 33 for the near and far walls of the inner ring and for the moderator tank wall. A net loss of $030 \%$ in thermal flux at the inner ring compared to the ideal Case 1 (superimposed) occurs because of neutron absorption in the steel walls.

Figure 34 (Case 5) is the calculated change in thermal flux with distance for the inner irradiation ring of an $\mathrm{H}_{2} \mathrm{O}-\mathrm{D}_{2} \mathrm{O}$ m moderated system (i.e., Regions 7 through 11 are $b_{2} 0$ ). As shown in Table 6 , replacing the $\mathrm{H}_{2} \mathrm{O}$ with $\mathrm{D}_{2} \mathrm{O}$ does not raise the themal flux significantly at the inner ring. The stainless steel reduces the thermal flux 27.3\% at the inner ring compared to Case 2. Figure 35 shows the calculated ratios of thermal fluxes (Case 5/ Case 4). Averaged over an entire inner ring volume, this ratio does not deviate significantly from one; thus the flux enhancement is no greater with $\mathrm{D}_{2} \mathrm{O}$ moderator than that with $\mathrm{H}_{2} \mathrm{O}$ moderator.

Figure 36 (Case 6) shows the calculated change in thermal flux with distance for the outer stainless steel irradiation ring for an all $\mathrm{H}_{2} \mathrm{O}$ moderated system. Compared to the ideal case, the thermal flux is reduced by $230 \%$ [from $5.33 \times 10^{8}$ to $3.75 \times 10^{8}$ neutron $\left./\left(\mathrm{cm}^{2}-\mathrm{sec}\right)\right]$ by inclusion of the stainless steel. 


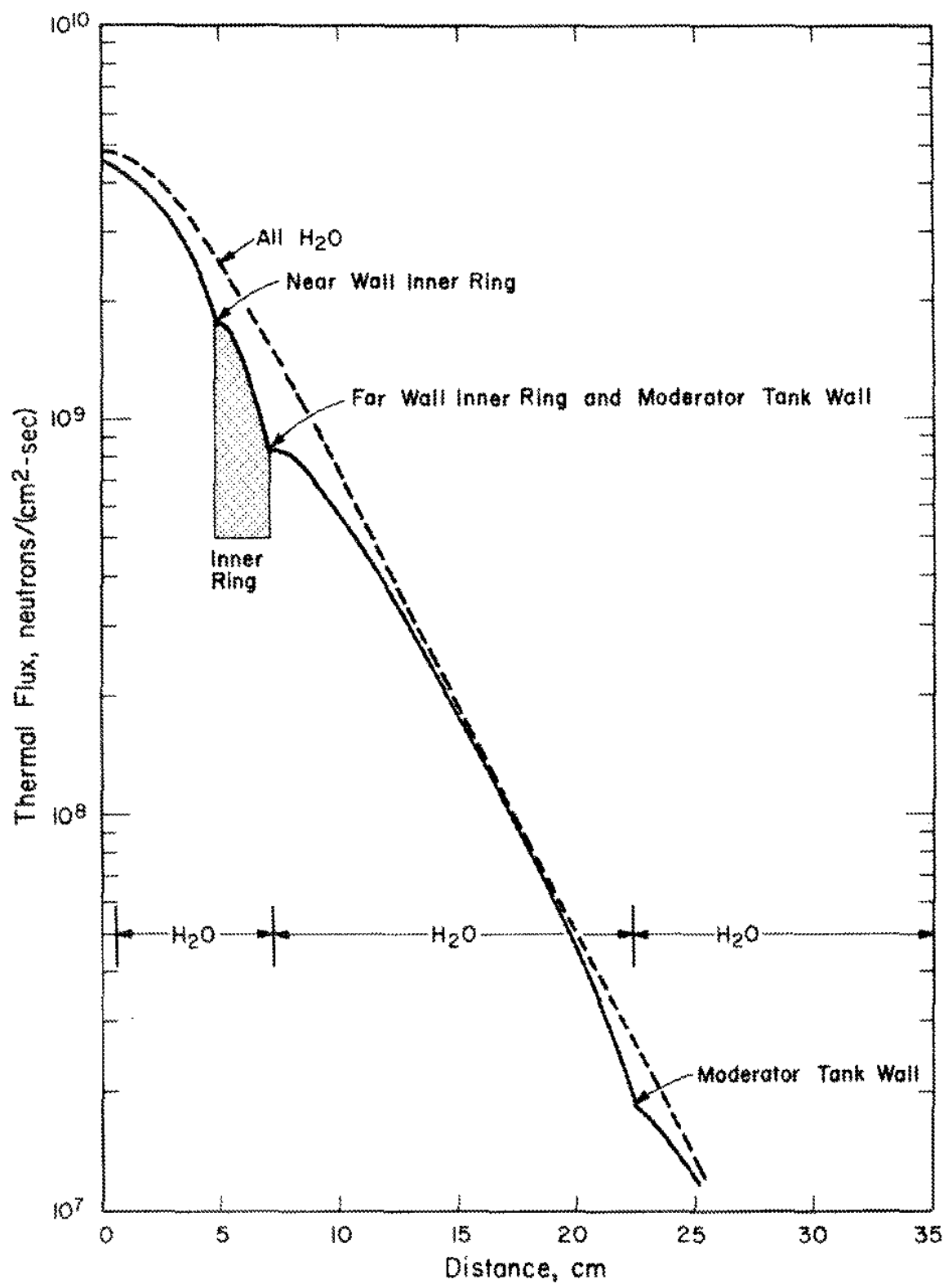

FIGURE 33. Calculated Thermal Flux for Inner Ring in Non-Ideal System with $\mathrm{H}_{2} \mathrm{O}$ Moderator (Case 4) 


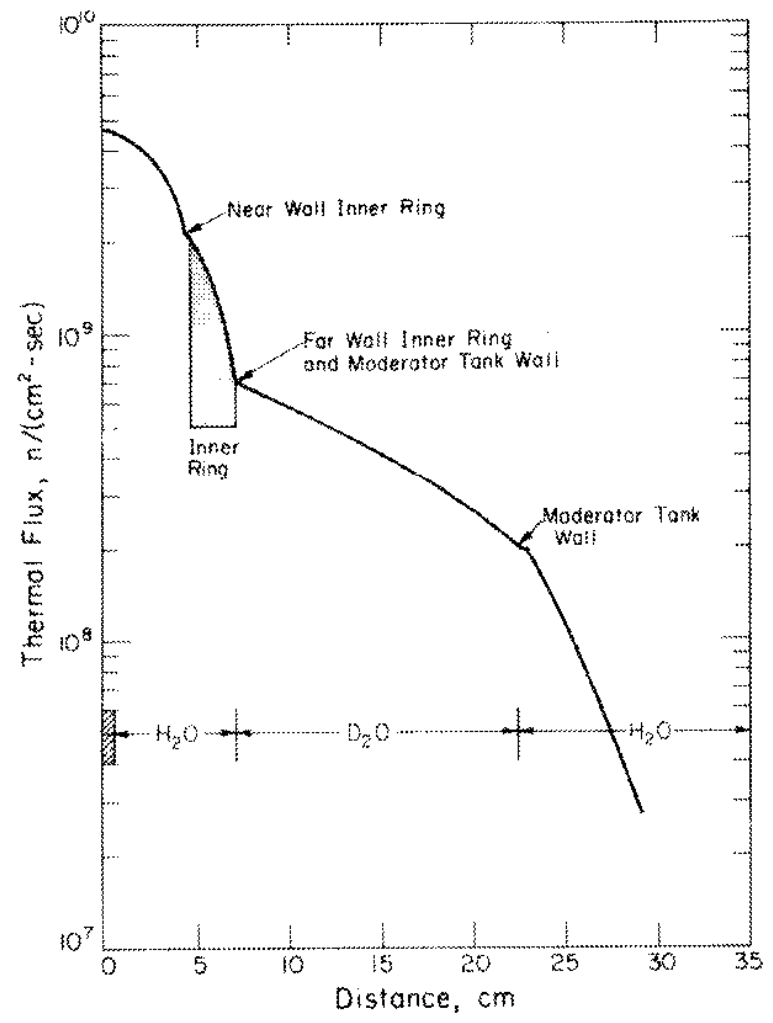

FrgURE 34. Calculated Thermal Flux for Inner Ring in Non-Ideal System with $\mathrm{H}_{2} \mathrm{O}-\mathrm{D}_{2} \mathrm{O}$ Moderator (Case 5)

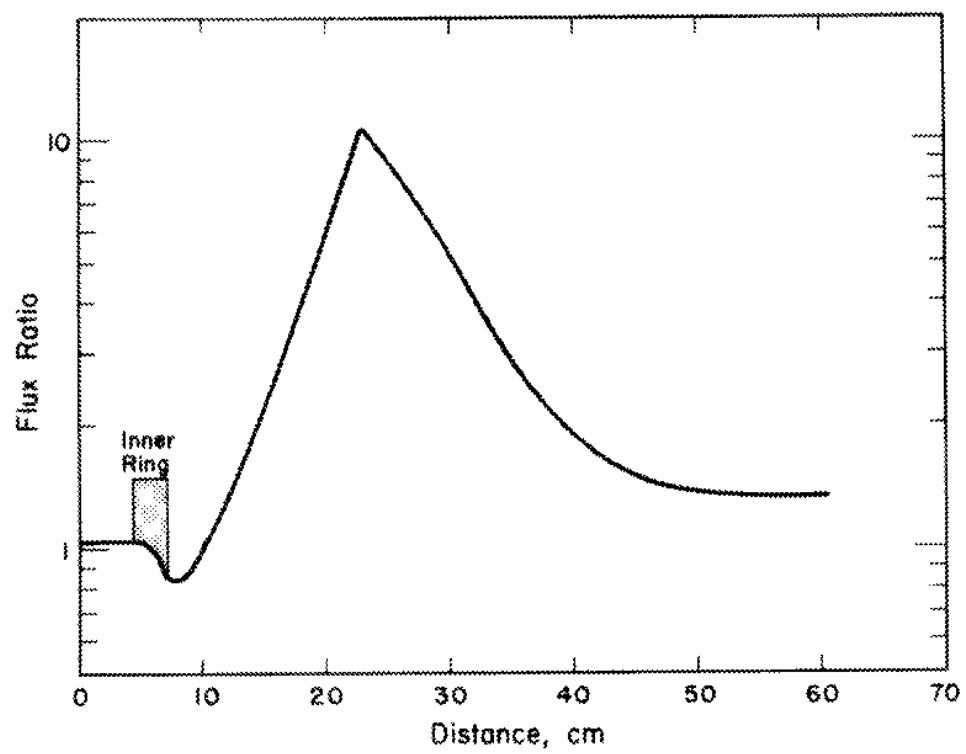

FIGURE 35. Calculated Thermal Flux Ratio for Inner Ring in Non-Ideal System with $\mathrm{H}_{2} \mathrm{O}-\mathrm{D}_{2} \mathrm{O}$ Moderator (Case 5/Case 4) 
TABLE 6

Flux Calculations that Include Effects of Stainless Steel

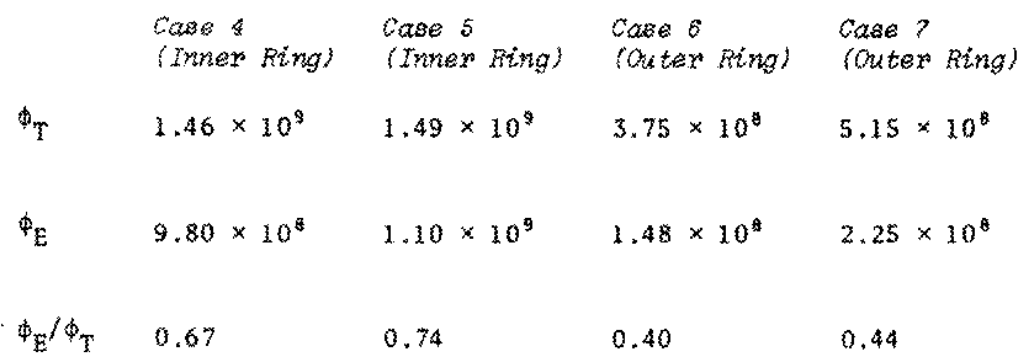

a. Case 4, ail $\mathrm{H}_{2} \mathrm{O}$ moderztor and aqueous sample inner ring; Case 5, $\mathrm{H}_{2} \mathrm{O}-\mathrm{D}_{2} \mathrm{O}$ moderator and aqueous sample inner ring; Case 6 , all $\mathrm{H}_{2} \mathrm{O}$ moderator and aqueous sample outer ring; and Case $7, \mathrm{H}_{2} \mathrm{O}-\mathrm{D}_{2} \mathrm{O}$ moderator and aqueous sample outer ring. Cadmin cutofe enorgy is $0.414 \mathrm{ev}$.

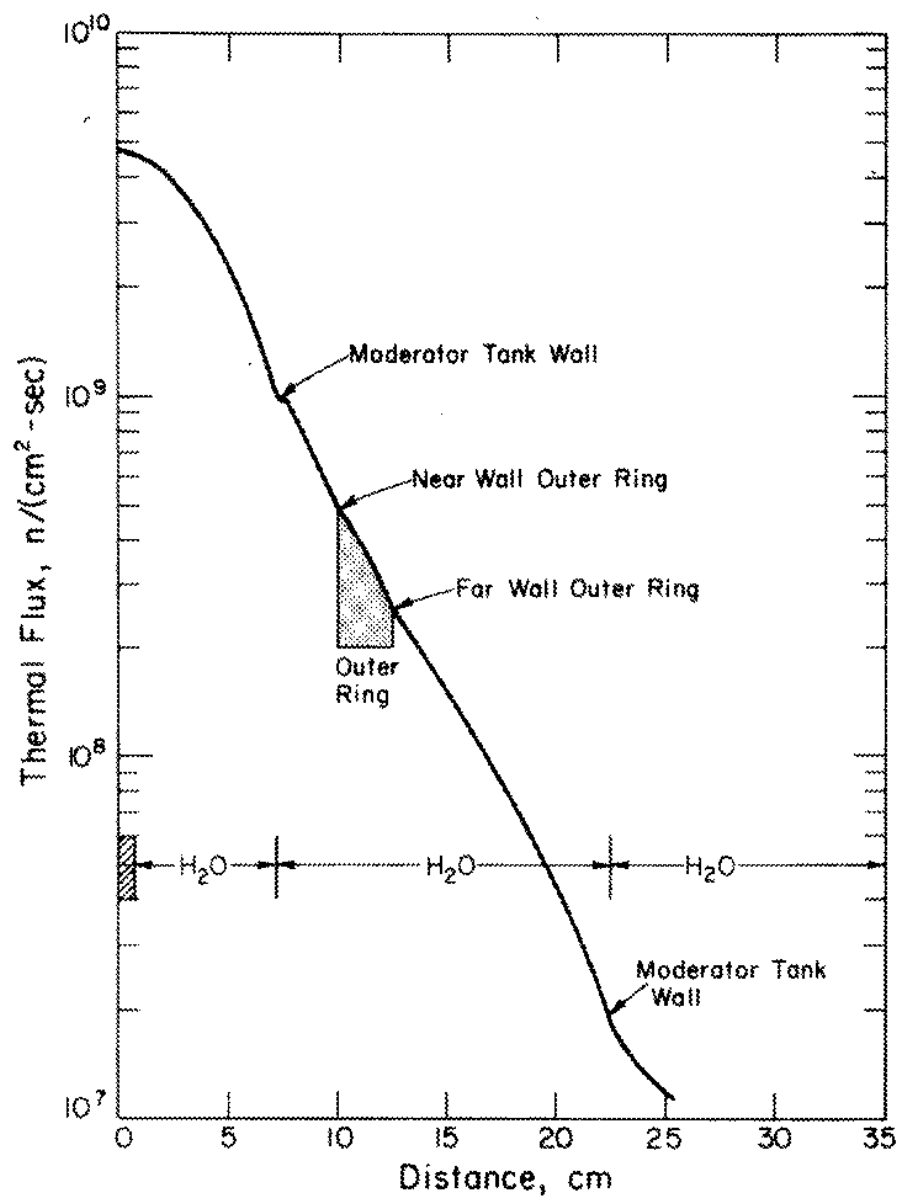

FIGURE 36. Calculated Thermal Flux for Outer Ring in Non-Ideal System with $\mathrm{H}_{2} \mathrm{O}$ Moderator (Case 6) 
Figure 37 (Case 7) shows the calculated change in thermal flux with distance for the outer stainless steel irradiation ring for the $\mathrm{H}_{2} \mathrm{O}_{2} \mathrm{O}_{2} \mathrm{O}$ moderated system. Compared to Case 6 , the $\mathrm{D}_{2} \mathrm{O}$ increases the thermal flux at the center of the outer ring over an a11- $\mathrm{H}_{2} \mathrm{O}$-moderated system by $237 \%$. Compared to Case 2 , the combined effects of the stainless steel and thermal neutron absorption within the aqueous sample itself reduce the thermal flux by $44 \%$ [from $9.19 \times 10^{8}$ to $5.15 \times 10^{8}$ neutrons $/(\mathrm{cm}-\mathrm{sec})$ ]. Compared to Case 3 , which is identical to Case 7 , except that no stainless steel was assumed to be present, neutron absorption by the steel reduces the thernal flux by $39 \%$.

Figure 38 shows the themal flux ratio of Case $7 /$ Case 6 . A gain in thermal flux of $230^{\circ}$ over the outer ring sample region is seen for the $\mathrm{H}_{2} \mathrm{O}-\mathrm{D}_{2} \mathrm{O}$ moderator system.

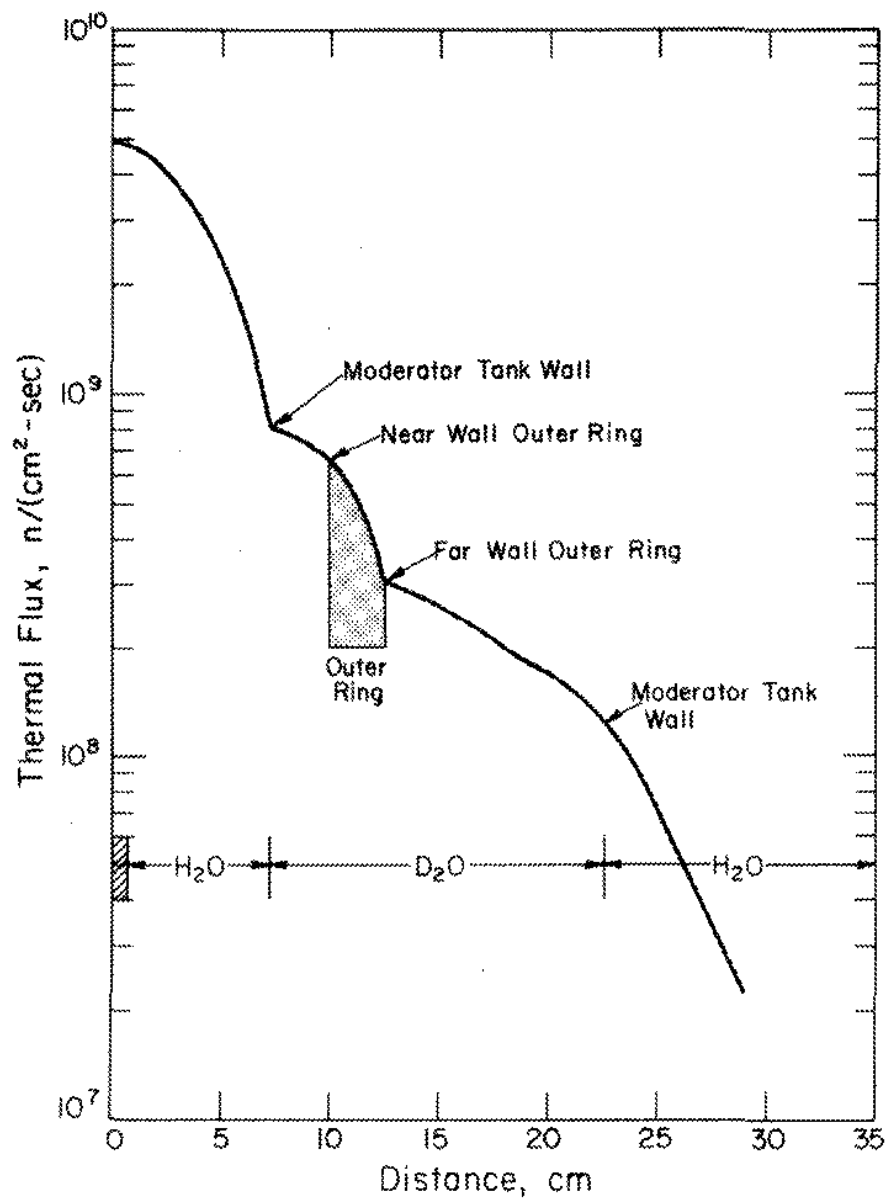

FIGURE 37. Calculated Thermal Flux for Outer Ring in Non-Ideal System with $\mathrm{H}_{2} \mathrm{O}-\mathrm{D}_{2} \mathrm{O}$ Moderator (Case 7) 


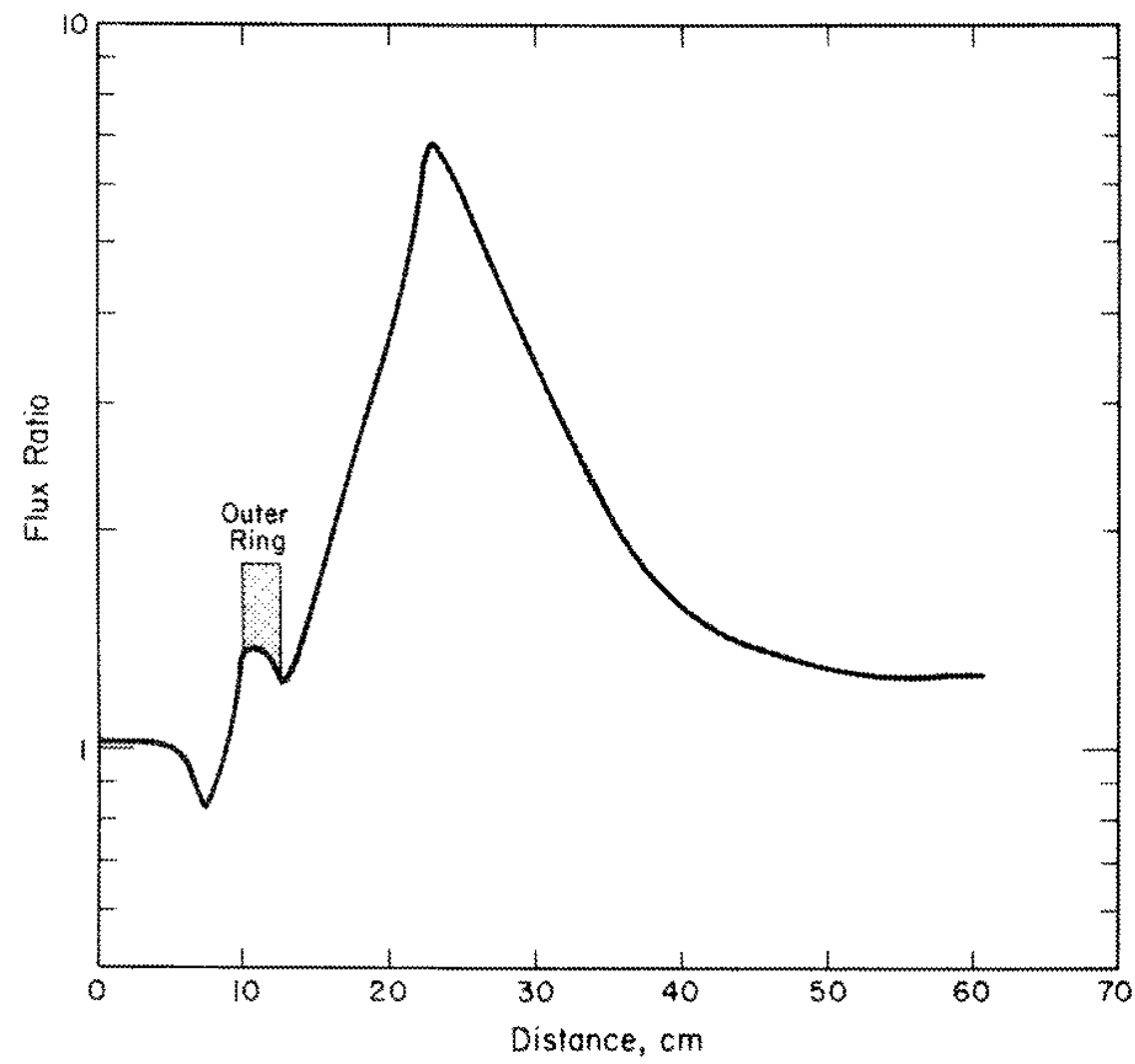

TruRE 38. Calculated Thermal Flux Ratio in Outer Ring in Non-Ideal System with $\mathrm{H}_{2} \mathrm{O}$ Moderator (Case 7/Case 6)

Comparison of Calculated and Measured Whaxes

Pure gold wires and gold wires within cadmium tubes of 0.002 -inch-diameter were irradiated at the center of both the inner and outex rings of irradiation sites. During these measurements, the other tubes were filled with polyethylene. whe irradiated wires were dissolved and counted with a calibrated detector. The net thermal-induced ${ }^{198} \mathrm{Au}$ specific activities were obtained by subtracting the measured epithermal specific activities of wres irradiated inside the cadnium tubes. The saturated gold activity (thermal) A that, at the end of irradiation is then related to the thermal flux by

$$
\phi_{T}=\frac{A \frac{\text { th }}{N_{397}}\left(\frac{\pi}{4} \frac{T}{T_{0}}\right)^{-1 / 2} \sigma_{2200}}{F_{t h}}
$$


where

$N_{19}=$ Number of gold atoms in each wire

$$
\begin{aligned}
& \left(\frac{\pi}{4} \frac{\mathrm{T}}{\mathrm{T}}\right)^{1 / 2}=0.886 \text { at } 298^{\circ} \mathrm{K} \\
& \sigma_{2200}=98.8 \text { bams } \\
& F_{\text {th }}=\text { thermal flux depression factor }=0.976
\end{aligned}
$$

The measured themal neutron fluxes with the $\mathrm{H}_{2} \mathrm{O}-\mathrm{D}_{2} \mathrm{O}$ moderator system for the centex of the inner and outer irradiation rings $(5.87 \mathrm{~cm}$ and $11.19 \mathrm{~cm})$ were $(1.21 \pm 0.10) 10^{9}$ and $(4.25+0.20) 10^{8}$ neutron/ $\left(\mathrm{cm}^{2} \mathrm{msec}\right)$ using the gold wire technique.

Because of the limitations of the one-dimensional ANISN flux calculation, the calculated thermal fluxes for Case 5 and Case 7 only approximate experimental conditions. The experimental-tocalculated thermal flux ratio is 0.812 for the inner irradiation rings and 0.825 for the outer irradiation ring. This discrepancy is caused by limitations of the calculational technique. When calculating the thermal flux in the inner ring, the effect of stainless steel outer irradiation was not considered. When calculating the themal flux in the outer ring, the effect of stainless steel inmer tubes was not considered. The effect of one ring on the other as well as the effect of adjacent steel irradiation tubes could account for most of the observed flux depression.

\section{EVALUATION OF THE $\mathrm{H}_{2} \mathrm{O}-\mathrm{D}_{2} \mathrm{O}$ SYSTEM}

Three separate methods are used to evaluate the $\mathrm{H}_{2} \mathrm{O}-\mathrm{D}_{2} \mathrm{O}$ moderator system. First, the ANISN calculations (Table 4) for ideal systems (Case 1 and Case 3) indicate no net themal flux increase in the imner sample irxadiation zone compared to an all $\mathrm{H}_{2} \mathrm{O}$-moderated system $\left[2.09 \times 10^{9}\right.$ compared to $2.08 \times 10^{9}$ neutron/ $\left.\left(\mathrm{cm}^{2}-\mathrm{sec}\right)\right]$. In theory, however, the $\mathrm{H}_{2} \mathrm{O}-\mathrm{D}_{2} \mathrm{O}$ moderator system is advantageous because the thermal flux in the outer sample irradiation zone is increased significantly. In practice, the stainless steel construction material offsets this advantage. Stainless steel was selected as the construction material for the irradiation tubes and annular tank because it is readily available and structurally strong and because more ideal materials, such as zircaloy and aluminum, are more difficult to fabricate. Calculationally, inclusion of the steel is shown to reduce the themal fluxes compared to the ideal systems by $229 \%$ for inner rings and $39 \%$ for outer rings (compare Case $5 /$ Case 1 and Case 7/Case 1). Calculationally, however, inclusion of 
stainless steel does not affect the gain in thermal flux in the outer sample ring for the $\mathrm{H}_{2} \mathrm{O}-\mathrm{D}_{2} \mathrm{O}$ moderator system [gain is $3.75 \times 10^{8}$ to $5.15 \times 10^{8}$ neutron $\left./\left(\mathrm{cm}^{2}-\mathrm{sec}\right)\right]$ for a net gain of 37 (Case 6/Case 7).

The benefit of the $\mathrm{H}_{2} \mathrm{O}-\mathrm{D}_{2} \mathrm{O}$ moderator also has been demonstrated experimentally. The experimental ratio of thermal fluxes (outer-tominer) was 0.351 compared to that calculated from the ideal all $\mathrm{H}_{2} \mathrm{O}$ system of 0.255 . The calculated ratio including the effect of steel of 0.346 agrees well with the experimental value. Results of the definitive experimental flux measurement using gold solutions with $\mathrm{H}_{2} \mathrm{O}$ and $\mathrm{D}_{2} \mathrm{O}$ in the outer ring indicate a gain of $28.3 \%$ in thermal flux, the absolute thermal fluxes are $3.40 \times 10^{8}$ neutron/ $\left(\mathrm{cm}^{2} \mathrm{msec}\right)$ for $\mathrm{H}_{2} \mathrm{O}$ and $4.33 \times 10^{8}$, neutrons/ $\left(\mathrm{cm}^{2}-\mathrm{sec}\right)$ for $\mathrm{D}_{2} \mathrm{O}$. The experimental flux measurements indicate that $0_{2} \mathrm{O}$ reduces the themal flux in the inner ring by about $3 \%$. The measured thermal flux in the inner ring for the al1- $\mathrm{H}_{2} \mathrm{O}$ system was $9.6 \times 10^{8}$ neutrons $/\left(\mathrm{cm}^{2}-\mathrm{sec}\right)$ compared to $9.3 \times 10^{8}$ neutrons/( $\mathrm{cm}^{2}$ msec) for the dual systems.

An alternate construction material such as aluminum would have been better than stainiess steel in the $\mathrm{H}_{2} \mathrm{O}-\mathrm{D}_{2} \mathrm{O}$ moderator system.

\section{OPTIMIZED FISSILE MATERIAL ANALYSIS WITH CYCLIC NEUTRON ACTIVATION AND DELAYED NEUTRON COUNTING}

Several laboratory programs, including the National Uranium Resource Evaluation program, require rapid, specific, and sensitive assays of natural uranium and other fissile isotopes, e.g., $233_{\mathrm{U}}, 239,24 \mathrm{pu}$, and $245 \mathrm{Cm}$. Automated neutron activation analysis based on cyclic neutron activation and delayed neutron counting was developed using the $17 \mathrm{mg}{ }^{25} \mathrm{Cf}$ facility. procedures have been optimized for as many as 200 samples/day. Sensitivities are $<0.5 \mathrm{ppm}$ for natural uranium and $\leq 10 \mathrm{ppb}$ for ${ }^{23} \mathrm{Pu}$ in the $100 \mathrm{mg}{ }^{252} \mathrm{Cf}$ facility. Cyclic irxadiation and counting procedures are used to improve analytical sensitivity for measuring short halfilife (sminute) activated species.

\section{Delayed Neutron Analysis}

A rigorous mathematical optimization for assaying fissile material by cyclic neutron activation analysis is not yet possible because the factors that determine neutron detector response for a particular fissile isotope are complex. The fission process itself is complex. For 233 , fission is known to yield over 50 beta-delayed, neutron-emitting precursors, each with a characm teristic half life and delayed neutron emission probability.8.9 
The fission yield of each of these precursors is dependent on the mass of the fissioning nucleus (especially those products with lighter mass), charge distribution characteristics, and on the energy of the incident neutron on the fissioning mucleus. An additional mathematical complexity is the growth and decay of isobaric short-lived fission products that decay by delayed neutron emission; examples ${ }^{10}$ are ${ }^{92,93} \mathrm{Kr},{ }^{92,},{ }^{3} \mathrm{Rb},{ }^{141},{ }^{14} \mathrm{Xe}$, and ${ }^{341,142} \mathrm{Cs}$. A final complexity in estimating the delayed neutron detector response is the effect of the different neutron energy groups emitted from the different activation products. ${ }^{8,11}$

Delayed neutron emission has long been a matter of great importance in reactor control and design. Although a large number of delayedmneutron precursors have been identified, reactor kineticists are in almost universal agreement that a simplified six-group treatment is adequate for treatment of the phenomena. Efforts to identify other delayed groups and to refine the group yields reported by Keepin ${ }^{2}$ have not resulted in significant revision of the six-group theory. ${ }^{3-15}$

\section{Optimization of Cyclic Analysis Procedures for Fissile Material}

The six-group model of delayed neutron emission is used to optimize procedures for cyclic analysis of different fissile materials. The multigroup flux calculations were combined with multigroup fission cross sections from the ENDF $-B$ 1ibrary ${ }^{5}$ to calculate specific saturated fission rates for each fissile naterial, $R_{f}$. The thermal neutron flux and the specific fission rates (Table 7) were shown experimentally to be accuxate to whin $\pm 5 \%$.

The number of counts recorded in a cyclic irradiation and counting procedure for a single, short-lived activation species is

$$
K=\frac{E \operatorname{ESDCF}}{\lambda}
$$

where $x$ is the saturated production rate for the particular product being measured and $\mathrm{F}$ is the cyclic gain factor.

In the six-group model of delayed neutron emission, the spectic saturated rate of production of each of the six halflife, delayed-neutron groups $r_{i}$ is given by the product of the specific fission rate $R_{f}$ and the delayed neutron group yields $Y_{1}$ listed in Tables 8 and 9.

$$
\mathrm{r}_{\mathrm{i}}=\mathrm{R}_{\mathrm{f}} \mathrm{Y}_{\mathrm{i}}
$$


TABEE ?

Calculated Spectfic Fission Rates in the $2{ }^{2} \mathrm{Cf}$ Facillty

\begin{tabular}{|c|c|}
\hline rootopes & 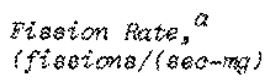 \\
\hline $233 \xi$ & $3.99 \times 10^{5}$ \\
\hline $23 \mathrm{~s}_{0}$ & $4.44 \times 10^{5}$ \\
\hline $2.38 \mathrm{U}$ & $1.14 \times 10^{2}$ \\
\hline Natural 1 & $3.31 \times 10^{3}$ \\
\hline${ }^{238} \mathrm{pu}$ & $6.21 \times 10^{5}$ \\
\hline${ }^{24}{ }^{\circ} \mathrm{Qu}$ & $4.97 \times 10^{2}$ \\
\hline $2+1 p_{u}$ & $7.90 \times 10^{5}$ \\
\hline
\end{tabular}

a. Calculated from $84 \sim$ group neutron 2 lux and cross section bata. The thermal and epthormal flux values $(0.632+\mathrm{ev}$ cutoff $)$ are $3.53 \times 10^{6} \mathrm{n} /\left(\mathrm{cm}^{2}-\mathrm{sec}\right)$ and $3.22 \times 10^{8} \mathrm{n} /\left(\mathrm{cm}^{2} \mathrm{sec}\right)$, respoctively.

TABEE 8

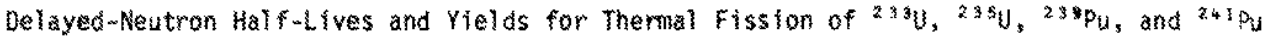

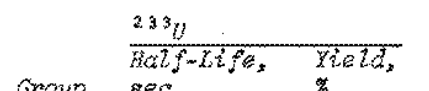

Group

1

2

3

4

5

6

Total

5.00

0.166

2. 13

0.384

0.615

0.022

0.277

0.66
$23 x_{y}$

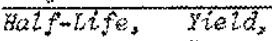
$s e c$

230

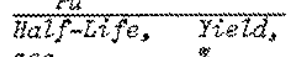

sec

0.052

0.346

0.310

0.624

0.182

0.066

5.58

54.28

0.021

23.04

0.182

6.22

5.60

0.129

0.61

2.13

0.199

0.23

0.638

0.052

$3 \times 58$

0.257

0.027

0.61

$245 / x_{1}$

katf-itife, yielas

54.0

0.015

23.2

0.365

5.6

0.275

3.97

0.620

1. 57

TABLE 9

Delayed-Reutron Half-Lives and Yields for Fast Neutron Fission of 2.3913 and $240 \mathrm{Pu}$

\begin{tabular}{|c|c|c|c|c|}
\hline Wroug & 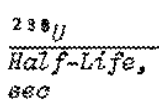 & yon, & $\begin{array}{l}240 \mathrm{p} \\
\text { Hat f w thes } \\
\text { 3\&c }\end{array}$ & $\begin{array}{l}\text { Yista, } \\
z\end{array}$ \\
\hline 1 & 52.38 & 0.054 & 53.56 & 0.022 \\
\hline 2 & 21.58 & 0.564 & 22.14 & 0.238 \\
\hline 3 & 5.00 & 0.667 & 5.14 & 0.162 \\
\hline 4 & 1.93 & 1.599 & 2.08 & 0.315 \\
\hline 5 & 0.49 & $0.32 \mathrm{y}$ & 0.51 & 0.119 \\
\hline 6 & 0.37 & 0.300 & 0.17 & 0.028 \\
\hline Tatsi & & 4.12 & & 0.88 \\
\hline
\end{tabular}


Table 10 lists these specific saturated emission rates for delayed neutrons calculated for natural uranium, plutonium, and specific isotopes irradiated in the ${ }^{252}$ Cf activation facility.

From Equation 11 , the neutron response for the $i_{\text {th }}$ delayed neutron group is

$$
K_{\dot{1}}=G_{\dot{1}} F_{i}
$$

where

$$
\begin{aligned}
& G_{i}=\frac{r_{i} S_{i} C_{i} D_{i} E}{\lambda_{i}} \text { and } \\
& F_{i}=\frac{M}{1-Q_{i}}-\frac{Q_{i}\left(1-Q_{i} M^{2}\right.}{\left(1-Q_{i}\right)^{2}}
\end{aligned}
$$

Neutron detection efficiencies for all groups are assumed equal. The detector response $\mathrm{R}_{\mathrm{d}}$ actually recorded is the sum of the six groups:

$$
R_{d}=\Sigma_{i=1}^{6} G_{i} F_{i}
$$

TABLE 10

Specific Saturated Delayed-Neutron Emission Rates Calculated for Fissile sotopes

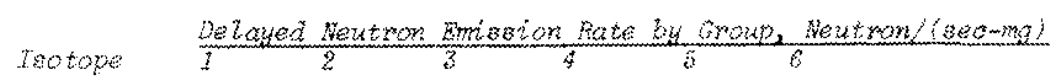

$\begin{array}{lllllll}233 & 227 & 786 & 662 & 734 & 136 & 88\end{array}$

$\begin{array}{lllllll}235 & 233 & 1536 & 1376 & 2769 & 808 & 293\end{array}$

$\begin{array}{lllllll}233_{0} & 0.061 & 0.64 & 0.76 & 1.82 & 1.05 & 0.35\end{array}$

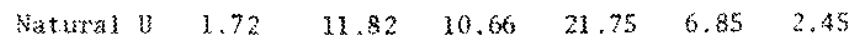

$\begin{array}{lllllll}239 \mathrm{p}_{12} & 130 & 1331 & 801 & 1236 & 323 & 168\end{array}$

$\begin{array}{lllllll}24 \mathrm{~g}_{\mathrm{p}} & 0.1 & 1.4 & 1.0 & 1.9 & 0.7 & 0.1\end{array}$

$\begin{array}{llllll}243 & 119 & 2883 & 2173 & 4898 & 2291\end{array}$

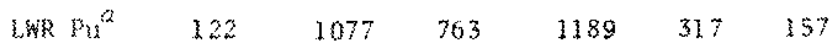

a. Assumed $P_{a}$ isotopic concentrations:

$\begin{array}{ll}\text { Mase Wo. } & \text { Atom \% } \\ 238 & 1.2 \\ 239 & 59.2 \\ 240 & 23.7 \\ 241 & 11.9 \\ 242 & 4.0\end{array}$


The delayed neutron emission rates for specific groups listed in Table 10 are combined with Equations 33 and 34 to calculate the group responses $K_{i}$ and detector response $R_{d}$ as functions of different experimental parameters.

Figures 39-44 show delayed neutron detector responses calculated for samples containing $1 \mathrm{mg}$ of fissile material analyzed in the $17-\mathrm{mg}{ }^{252} \mathrm{Cf}$ facility by the cyclic technique. Calculations are based on the six-group model.

\section{Effect of Transit Time on Detector Response}

Figure 39 shows the group response $K_{i}$ for each of the six groups and the expected measurable response $\mathrm{Rd}$ (the sum of the six groups) for a cyclic irradiation and counting regime for natural uranium. The total analysis time is $600 \mathrm{sec}$, and the sample transit time is $0.25 \mathrm{sec}$. Figure 40 show the effect of increasing the transit time to $1.0 \mathrm{sec}$. The najor difference is that the response from the $2.30 \mathrm{sec}$ delayed-neutron group is less because of an increased decay during transit in the latter case. The calculated detector response $\mathrm{R}_{\mathrm{d}}$ (Figure 41 ) for a range of transit times for natural uranium is based on an assumed total analysis time of $600 \mathrm{sec}$.

\section{Optimization Parameters}

Table 11 shows the percentage of the detector response, by group, at the optimum number of cycles for different transit times. Table 12 sumnarizes the optimum experimental paraneters for natural uranium analysis. As the transit time is increased from $0.25 \mathrm{sec}$ to $2.50 \mathrm{sec}$, the optimum number of cycles decreases from 83 to 20 and the detector response decreases from 6048 to 2868. The ovexall detector response (Table 11) is controlled largely by the $22.72,6.22$, and $2.30 \mathrm{mec}$ half-life groups. The 55.72 sec group does not make a major contribution even for the $2.50-\mathrm{sec}$ transit time. The relative contribution of the $2.30 \mathrm{sec}$ group decreases rapidly with increasing transit time. Table 13 lists the optimum experimental parameters for cyclic analysis of different fissile isotopes.

Figure 42 compares the calculated detector response $R_{d}$ for $1 \mathrm{mg}$ of the common fissile isotopes. For these calculations, a transit time of $1.0 \mathrm{sec}$ and an experiment time of 600 sec were assumed. Although the thermal fission cross section for ${ }^{239} \mathrm{pu}$ is 742 barns compared to 580 barns for ${ }^{235} \mathrm{U}$, the detector response is much higher for ${ }^{235} \mathrm{U}$ because of the high delayed neutron group yields for this isotope. 


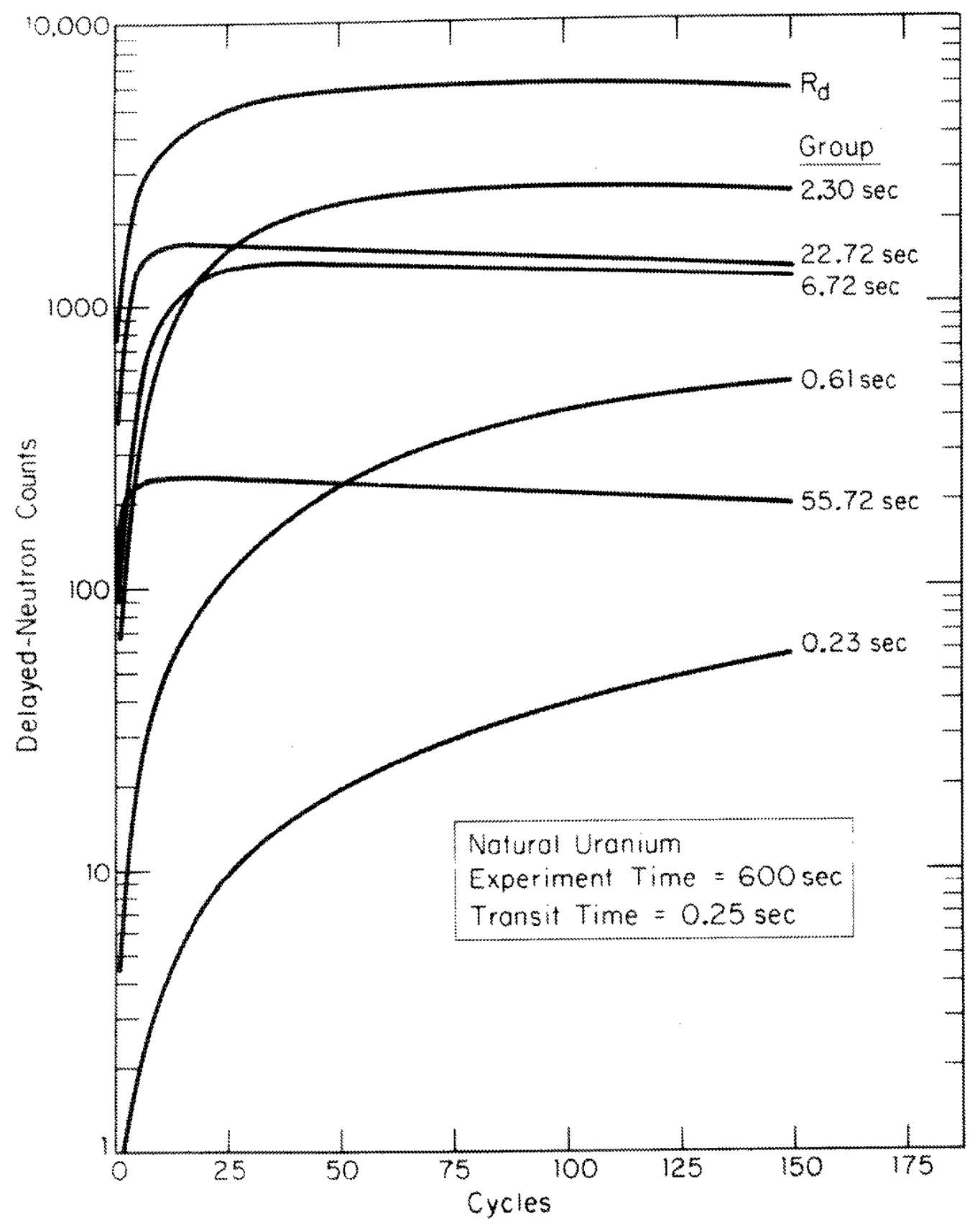

FGURE 39. Calculated Group Response and Detector Response for Natural Uranium for Transit Time of $0.25 \mathrm{sec}$ 


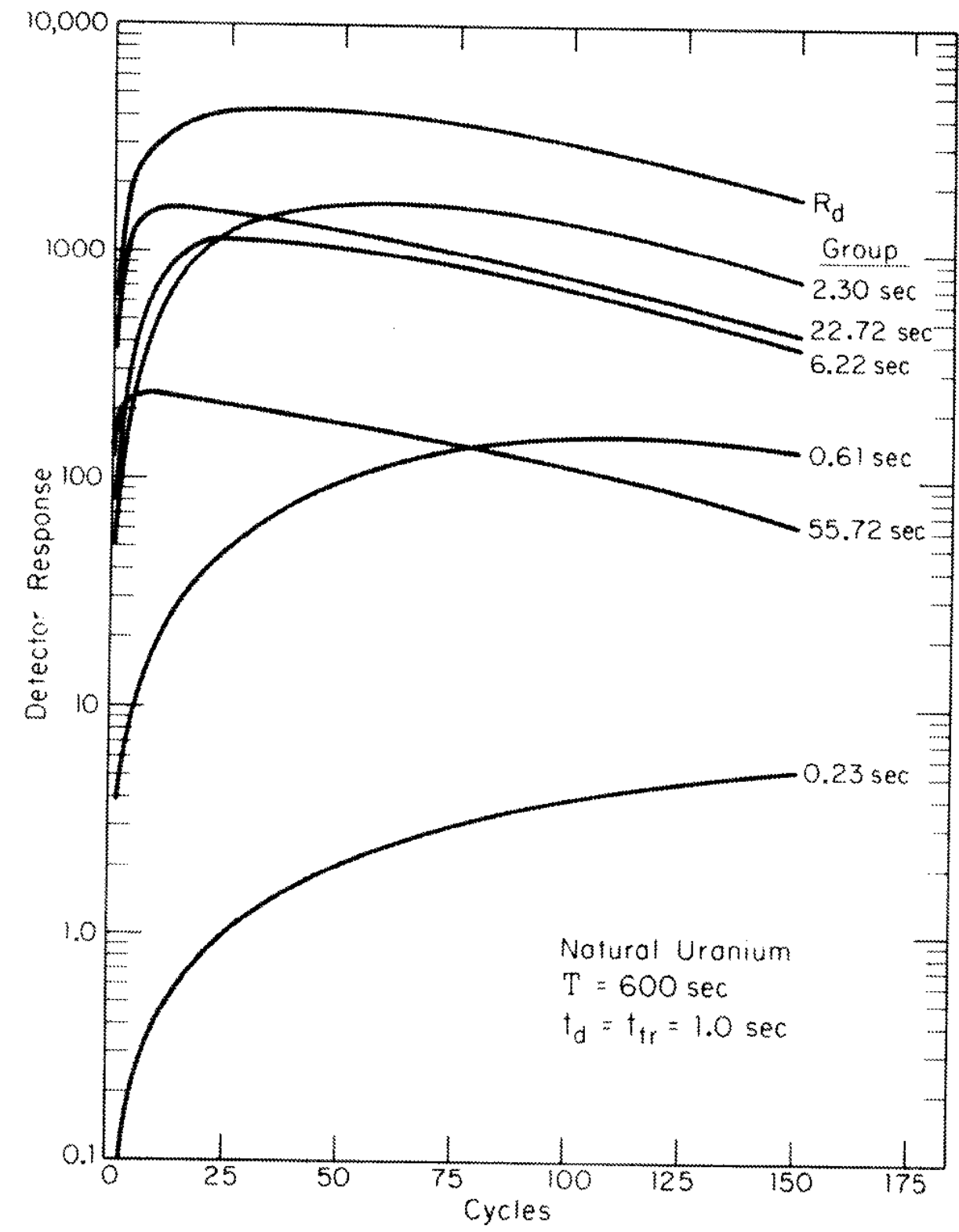

FIGURE 40. Calculated Group Response and Detector Response for Natural Uranium for Transit Time of $1.0 \mathrm{sec}$ 


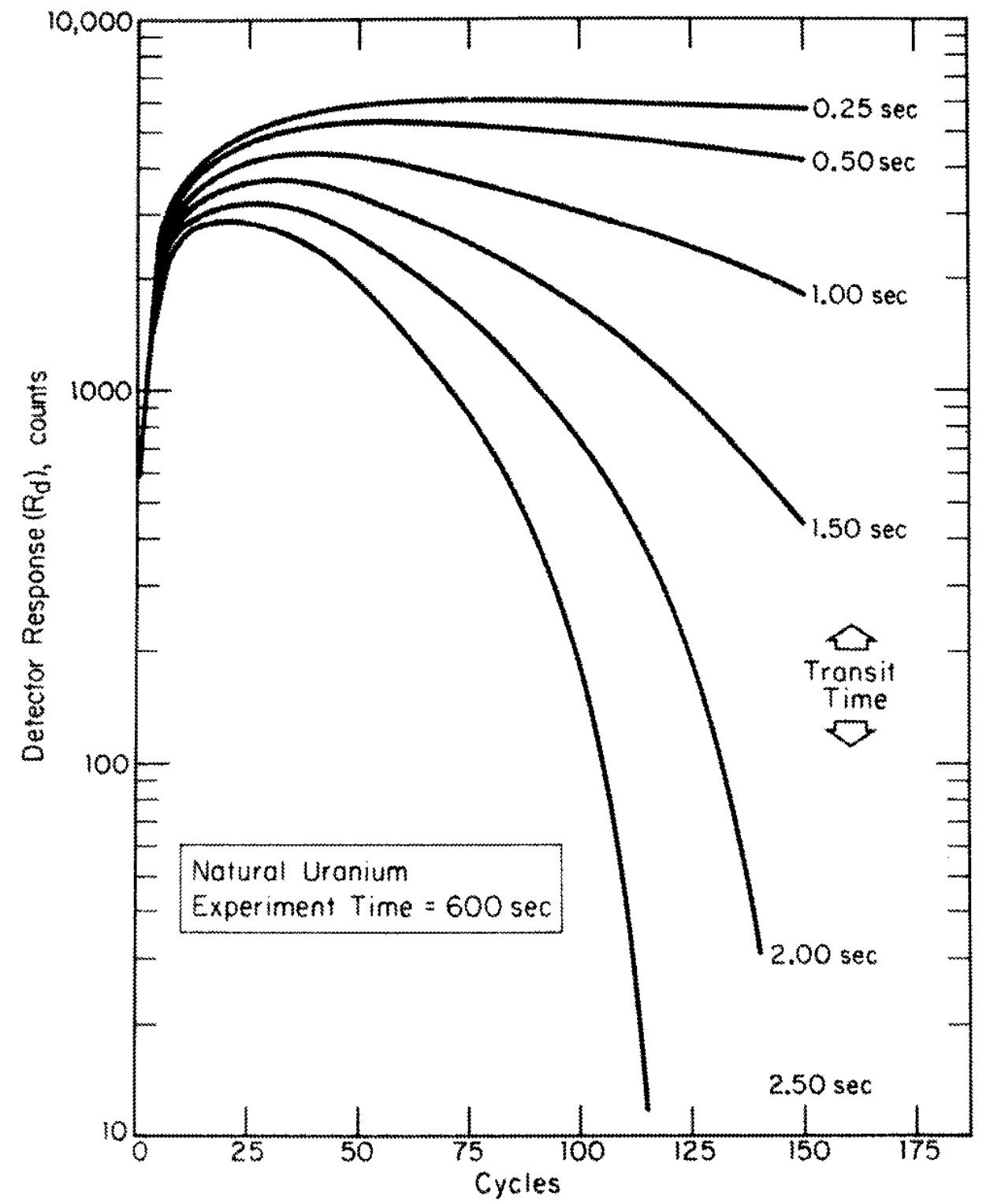

FIGURE 41. Effect of Sample Transit Time on Detector Response for Natural Uranium 
TABLE II

Changes in Calculated Detector Response with Changes in Sample Transit Time for the Optivam kumber of Eycles for Matural Urantum

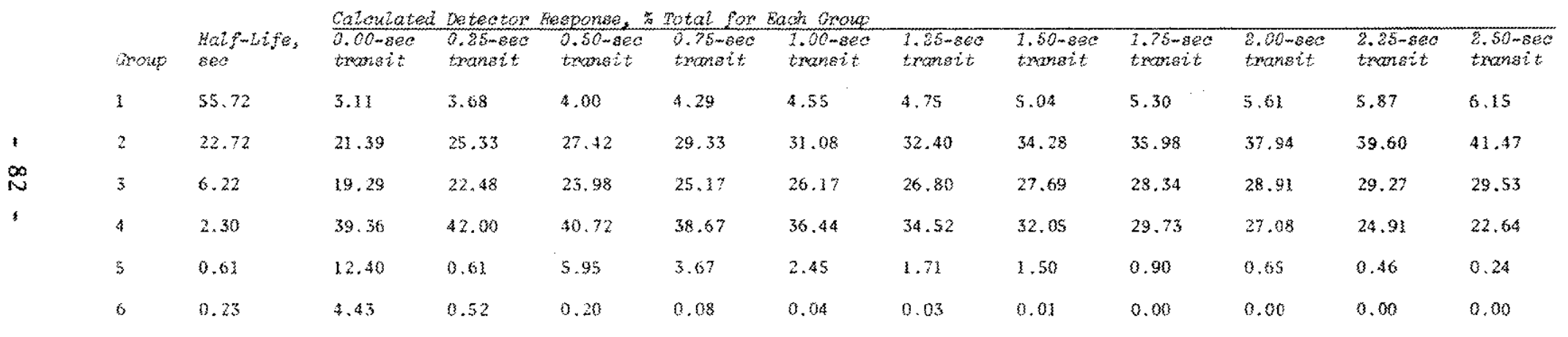

a. Total experiment time is $600 \mathrm{sec}$. 
TABLE I?

Optimum Experimental Conditions for Cyclic Rnalysis of Natural Uranium (1 mg)

\begin{tabular}{|c|c|c|c|c|c|c|c|c|c|c|}
\hline $\begin{array}{l}\text { Tronght Thene, } \\
\operatorname{sed}^{2} \rightarrow\end{array}$ & 0.25 & 0.50 & 0.75 & 3.00 & 1.25 & 1.60 & 3.76 & 2.00 & 9,76 & 2.50 \\
\hline Cycles & 83 & 57 & 45 & 38 & 33 & 30 & 27 & 24 & 22 & 20 \\
\hline $\begin{array}{l}\text { Irradiation - } \\
\text { cout interval, } \\
\text { sec }\end{array}$ & 3.36 & 4.76 & 4.92 & 6.89 & 7.84 & 8.25 & 9.36 & 10.50 & 11.39 & 12.50 \\
\hline $\begin{array}{l}\text { Newtron } \\
\text { detector } \\
\text { response } R_{d} \text {, } \\
\text { counts }\end{array}$ & 6048 & $52 \xi_{2}$ & 4719 & 4298 & 3955 & 3667 & 3424 & 3213 & 3030 & 2868 \\
\hline
\end{tabular}

a. Equal trassit times to and from the detector are assumed.

3. Equal irradiation and counting times are assimed.

TABLE 13

Optimum Experimental Condtions for Cyclic Analysis of Common Fissile Materials

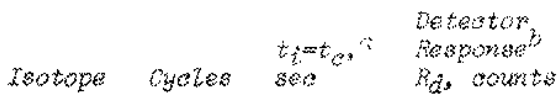

$233_{3} \quad 33 \quad 8.09 \quad 234,100$

$2354 \quad 38 \quad 6.89 \quad 553,300$

$\begin{array}{llll}239 \mathrm{p}_{13} & 35 & 7.57 \quad 313,700\end{array}$

${ }_{24} \mathrm{P}_{4} \quad 41 \quad 6.32 \quad 88 \%, 800$

LWR Pu $\quad 37 \quad 7.11 \quad 286,600$

a. Equal irradiation and counting intervals.

b. One-milligram samples and an experiment time of $600 \mathrm{sec}$ are assumet; transit time is $x .00 \mathrm{sec}$ 


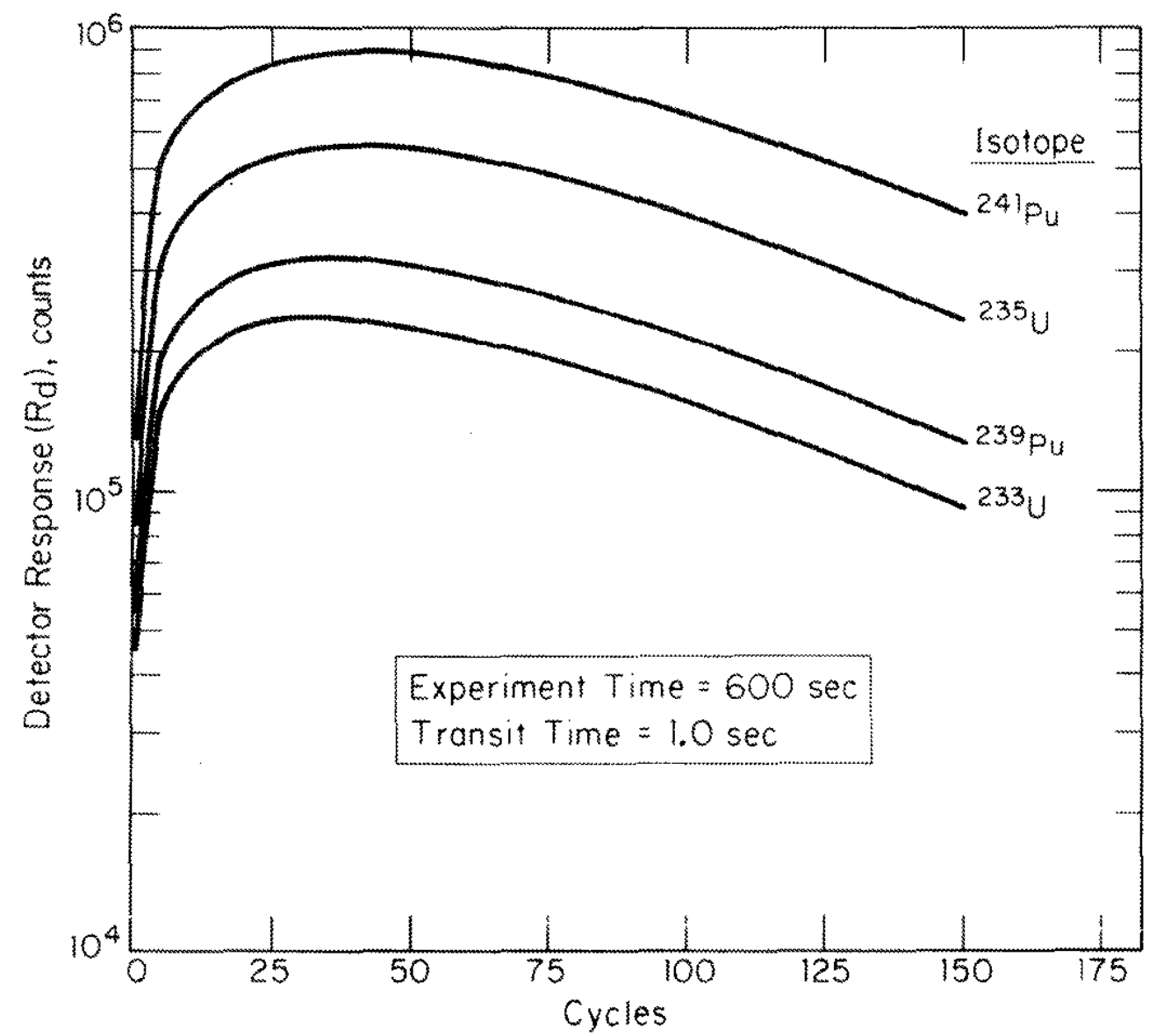

FIGURE 42. Relative Detector Response for Fissile Isotopes

Comparison of Calculated and Measured Detector Responses

Samples of approximately $1 \mathrm{mg}$ of enriched $(97.66 \%)^{235} \mathrm{U}$ were cyclically irradiated and counted in the 17 -mg $252 \mathrm{Cf}$ facility for comparison with the calculated detector response curves. The pressure of the pneumatic sample transfer system was adjusted to give transfer times of $1.0 \pm 0.1$ sec. A total analysis time of $600 \pm 10 \mathrm{sec}$ was maintained by adjusting irradiation and counting intervals, according to the number of cycles used. Results are shown in Figure 43. The experimental points were adjusted for sample weight and counter efficiency. Agreement is excellent except where large numbers of cycles were used. Comparison of curve shapes (Figure 41) calculated for various transit times indicates an actual experimental transit time of about $1.1 \mathrm{sec}$. 


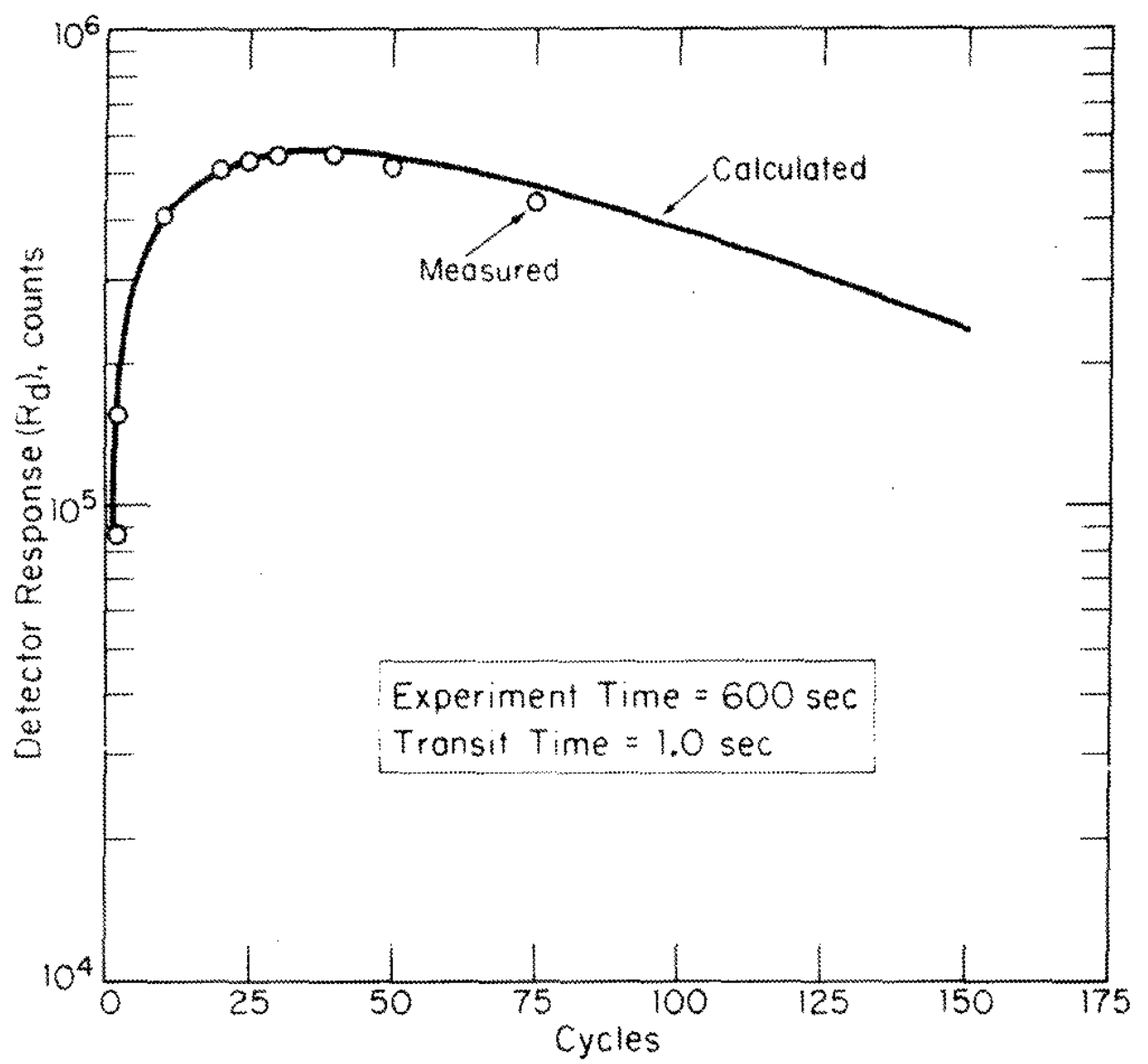

FIGURE 43. Comparison of Calculated and Measured Detector Responses for Cyclic Analysis of $235 \mathrm{U}$

Oxygen-17 Interference in Analysis of Low-Level Aqueous Samples

For cyclic determinations of low-level quantities of fissile materials in aqueous or oxygen-containing matrices, undesirable background from delayed neutrons produced from ${ }^{1}{ }^{3}$ by the fast-neutron reaction must be considered.

$$
{ }^{17} \mathrm{O}(\mathrm{n}, \mathrm{p}){ }^{17} \mathrm{~N} \frac{\mathrm{B}^{-}}{4.4 \mathrm{sec}}{ }^{17} \mathrm{O}^{*} \stackrel{0.95}{\longrightarrow}{ }^{35} \mathrm{O}+\mathrm{n} \text { (delayed) }
$$

The threshold neutron energy for this reaction is $8.2 \mathrm{MeV}$. The average cross section for the fast-neutron reaction of ${ }^{17} 0$ has been measured in the ${ }^{252} \mathrm{Cf}$ facility with ${ }^{1 /} 0$-enriched $(37.1 \%)$ water. If a detection efficiency for delayed neutrons produced in this reaction is assumed to be the same as for those produced in fission, and if the fast neutron flux $\phi_{\mathrm{F}}\left(\mathrm{E}_{\mathrm{n}}>7.8 \mathrm{MeV}\right)$ is $1.0 \times 10^{6}$ (as calculated by ANISN), the measured average cross section $\sigma_{n, p}$ is $1.7 \mathrm{mb}$. 
Equation 11 may be used to calculate the ${ }^{17} 0$ interference at any irradiation location in a cyclic analysis if the fastneutron flux is known. The saturated rate of production of delayed neutrons from the ${ }^{17} \mathrm{O}$ reaction is

$$
R=0.95 \sigma_{n, p} \phi \mathrm{F}
$$

As an example, Figure 44 and Table 14 sumarize the calculated ${ }^{2} \mathrm{O}$ effect for a hypothetical $10 \mathrm{ml}$ sample containing $10 \mathrm{ppm}$ natural uranium analyzed in the ${ }^{252} \mathrm{Cf}$ activation facility. The experimental counter background of 8 counts/min was used to calculate background counts. Equations 11 and 34 were used to calculate counts from ${ }^{17} 0$, and the counts from natural uranium were calculated as described previously. Transit times of 1.0 sec were as sumed.

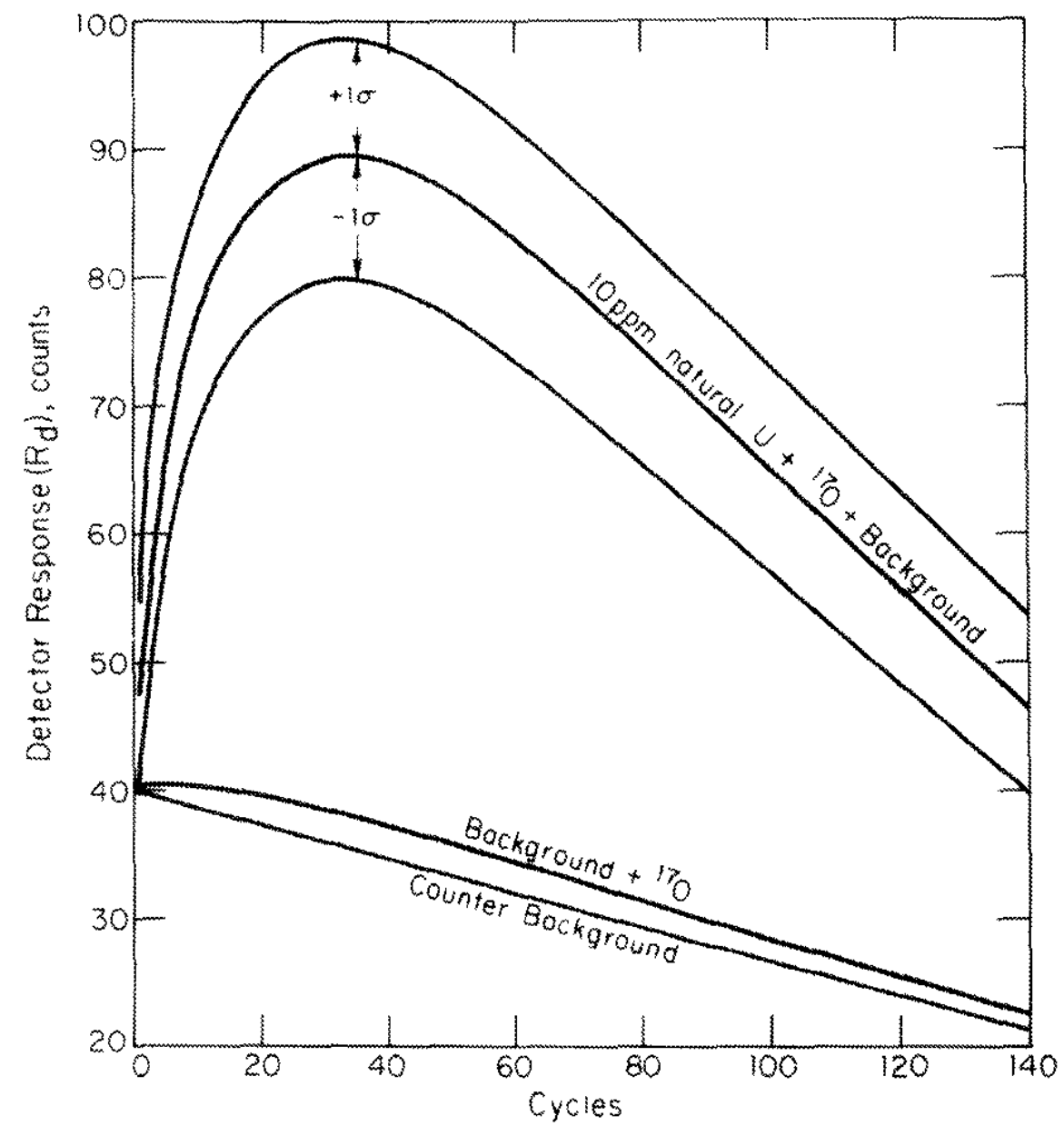

FIGURE 44. Calculated Detector Response for Aqueous Samples Containing 10 ppm Natural Uranium 
TABLE 14

\begin{tabular}{|c|c|c|c|c|}
\hline Cyoles & $\begin{array}{l}\text { Counts } \\
\text { from } \\
170\end{array}$ & $\begin{array}{l}\text { Background } \\
\text { Counte }\end{array}$ & $\begin{array}{l}\text { Counts } \\
\text { from } \\
\text { Uranium }\end{array}$ & $\begin{array}{l}\text { Signat- } \\
\text { to-Noise } \\
\text { Ratiob }\end{array}$ \\
\hline 1 & 0.14 & 39.9 & 7.8 & 0.56 \\
\hline 5 & 0.68 & 39.3 & 27.2 & 1.7 \\
\hline 10 & 1.34 & 38.7 & 37.2 & 2.1 \\
\hline 20 & 2.18 & 37.3 & 46.8 & 2.5 \\
\hline 30 & 2.45 & 36.0 & 50.7 & 2.7 \\
\hline 40 & 2.47 & 34.7 & 51.6 & 2.7 \\
\hline 50 & 2.39 & 33.3 & 50.6 & 2.7 \\
\hline 100 & 1.63 & 26.7 & 36.8 & 2.3 \\
\hline 150 & 0.93 & 20.0 & 21.8 & 1.7 \\
\hline
\end{tabular}

a. Equal counting and irradiation intervals; transit times $=1.0 \mathrm{sec}$.

b. The signal-to-noise ratio is defined as:

$S / N=$ counts from uranium $/ 2 \sqrt{\text { sum of counts from all sources }}$

The calculated signal-to-noise ratio (Table 14$)=($ ratio of calculated uranium counts) $/ 2$ (sum of neutron counts from all

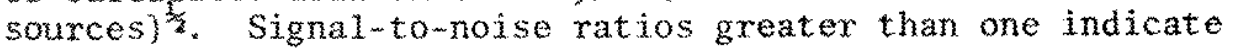
that 10 ppm of natural uramium is detectable at the $2 \sigma$ confidence level.

Identical calculations were made for the $100-\mathrm{mg}{ }^{252} \mathrm{Cf}$ facility to determine detection sensitivities for natural uranium $(0.5 \mathrm{ppm})$. For analyses near the detection linit, the 170 interference is calculated and removed from the detector response as a background contribution. 


\section{COMPUTER DATA PROCESSING}

The master equations of activation analysis has been derived previously. This equation includes cyclic considerations and is included in this section for reference; the elemental concentration in ppn is given by:

$$
\mathrm{p}=\frac{\mathrm{K}}{\mathrm{EW}} \cdot \frac{\mathrm{A} 10^{6}}{\mathrm{~B} \mathrm{NO}} \cdot \frac{\lambda}{\mathrm{ISCDF}} \cdot \frac{\frac{1}{\mathrm{R}}}{\mathrm{SCD}}
$$

The $\mathrm{K} / \mathrm{EW}$ term depends on experimental parameters:

$K=$ photopeak area, counts

$\mathrm{E}=$ detector efficiency for the particular garma ray energy

$W=$ sample weight in grams

The $A \cdot 10^{6} / B \cdot$ No term depends on the target nuclei:

$A=$ atomic weight of target

$B=$ i.sotopic abundance of target

No = avogadro's number

The $\lambda /$ ISCof term involves timing information and decay parameters of the product nucleus:

$\lambda=$ decay constant, $\sec ^{-1}$

I $=$ gamma ray abundance

$S, C, D, F=$ irradiation, counting, decay, and cyclic factors previously defined.

The $1 / R$ term depends on the cross section of the induced reaction and on the neutron flux and energy distribution at the irradiation site.

The specific rate $R$ is the specific neutron capture reaction rate in captures/(sec-g). 
Data are reduced sequentially by programs in the computer, the last of which solves this master activation analysis equation. The data reduction flow sheet is illustrated in Figure 45 ; boxes denote program names and all-capital names refer to tape or disc data files.

\section{TRANSCRIBE}

The first step in the data reduction flowsheet is the accumulation of the gamma ray spectrum in the 4096-channel multichamel analyzer memory. Baseline and gain adjustments are normally set at 2.00 channels/keV. The accumulated spectrum is then transferred to the nine-track magnetic tape along with an identifier tagword. The tape containing the spectra of all samples counted during a one-day period and a header record are transferred by TRANSCRIBE to a temporary numbered storage tape. The header record contains other experimental information eventually used by program SIFTER to solve the master equation. The header information is supplied manually by the facility operator on a standard FORTRAN coding form. This operatorsupplied experimental data is in a coded format listed in Table 15 . The output of TRANSCRIBE is manually checked to ensure that the correct header record was attached to the spectrum. A sample TRANSCRIBE output is shown in Table A-1.

As indicated in the flowsheet, ADDER and COPY may be used to assemble a master storage tape and a duplicate tape for permanent retention of all gamma ray spectra and of header records for every sample analyzed.

RAGS

Program RAGS ${ }^{16}$ sequentially analyzes the gamma ray spectra stored on the temporary storage tape and writes the peak energies, peak areas, and the 20 statistical uncertainty in the peak areas, and the header record onto disk data file RAGout. The hard copy output from RAGS may be examined manually before execution of STFER. Table A-2 is a sample RAGS output.

\section{SIFTER}

The oxigin and content of each disk data file used by SIFTER, as shown in the data reduction flowsheet, are considered below. These data libraries are stored in EDIT library disk space and are called as needed by SIFTER. After RAGS has operated on the gamma ray spectrum, the RAGOUT file has all of the experimental information required for qualitative and quantitative analysis by SIFTER. 


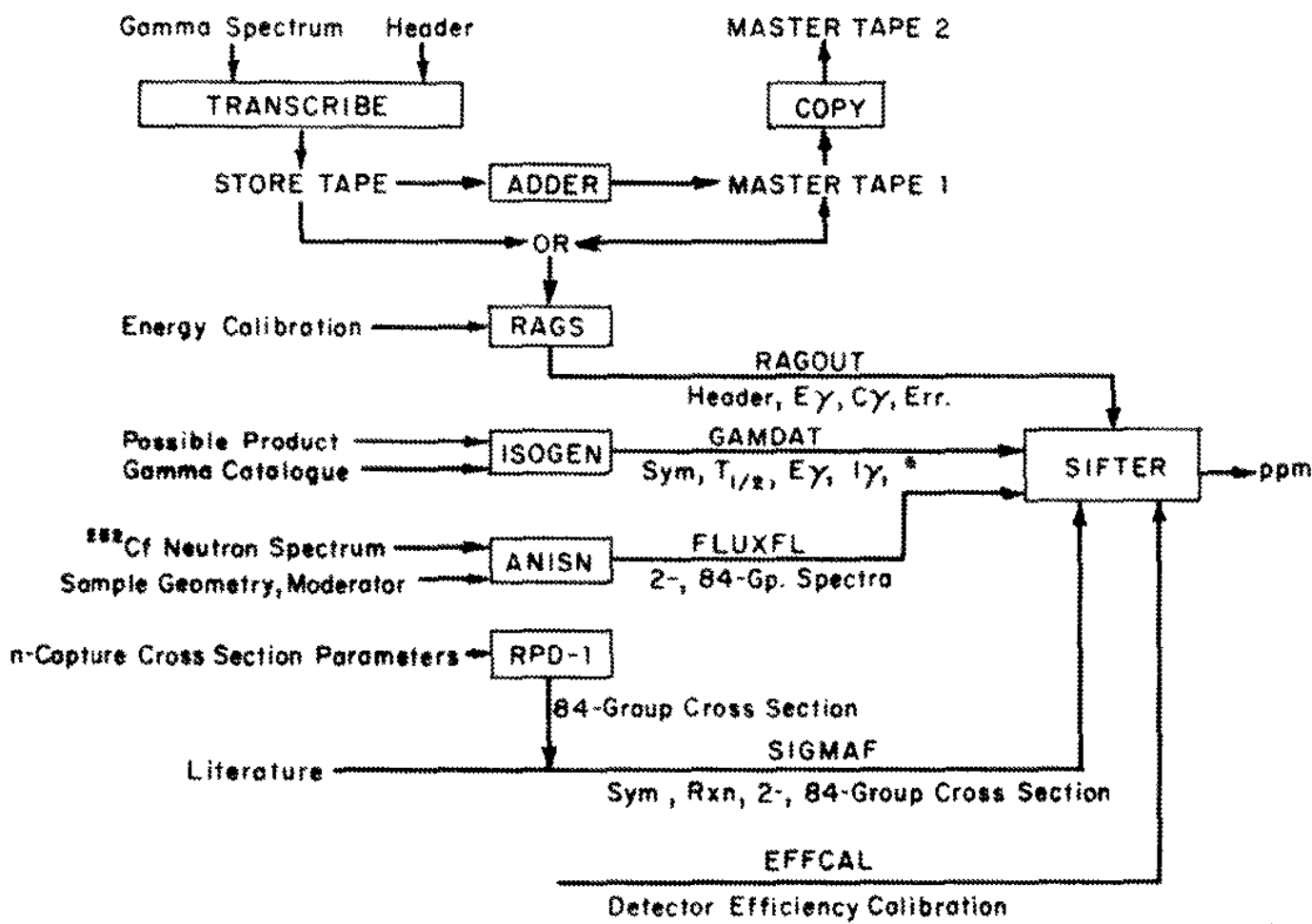

FIGURE 45 . Data Reduction Flowsheet

TABLE 15

Coding Format for Header Records

\begin{tabular}{|c|c|c|}
\hline Cotumn & Information type & Bxixmple \\
\hline 1,2 & Year & \\
\hline 3,4 & Month & 760331144600 Count Start occurred \\
\hline 5,6 & bay & at $14: 46: 00(2: 46: 00$ p.m. $)$ on \\
\hline 7,8 & Houx & March $31 \times 1976$ \\
\hline 9,10 & Minute & \\
\hline 11,12 & Second & \\
\hline 13,14 & Counting Arrangenent & $(01-05)$ \\
\hline $15-18$ & Counting Time & $\left(3003=3.00 \times 10^{3} \mathrm{sec}\right)$ \\
\hline $19-22$ & Decay Time & $\left(305=1.30 \times 10^{5} \mathrm{sec}\right)$ \\
\hline $23-27$ & Sample Weight & $\left(12343=1.234 \times 10^{3} \mathrm{mg}\right)$ \\
\hline $28-3.3$ & Trxadiation Time & $\left(1003=1.00 \times 10^{3} \mathrm{sec}\right)$ \\
\hline 32,33 & $\begin{array}{l}\text { Number of Imadiation- } \\
\text { Counting Cycles }\end{array}$ & \\
\hline 34,35 & Yrradiation Tube & $(12=$ Ring 1, Tube 2) \\
\hline $36-37$ & Coments & \\
\hline 78,79 & Tagword & \\
\hline
\end{tabular}




\section{EDIT Data Flles}

GANDAT file (Table A-3) contains the spectroscopic decay data for all gamma rays enitted by each possible neutron activation product as well as by other commonly observed fission product nuclides. These data were obtained from Reference 6; they include product nuclide symbol, half life, and the tabulated gamma xay enexgies and absolute decay abundances listed in decreasing order of abundance.

Flux file (Table A-4) is a library of normalized 2mgroup and 84 mroup neutron fluxes for each source/moderator/sample configuration. The 2-group (thermal and epithermal) fluxes used in the 100 mg ${ }^{252} \mathrm{Cf}$ facility were measured experimentally at each of the two rings of irradiation sites. The $84 \mathrm{mgroup}$ fluxes (used only in the $17-\mathrm{mg}^{252} \mathrm{Cf}$ facility) were taken from the ANISN computer code.

STGMA file (Table A-5) contains data specific to the particular nuclear reaction forming the product nuclide. The file includes the product nuclide symbol, the reaction symbol, the target isotopic abundance and atomic weight, and the tabulated $2200 \mathrm{~m} / \mathrm{sec}$ cross section and resonance integral for the reaction. Cross sections listed in 84-group fomat are included when available.

EFFCAL file (Table A-6) contains the absolute detector efficiency $v s$. energy calibration data measured experimentally For each numbered detector-sample geometry. The reciprocal of the absolute efficiency is listed for each energy for count ing arangements used in the $100-\mathrm{mg}{ }^{252} \mathrm{Cf}$ facility.

\section{SIFTER Flow Diagram}

Figure 46 is a simplified flow diagram of SIFrer. After intialization, the RACOUT data file containing header infor mation, peak energies, areas, and uncertainties from the first spectrum are read into sTFTER. The peak energies found by RAGS are matched to a tabulated set of self-consistent and accurately measured photopeak energies of isotopes commonly produced in samples by neutron irradiation. The photopeak energies in RACOUT are refitted by the least squares method to this consistent set. If the counting geometry contained in the header record IGEO matches that in an EFFCAl file, the photopeak areas are multiplied by the inverse of the efficiency as interpolated by a least squares energy fit from the data stored in EFFCAL. If a calibrated counting arrangement was not used, the efficiency is set to one. Next. FLUX file is searched for the appropriate flux for the ixradiation position. No match means that the 
absolute neutron capture rate camot be calculated, and a dis/(mining) value is calculated. If a tube match is found, the flux is corrected for decay of ${ }^{252} \mathrm{CF}$ from the calibration data to the date of activation. Next, the first isotope iso listed in the GAMDAT file and its spectroscopic decay data listed in order of decreasing decay abundance are read. The photopeak energy ENY of the most-abundant gamma ray in $1 S O$ is searched against the list of RAGOUT refitted energies Ey. When a match is found, $\mathrm{ENY}=\mathrm{EY} \pm 0.3 \mathrm{MeV}$, the $S, C, D$, and F terms are calculated from the listed half-life in GAMDAT, from the experimental ixradiation, decay, and counting times, and from the number of irradiation cycles listed in RAGOUT. If no gamma ray match is found, the next-most-abundant gamma ray listed in ISO is searched against RAGOUT. This indexing continues through the gamma ray list of ISO. At the end of data for the ISO, the next isotope listed in GAMDAT' is read, and the energy match is continued. If a gamma match has been found and the $S, C, D, F$ terms have been calculated, the dis/(minmg) is calculated and printed out if flux data are absent. If flux parameters are available, the STGMAF file is searched for a match between ISO and the first reaction product symbol JSO. A match signals a RATE calculation using the nomalized 84 group fluxes and cross sections. If $84-g$ roup data are not available, 2 -group fluxes and cross sections axe used. If neither multigroup nor 2-group cross section data exist, the RATE is set to one, and a relative concentration is printed. Calculations for RATE $=1$ indicate that a comparative standard must be run for that element.

At this point, all of the experimental and tabulated inform mation required for the calculation of the concentration and the uncertainty of the neutron capture parent of ISO is avail m able. This concentration (ppm), its uncertainty, the nuclide symbol, the reaction symbol, and the RATE calculation comment (Rate $=1,84 \sim$ group or 2-group) are printed out (Table A-7).

often a particular nuclide can be produced by neutron reactions such as $(n, p),(n, \alpha)$, and $(n, y)$ reactions on different parent nuclides. SIGMAF file includes all possible production mechanisms for each product JSO. To account for these reactions, the entire STGMAF file is searched for all possible symbol matches. Very little fast neutron $(n, p)$ or $(n, \alpha)$ cross section data are avaliable for inclusion in 84 -group format; therefore, a RATE $=1$ calculation normally signals possible interference.

The end of the SIGMAF file signals the search against RAGOUT of the next-most-abundant gamma ray in the product ISO. The process is continued until the end of the list of possible gamma rays for the product ISO is reached, and then a new ISO is searched in the same mamer. This searching loop continues until the end 


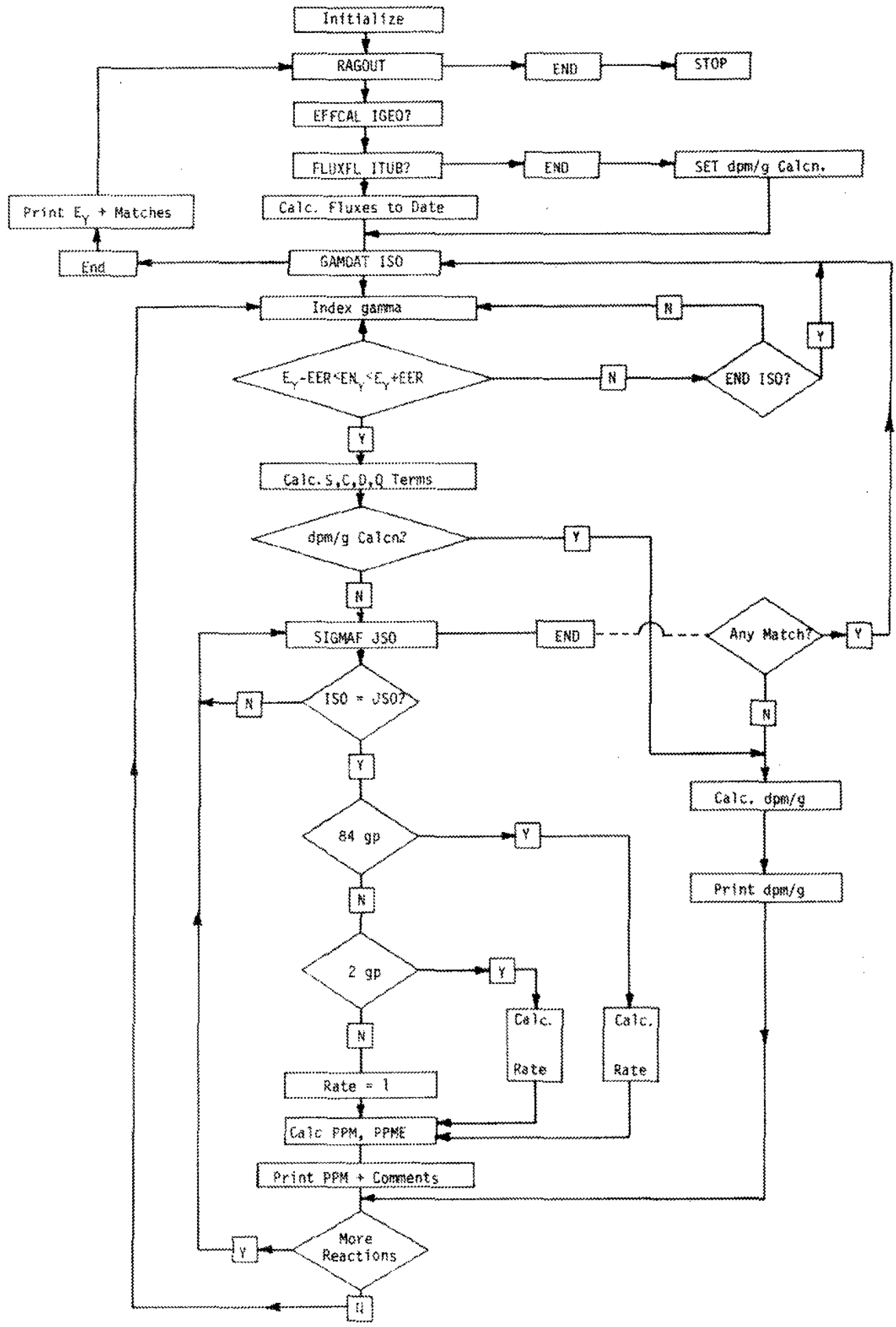

FIGURE 46. SIFTER Program Flowsheet 
of the GAMDAT file is reached. Next a listing is made of each refitted RAGOUT photopeak energy EY, photopeak areas corrected for efficiency, percent uncertainty in the area, and all nuclide symbols which had a gamma ray matching that energy (Table A-7). This latter listing provides a quick check and demonstrates whether all significant gamma rays were accounted for in the search prom cedure and also whether legitimate interferences between isotopes have occurred which would render the calculated concentration questionable.

Following this listing, the next spectral analysis RAGouT block is read and the entire process repeated until all spectra have been scanned.

\section{Interpretation of SIFTER Output}

Interpreting SIFTER outputs is not always straightforward because: 1) the same product nuclide can be formed by different reaction mechanisms, e.g., ${ }^{23} \mathrm{Na}(\mathrm{n}, y){ }^{24} \mathrm{Na}$ and ${ }^{27} \mathrm{Al}(\mathrm{n}, \alpha){ }^{24} \mathrm{Na}$; 2) most nuclides have more than one intense gamma ray and multiple values for the calculated concentration. (for example, ${ }^{60}$ Co emits garma rays of 1333.495 and $1172.210 \mathrm{MeV}$ ); 3) some judgment is required to determine whether the expeximental timing conditions allow for a particular product to be present; 4) poor counting statistics may skew a peak so that the peak-centered energy calculated by RAGS does not match ( $+0.3 \mathrm{MeV})$ the gamma energy listed in GAMDAT; 5 ) doublemescape and single-escape peaks are not recognized as such; 6) no partitioning of activity among isomers is made (for example, ${ }^{152}$ Eu and ${ }^{152 M}$ Eu both contribute to the intensity of the $121.78 \mathrm{~m}$ and $344.31 \mathrm{keV}$ ganma ray photom peaks); 7) statistical fluctuations in the spectrum may occasionally be analyzed as a photopeak and indicates matched nuclide that may not actually be present in the sample; 8) jf tabulated cross sections axe not yet available for reaction, the rate is set to one and no concentration can be calculated for that element; 9 concentration values of the same element taken from multiple counts of a parti cular sample must be edited to arrive at a single best value.

These limitations to a straight forward interpretation currently require that STFTER outputs be examined by trained pexsonnel and that judgments made in the final interpretation.

Table A-7 and Table A 8 are STFTER outputs of a freezemdried vegetation sample. The header record infomation at the top of the output indicates that the spectrum tagword is 26 and that the analysis was performed at $11: 17 \mathrm{p} . \mathrm{m}$. on $3 / 17 / 76$. The count time (CT) decay time oT and irradiation times TIR are indicated in seconds. The sample weight Wt, count geometry IGEO, irradiation 
tube ITUB and the number of cycles ICYC are also shown. The sample description $\dot{x}$ s listed next as well as the number of statistically significant photopeaks NPK. The photopeak energies (not refitted) found by RAGS are listed in the seven columns in order of increasing energy. The RAGour energies which matched an abbreviated list of self-consistent energies for common activation products are isted. A thirdmorder, least squares energy refit was performed on the 18 matched photopeak energies. The columns in Figure A-7a are: product melide symbol, the refitted experimental gamna ray energies, the reaction symbol [for example, $G O=(n, \gamma), A O=(n, \alpha)$, $\mathrm{pO}=(n, p)$, and $\mathrm{Gl} \approx(n, \gamma)$ reaction leading to the first mestastable state of the product isotope], the concentration (ppm) and statistical error, and a comment denoting the method of calculating the specific neutron capture rate.

Table A-10 lists each photopeak energy, peak area (corrected for efficiency), percent uncertainty in peak area, and the symbols of products having energy matches to that photopeak.

Many of the difficulties in interpreting SIFTER outputs are evident in these two tables. For example, the $312.90-\mathrm{keV}$ photopeak has never proven reliable for the analysis of potassium, probably because the absolute gamma ray abundance is incorrect. The $102.70 \mathrm{mkV}$ photopeak attributed to ${ }^{8} \mathrm{~m}_{\mathrm{Se}}$ is actually the $103.20 \mathrm{keV}$ photopeak of ${ }^{153} \mathrm{Sm}$. The five ${ }^{2} \mathrm{Bx}$ ppm values must be weighted to arrive at a best value; however, such multiple energy matches provide unequivocal evidence of the presence of bromine. The $487.40^{*}$ photopeak listed for tellurium is actually the 487.10mkeV peak from ${ }^{140} \mathrm{La}$. (The asterisk indicates a relative ganma ray abundance and a relative ppm value.) The $121.78-\mathrm{keV}$ photopeak is the result of decay of both ${ }^{15}$ Eu and ${ }^{152 \mathrm{MI}} \mathrm{Eu}$ which results in an abnormally high concentration of both. The 328.50 keV ${ }^{193} \mathrm{Ir}$ peak actually is ${ }^{40} \mathrm{La}$. All other values are judged correct.

Data reduction program development in progress includes a routine to calculate "less than or equal to" values for elements not detected based on experimental parameters and on an interpolation of backgrounds between the two nearest real photopeaks. The GAMDAT library will be updated to contain a completely selfconsistent set of photopeak energies which will eliminate many false energy matches. Finally, SIFTER will be replaced with RICHES, 17 a program designed to output a single best value for each element detected based on all counting data (multiple spectra, isotopes, and gamma rays) from each sample. 


\section{Analysis of Test Mixture}

An earlier version of STFTER was used as the basic data reduction routine in the original $17-\mathrm{mg}{ }^{252} \mathrm{Cf}$ facility. To verify the applicability of the absolute technique to complex mixtures, a test mixture supplied in 1973 by the USAEC as part of an evaluation of activation analysis using ${ }^{252} \mathrm{Cf}$ sources was analyzed. This test mixture had been analyzed previously at Savannah River by classical comparative standard methods. The first analysis was performed before the pneumatic rabbit system was operational, and the results were based on counting of nomally used longer-1ives ( $>2$ minutes) activation products. After installation of the rabbit system and development of SIFTER, the test mixture was analyzed again using automated absolute activation analysis (AAAA).

Results and comparison of the two techniques are summarized in Table 16. The precision and accuracy of AAAA is equivalent to the comparative technique. The analysis time for the absolute technique, however, is reduced because: 1) comparative standards were not prepared, irradiated, and counted; 2) the pneumatic transfer system permits analysis based on short half-life product isotopes; and 3) data reduction time using SIFTER is much less than normal reduction time for comparison to standard data. 
TABLE 16

Analysis of Test Mixture

\begin{tabular}{|c|c|c|c|}
\hline & Coneentratio & $p p m$ & \\
\hline Ezement & Comparative & $\begin{array}{l}\text { Absolute } \\
(A A A)\end{array}$ & $\begin{array}{l}\text { USAEC } \\
\text { Reported }\end{array}$ \\
\hline Se & - & $870 \pm 10$ & 840 \\
\hline v & $20 \pm 1$ & $17 \pm 1$ & 20 \\
\hline Al & $420 \pm 40$ & $330 \pm 20$ & 370 \\
\hline $\mathrm{Cu}$ & $130 \pm 30$ & $60 \pm 30$ & 95 \\
\hline $\mathrm{Co}$ & $140 \pm 8$ & $150 \pm 5$ & 140 \\
\hline Mo & $3200 \pm 300$ & $3300 \pm 100$ & 2910 \\
\hline $\mathrm{Mn}$ & $5.8 \pm 0.8$ & $4.5 \pm 0.5$ & 5 \\
\hline As & $81 \pm 5$ & $72 \pm 2$ & 70 \\
\hline Eu & $0.94 \pm 0.06$ & $0.88 \pm 0.06$ & 0.9 \\
\hline $\mathrm{Na}$ & $731 \pm 9$ & $630 \pm 10$ & 690 \\
\hline Hg & $985 \pm 25$ & $900 \pm 100$ & 930 \\
\hline$z_{n}$ & $935 \pm 45$ & $680 \pm 110$ & 930 \\
\hline $\mathrm{Cd}$ & $2092+44$ & $2100 \pm 80$ & 2330 \\
\hline $\begin{array}{l}\text { Average } \\
\text { Deviation }\end{array}$ & $\pm 10 \%$ & \pm 110 & \\
\hline $\begin{array}{l}\text { Preparation, } \\
\text { Irxadiation } \\
\text { Time }\end{array}$ & 30 days & 2 days & \\
\hline $\begin{array}{l}\text { Counting, } \\
\text { Data Analysis }\end{array}$ & 4 days & 1 day & \\
\hline
\end{tabular}




\section{RESULTS AND APPLICATIONS}

This section discusses results of the application of AAAA to many known multielenent standards. Some unique applications of AAAA to Savannah River programs are presented. For comparison purposes, only those samples analyzed in the $100 \mathrm{mg}{ }^{252} \mathrm{Cf}$ facility (since July 1975) are considered here; however, many samples were analyzed with quite similar results with the $17 \mathrm{mg}{ }^{252} \mathrm{Cf}$ source (July 1973 - July 1975). The results shown in this section were edited from actual SIFTER outputs as described in the previous section.

\section{SOLID STANDARDS}

\section{Standard Coal (NBS Standard SRM-1632)}

Two $10 \mathrm{ml}$ samples of standard coal from the National Bureau of Standards (NBS) were weighed into sample irradiation containers. This material was used as received in finely ground and blended forms. Enough distilled water was added to displace all air from the containers. The first sample was irradiated $(10-\mathrm{sec})$ and counted $(10-\mathrm{sec})$ cyclically $(40$ cycles $)$ for delayed neutrons (natural uranium analysis) and for short-lived gamma activities

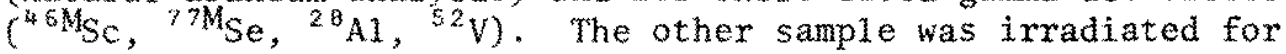
2 weeks, and then gamma counts were taken after decay periods of 60 seconds, 1 day, 7 days, and 14 days for medium-lived and longm lived species. Results of the absolute analysis are shown in Colum 4 of Table 17. The concentration values certified by NBS are indicated as well as the values found by comparative analyses conducted by four separate laboratories using classical instrumental reactor neutron activation analysis (INAA). AAAA results are as precise and accurate as those reported by INAA using high flux $\left[10^{22}\right.$ to $10^{33}$ neutrons/( $\left.\left.\mathrm{cm}^{2}-\mathrm{sec}\right)\right]$ irradiations and comparative standards.

\section{Standard Fly Ash (NBS Sample SRM-1633)}

Table 18 summarizes the results obtained by AAA for the standard fly ash. As with the standard coal, agreement between INAA and AAAA values is quite good. Another very important factor involved in the absolute technique which must be considered is the effect of the matrix. Based on a comparison of 11 key elements measured by AAAA and INAA in NBS samples SRM-1632 and $S R M-1633$, the increase in self-absorption between the coal and fly ash is $\leq 4 \%$. The 11 key elements are major constituents 
TABLE 17

Analysis of NBS Coal Standard SRM-1632

\begin{tabular}{|c|c|c|c|}
\hline & Cono & & \\
\hline sement $2^{a}$ & mBS & $\operatorname{TNNA^{a}}$ & $A A A A^{2}$ \\
\hline Al & & $1.85 \pm 0.13$ & $1.62 \pm 0.13$ \\
\hline fe & $0.87 \pm 0.03$ & $0.84 \pm 0.04$ & $0.89 \pm 0.03$ \\
\hline $\mathrm{x}$ & & $0.28 \pm 0.03$ & $0.30 \pm 0.02$ \\
\hline $\mathrm{Mg}$ & & $0.20 \pm 0.05$ & $0.82 \pm 0.20$ \\
\hline $\mathrm{Na}$ & & $414 \pm 20$ & $380 \pm 3$ \\
\hline $\mathrm{Cl}$ & & $890 \pm 125$ & $800 \pm 50$ \\
\hline $5 \mathrm{c}$ & & $3.7 \pm 0.3$ & $3.98 \pm 0.04$ \\
\hline $\mathrm{Ti}$ & 800 & $1040 \pm 110$ & $995+100$ \\
\hline v & $35 \pm 3$ & $36 \pm 3$ & $33 \pm 3$ \\
\hline$C x$ & $20.2 \pm 0.5$ & $19.7 \pm 0.9$ & $18.5 \pm 1.7$ \\
\hline $\min$ & $40 \pm 3$ & $43 \pm 4$ & $43 \pm 1$ \\
\hline $\mathrm{Co}$ & 6 & $5.7 \pm 0.4$ & $6.0 \pm 0.02$ \\
\hline $\mathrm{zn}$ & $37 \pm 4$ & $30+10$ & $52 \pm 4$ \\
\hline As & $5.9 \pm 0.6$ & $6.5=1.4$ & $4.7 \pm 0.5$ \\
\hline $\mathrm{Br}$ & & $19.3 \pm 1.9$ & $15 \pm 1$ \\
\hline$S x$ & & $161+16$ & $170+20$ \\
\hline $\mathrm{Ba}$ & & $350+30$ & $310+30$ \\
\hline Sb & & $3.9 \pm 1.3$ & $3.8 \pm 0.2$ \\
\hline $\mathrm{Cs}$ & & $1.4 \pm 0.1$. & $3.5 \pm 1.3$ \\
\hline L,a & & $10.7 \pm 1.2$ & $8.3 \pm 0.2$ \\
\hline $\mathrm{Ce}$ & & $19.5 \pm 1.0$ & $26 \pm 5$ \\
\hline $5 m$ & & $1.7 \pm 0.2$ & $1.4 \pm 0.10$ \\
\hline $\mathrm{xb}$ & & $0.7 \pm 0.1$ & $1.0 \pm 0.2$ \\
\hline$y$ & & $1.41+0.07$ & $1.34 \pm 0.50$ \\
\hline Eis & & $0.33+0.03$ & $0.30 \pm 0.10$ \\
\hline Ga & & & $5 \pm 1$ \\
\hline Dy & & & $1.0 \pm 0.1$ \\
\hline Se & & $3.4 \pm 0.2$ & $3.1 \pm 0.6$ \\
\hline
\end{tabular}

a. Value reported by Instrumental Neutron Activation Aralysis Round Robin, 3. M. Ondov, et al., Anal. Chem, 47, 1102 (1975).

b. Value found by absolute activation analysis at SRl. Uncertainties based on counting statistics only. 
TABLE 18

Analys is of NBS Fly Ash Standard SRM- 633

\begin{tabular}{|c|c|c|c|}
\hline & Coneenting & & \\
\hline Ezement & WBS & INAA & $\operatorname{RAAA}$ \\
\hline $\mathrm{Fe}$ & & $6.2 \times 0.3$ & $6.3 \pm 0.1$ \\
\hline $\mathrm{Mgg}$ & & $1.8 \pm 0.4$ & $6.3 \pm 0.3$ \\
\hline $\mathrm{Al}$ & & $12.7 \quad 40.5$ & $10.4 \pm 0.6$ \\
\hline Si & & 2122 & \\
\hline $\mathrm{Ca}$ & & $4.7 \pm 0.6$ & \\
\hline K & & $1.63 \pm 0.15$ & $1.51 \quad 20.05$ \\
\hline Na & & $3200 \pm 400$ & $2820+50$ \\
\hline Sc & & $27 \pm 1$ & $26.8 \pm 0.2$ \\
\hline $\mathrm{Mn}$ & $493+7$ & $496+19$ & $520+20$ \\
\hline $\mathrm{Co}$ & 38 & $42 \pm 1$ & $38 \pm 2$ \\
\hline As & $61+6$ & 5844 & $54 \pm 3$ \\
\hline$S \mathrm{r}$ & 1380 & $1700 \pm 300$ & $1340 \pm 100$ \\
\hline$S b$ & & $6.9 \pm 0.6$ & $7.4 \pm 0.3$ \\
\hline 83 & & $2700 \pm 200$ & $3200 \pm 400$ \\
\hline 13 & & $82 \pm 2$ & $68 \pm 2$ \\
\hline$S m$ & & $12.4 \neq 0.9$ & $11 \div$ \\
\hline Dy & & & $9 \pm 2$ \\
\hline He & & $7.9+0.4$ & 7.520 .4 \\
\hline W & & $4.6 \pm 1.6$ & $6 * 1$ \\
\hline $\mathrm{Cr}$ & $131 \pm 2$ & $127 \pm 6$ & $120 \pm 5$ \\
\hline$B r$ & & $12+4$ & $6 \pm 1$ \\
\hline $\mathrm{Ce}$ & & $346 \pm 15$ & $176 \pm 4$ \\
\hline$r b$ & & $7+3$ & $4.7 \pm 0.4$ \\
\hline Lu & & $1 \pm 0.3$ & 4 i. \\
\hline $2 n$ & $210 \div 20$ & $216+25$ & $270+30$ \\
\hline 58 & $9.4+0.5$ & $10.2 \pm 1.4$ & $8.7+1.8$ \\
\hline $\mathrm{Cs}$ & & 8.6 k.1 & $8.5 \pm 0.5$ \\
\hline w & & 1.940 .3 & $1.2 \pm 0.2$ \\
\hline Ta & & $1.8 \pm 0.3$ & $2.0 \div 0.1$ \\
\hline $\mathrm{Cl}$ & & $42 \pm 10$ & $40 \pm 8$ \\
\hline$T i$ & & $7400 \quad 2300$ & $6000 \pm 400$ \\
\hline v & & $235 \pm 15$ & $196 \pm 10$ \\
\hline
\end{tabular}


and those elements which, by experience, have characteristically provided results which are both precise and accurate: Al, Fe, $K$, Na, Sc, $V, C r, M n, C o, L a$, and Sm. The average difference for these elements between AAAA and INAA is $4.5 \%$ for the coal and $8.2 \%$ for the fly ash. These results and those reported below for wetted USGS rock standards provide evidence for the lack of major matrix effects.

\section{Rock Standards (USGS Samples GSP-1 and BCR-1)}

Tables 19 and 20 summaxize results of AAAA on wetted samples of standard (powdered) rock from the U. S. Geologic Survey (USGS). Results for most elements agree with those values selected as "correct." Again, no matrix effects are evident for these solids. The serious discrepancy in the magnesium concentration by AAAA for coal, fly ash, and both rock standards is caused by ${ }^{2} \mathrm{Mg}$ produced by the fast neutron interference reaction ${ }^{27} \mathrm{Al}(\mathrm{n}, \mathrm{p})^{27} \mathrm{Mg}$ and by the desired themal neutron capture of magnesium. This interference as well as other potential interferences are flagged by the SIFTER output and require validity judgment. Another interference which has been noted is the ${ }^{27} \mathrm{Si}(\mathrm{n}, \mathrm{p}){ }^{28} \mathrm{Al}$ reaction, wich interferes with the analysis of aluminum in materials where the silicon/aluminum weight ratio exceeds $v 100$.

\section{LIQUID STANDARDS}

A series of dilute liquid elenental standards were analyzed by AAAA. The results and the percent deviation between the standard value and that found by AAAA axe listed in Table 21 . No uncertainties are listed for the standards which were prepared from comerciallymavailable atomic absorption standards.

These results and the results of the rock, coal, and fly ash analyses indicate that AAAA can be applied to many different solid and liquid samples such as other coals, ly ash, soils, vegetation, and process samples commonly submitted for analysis.

\section{ELEMENTAL DETECTION LIMITS}

TryCL, a version of the program SIFTER which solves the master activation program in reverse was written to provide an estimate of elemental detection sensitivities for samples irradiated and counted in the $100 \mathrm{mg}{ }^{252} \mathrm{Cf}$ facility. The detectable limit was assumed to be the 100 net counts in the photopeak of the most-abundant gamma ray derived from the neutron capture produce of each element. In the calculation, data files are the same as those in SIFTER, namely, EFFCAL, SIGMA, FILE, and 
TABLE 19

Analys is of USGS Rock Standard GSP-1

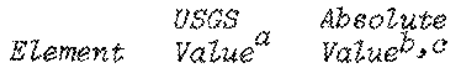

a. Major constituents, wt

$\begin{array}{lll}\mathrm{Na} & 2.08 & 2.04 \pm 0.04 \\ \mathrm{~K} & 4.59 & 4.9 \pm 0.6 \\ \mathrm{Fe} & 3.03 & 3.0 \pm 0.2 \\ \mathrm{Al} & 8.07 & 7.64 \pm 0.16 \\ \mathrm{~F} & 0.32 & 0.32 \pm 0.10 \\ \mathrm{Ti} & 0.399 & 0.41 \pm 0.03 \\ \mathrm{Mg} & 0.58 & 5.0 \pm 0.5\end{array}$

b. Mrnor constituents, ppm

$2 n \quad 98 \quad 150+30$

$\mathrm{Ce} \quad 394 \quad 440 \pm 100$

La $\quad 191 \quad 180 \pm 10$

Co $6.4 \quad 7.6 \pm 2.5$

Se $7,3 \quad 7.2 \pm 0,2$

Sb $3.1 \quad 3.320 .9$

Hf $15.9 \quad 36.3 \pm 0.5$

$v \quad 52.9 \quad 51 \pm 6$

Eu $\quad 2.4 \quad 2.0 \pm 0.5$

Cl $300 \quad 400+140$

$\mathrm{Mn} \quad 331 \quad 366 \pm 30$

Dy $5.4 \quad 3.3 \pm 1.5$

Sm $\quad 27.1 \quad 30 \pm 1$

$\mathrm{Hg} \quad 15.5 \quad$ II 5

Au $\quad 0.0016 \quad 0.024 \pm 0.009$

C. $12.5 \quad 19 \pm 7$

To $1.3 \quad 1.8 \neq 0.7$

$\mathrm{Ta} \quad 1.0 \quad 1.4 \pm 0.5$

a. F, J. Flanagan, Coochimioa et Cosmochimion Aera 37, 1189 (1973).

b. Value in ppm unless otherwise indicated.

c. Uncertainty based on counting statistics only. 


\section{TABLE 20}

Analys is of USGS Rock Standard BCR-1

$\begin{array}{lll} & \text { VSGS } & \text { Absolute } \\ \text { Element } & \text { Value } & \text { Valueb,o }\end{array}$

$\begin{array}{lll}\text { a. Major constituents, wt } \\ \mathrm{Na} & 2.43 & 2.53 \pm 0.05 \\ \mathrm{Mg} & 2.09 & 6.0 \pm 0.3 \\ \mathrm{~A} & 7.20 & 6.7 \pm 0.2 \\ \mathrm{~K} & 1.41 & 1.44 \pm 0.5 \\ \mathrm{Ti} & 1.28 & 1.29 \pm 0.25 \\ \mathrm{M} & 0.141 & 0.155 \pm 0.001\end{array}$

b. Minor constituents, ppm

$\begin{array}{lll}\mathrm{Ba} & 675 & 600 \pm 100 \\ \mathrm{~V} & 399 & 405 \pm 10 \\ \mathrm{Co} & 38 & 33 \pm 10 \\ \mathrm{Dy} & 6.3 & 5.7 \pm 0.7 \\ \mathrm{Sr} & 330 & 900 \pm 400 \\ \mathrm{Sc} & 33 & 40 \pm 1 \\ \mathrm{La} & 12.8 & 22 \pm 4 \\ \mathrm{Sm} & 6.6 & 6 \pm 1 \\ \mathrm{Yb} & 3.36 & 4 \pm 1 \\ \mathrm{Lu} & 0.55 & 2.5 \pm 0.4 \\ \mathrm{Cr} & 17.6 & 25 \pm 5 \\ \mathrm{Ce} & 53.9 & 36 \pm 5 \\ \mathrm{~Tb} & 1.0 & 1.9 \pm 0.3 \\ \mathrm{HE} & 4.7 & 6 \pm 1 \\ \mathrm{Sb} & 0.69 & 1.3 \pm 0.5 \\ \mathrm{Nd} & 29 & 68 \pm 20 \\ \mathrm{Ha} & 0.91 & 1.5 \pm 0.6\end{array}$

\footnotetext{
a. F. J. Flanagan, Geochimia et Cosmohimiea Aeta 3?, 1189 (1973).

b. Value in ppm unless otherwise indicated.

a. Uncertainty based on counting statistics only.
} 
TABLE 21

Absolute Analysis of Atomic Absorption Liquid Standards

\begin{tabular}{|c|c|c|c|}
\hline Ezement & $\begin{array}{l}\text { Stomdard } \\
\text { Yalue, } \\
\text { pem }\end{array}$ & $\begin{array}{l}\text { Absolutes } \\
\text { Yables, } \\
\text { pqm }\end{array}$ & $\begin{array}{l}\text { Percent } \\
\text { Dewation } \\
\text { from } \\
\text { stondand }\end{array}$ \\
\hline $\mathrm{Cs}$ & 97.9 & $100.3+2.7$ & +2.5 \\
\hline Se & 98.7 & $115.1 \pm 1.0$ & +16.5 \\
\hline $\mathrm{Co}$ & 98.8 & $109.6 \pm 4.0$ & +10.9 \\
\hline Se & 96.7 & $97.9 \pm 9.8$ & +1.2 \\
\hline $\mathrm{Cr}$ & 100.0 & $100+5$ & 0.0 \\
\hline Ta & 100.5 & $110 \pm 3$ & +9.5 \\
\hline $\mathrm{Ge}$ & 100 & $95 \pm 39$ & -5.0 \\
\hline oy & 9.93 & $10.1 \pm 1.0$ & +1.7 \\
\hline M & 99.4 & $94 \div 9$ & -5.4 \\
\hline Na & 100.1 & $103 \pm 4$ & +2.9 \\
\hline$k$ & 100.2 & $122+5$ & +21.8 \\
\hline \&a & 98.3 & $99 \pm 5$ & +0.7 \\
\hline As & 99.1 & $104 \pm 4$ & +4.9 \\
\hline wi & 105.6 & $93 \pm 2$ & -11.9 \\
\hline $\mathrm{Sm}$ & 9.77 & $9.3+0.3$ & -4.8 \\
\hline \$o & 10.0 & $10.3 \pm 1.0$ & +3.0 \\
\hline Yo & 100.2 & $91+19$ & -0.2 \\
\hline $\mathrm{Hg}$ & 99.8 & $130+30$ & +30.3 \\
\hline
\end{tabular}

GAMDAT. The most-sensitive product isotope from each element was selected from one of the four irradiation, decay, and counting regines listed in Table 22. The detection limits are interm ference free, and no effect of neighboring photopeaks or Compton background under the peak of interest is considered. As such, these limits have proven to be too low. As a rule of thumb, quantitative analyses in real samples usually require about 10 times higher concentration than those listed.

\section{SUMMARY OF ROUTINE ANALYSES}

The autonated and absolute activation analysis technique has been applied successfully to many different types of samples generated in different Savannah River programs. In some programs, activation analysis has been the only source of multielement data; in others, the technique is used in conjunction with other element analysis techniques to provide more-complete elemental analysis. These other techniques include inductively coupled plasma (ICP), $D C$ arc emission spectroscopy, $X$-ray fluorescence, spark source mass spectronetry, and atomic absorption spectroscopy. 


\section{TABLE 22}

Interference Free Elemental Detection Limits ${ }^{a}$ of the $100-m g{ }^{252} \mathrm{Cf}$ Fachility

Etemant

Eu, Dy

Mn, In, ${ }^{12 s} 1, I x_{3} A A_{1}$

Lu, Ho, Sm, Re, ${ }^{39} \mathrm{Pu}^{b}$

$\mathrm{Na}, \mathrm{Sc}, \mathrm{Co}, \mathrm{Ga}, \mathrm{Br}, \mathrm{Ag}$,

Sb, I, Cs, La, $\mathrm{Px}, \mathrm{Nm}$,

Yb, Ta, $\mathrm{Pt}, \mathrm{As}, \mathrm{Se}$

Ar, $\mathrm{K}, \mathrm{Cr}, \mathrm{V}, \mathrm{Cu}, \mathrm{Cd}$,

Ce, Nd, Gd, Th, Er, HF,

$\mathrm{Hg}, \mathrm{Ge}, \mathrm{Sr}, \mathrm{Nat} . \mathrm{w}^{b}$

Cl, $\mathrm{Zn}, \mathrm{Mo}, \mathrm{Ru}, \mathrm{Rh}$,

Pd, Te, Ba, Os

$\mathrm{F}, \mathrm{Mg}, \mathrm{Al}, \mathrm{Ti}, \mathrm{Ni}$,

$\mathrm{Sn}, \mathrm{Rb}, \mathrm{Y}$

$\mathrm{Ca}, \mathrm{Fo}, \mathrm{z}_{\mathrm{x}}$

$p_{b}, 0, s$
Deteotion limit, ppm

$<0.001$

$0.001-0.01$

$0.01-0.1$

$0.1 \sim 1.0$

$1.0-10$

$10-100$

$100 \times 1000$

$>1000$

a. Based on 100 counts in photopeak from 15 \% efficient $\mathrm{Ge}(\mathrm{L} i)$ detector. $10 \mathrm{mgram}$ sample is assumed. The lowest detection limit for each element was selected from one of the listed regimes:

$\begin{array}{lllll} & \text { Tmadiation } & \text { Decay } & \text { Cownt } & \\ \text { Regime } & \text { Time } & \text { Time } & \text { Thime } & \text { Gyoles } \\ 1 & 6 \mathrm{sec} & 1 \mathrm{sec} & 6 \mathrm{sec} & 50 \\ 2 & 1 \mathrm{hr} & 5 \mathrm{~min} & 30 \mathrm{~min} & 1 \\ 3 & 1 \mathrm{day} & 1 \mathrm{hr} & 30 \mathrm{~min} & 1 \\ 4 & 7 \text { days } & 1 \mathrm{hr} & 30 \mathrm{~min} & 1\end{array}$

b. Based on the 25 efficiency of the delayed neutron detector. 
Table 23 shows the types of samples analyzed and the range of elemental concentrations determined as a function of sample type. Many of the results were deternined in the $100-\mathrm{ng}{ }^{252} \mathrm{Cf}$ facility. The results in Table 23 were part of a study of the effects of stack releases from a coal-fired powerhouse on minor and trace element contents of neighboring soil and vegetation.

Many other routine analytical applications have been found for neutron activation analysis. Applications include:

- Chloride content of various plastic tapes and oils used at Savannah River.

- ${ }^{129} \mathrm{~T}$ and ${ }^{99} \mathrm{Tc}$ content of irradiated 1 ight water reactor fuels.

- Uranium and plutonium content of plant process streams and waste.

- Mercury content of fresh water fishes.

- Elemental composition of plant radioactive waste sludges.

- U/Al ratio measurements in reactor fuel fabrication studies.

- Analysis of trace elemental content of streams following ionexchange premconcentration.

- Stream pollutant source identification.

- River sediment characterization. 


\section{TABSE 23}

Elemental Concentration Ranges Measured in Typical Samples

\begin{tabular}{|c|c|c|c|c|c|}
\hline \multirow[b]{2}{*}{ Elemest } & \multicolumn{4}{|c|}{ Congeritration, $p D m$} & \multirow[b]{2}{*}{$\begin{array}{l}\text { Deteotion } \\
\text { senaitiving }\end{array}$} \\
\hline & Coots & $m_{Z} A s h$ & Soits & Vegetation & \\
\hline Se & $3-5$ & $30-35$ & $1-5$ & $0.3-0.2$ & $0.01-0.1$ \\
\hline v & $15-30$ & $150-300$ & $10-30$ & $5-10$ & $0.1 \sim 1$ \\
\hline M & $30-300$ & $200-500$ & $100-500$ & $200-300$ & $0.001-0.01$ \\
\hline As & $5-60$ & $20-500$ & $0.5-5$ & & $0.01-0.1$ \\
\hline$B r$ & $5-30$ & $s-100$ & $0.5-5$ & $10-50$ & $0.01 \times 0.3$ \\
\hline $5 x$ & $100-150$ & $500-1000$ & & & $0.1-1$ \\
\hline L.a & $5-10$ & $50-80$ & $10 \sim 50$ & $0.5-5$ & $0.01-0.1$ \\
\hline $5 \mathrm{~m}$ & $1-3$ & $10-20$ & $1-5$ & $0.1-0.5$ & $0.001-0.02$ \\
\hline $\mathrm{C} x$ & $15-25$ & $100-250$ & $5-15$ & $1-15$ & $0 . x-1.0$ \\
\hline$C_{0}$ & $5-10$ & $50-100$ & $1-2$ & $0.5-2$ & $0.02-0.1$ \\
\hline Ga & $5-10$ & $50-100$ & $1-10$ & & $0.01-0.1$ \\
\hline Sb & $\xi+5$ & $5-30$ & $0.2 \cdot 1$ & & $0.01-0.1$ \\
\hline$c \leqslant$ & $1 \sim 5$ & $10-20$ & $0.5 \times 5$ & $0.1-2$ & $0.01-0.1$ \\
\hline$C_{8}$ & $15-30$ & $100-300$ & $30-80$ & $0.1-10$ & $0.1-1$ \\
\hline$m$ & $0.2-3$ & $5-5$ & $0.3-2$ & & $0.1 \cdot 1$ \\
\hline$r$ & $0.5-2$ & $5-20$ & $0.5 \times 2$ & & $0.02-0.1$ \\
\hline ku & $0.5-1$ & $3-5$ & $0.5-1.5$ & & $0.001-0.01$ \\
\hline $\mathrm{H}$ & $0.5-1$ & $5-10$ & $5-10$ & & $0.1-1$ \\
\hline $\mathrm{h}$ & $1-5$ & $10-30$ & $5-20$ & $0.05-0.10$ & $0.5-5$ \\
\hline u & $1-3$ & $5-15$ & $1-5$ & & $0.5-5$ \\
\hline $2 n$ & $40-50$ & $300-800$ & $10-50$ & $10-200$ & $1-10$ \\
\hline se & $1-5$ & $10-20$ & $1-10$ & $0.03-0.15$ & $0.01 \sim 0.1$ \\
\hline nid & $20-40$ & $150-250$ & $10-50$ & & $0.1 \sim 1$ \\
\hline Eux & $0.2-5$ & $1-30$ & $0.1-0.5$ & & $<.001$ \\
\hline$T_{m}$ & & & & $3-15$ & $0.01-0.1$ \\
\hline $\mathrm{ra}$ & $0.2 \cdot 0.4$ & $1-2$ & $0.5-1.5$ & & $0.01 \times 0.1$ \\
\hline Ria & $100 \sim 250$ & $300-2000$ & $100-300$ & $150-250$ & $2=10$ \\
\hline Mo & $1-10$ & $20-100$ & & & $1-10$ \\
\hline$w$ & & $5 \times 20$ & $0.5-2$ & & $0.01-0.1$ \\
\hline W & $20 \times 50$ & $150 \sim 300$ & $10-30$ & $5-50$ & $10 \times 100$ \\
\hline By & $0.5-1$ & $5-10$ & $1-3$ & & $<0.001$ \\
\hline$F e(s)$ & & & $0.2 \sim 1.5$ & & $0.01-0.1$ \\
\hline$R a$ & & & $100-500$ & $10-300$ & $0.01-0.1$ \\
\hline$A \backslash\{(8)$ & & & $0.5-2$ & $0.007-0.09$ & $0.001-0.01$ \\
\hline 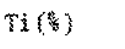 & & & $0.1-0.5$ & & $0.001-0.01$ \\
\hline$k(8)$ & & & $0.05-0.3$ & $0.6-2.3$ & $0.001-0.01$ \\
\hline $\mathrm{Mg}\left(\frac{1}{8}\right)$ & & & $0.5-2$ & N.D. - 0.4 & $0.001-0.01$ \\
\hline$C(B)$ & & & & $0.14 \sim 0.27$ & $0.001-0.01$ \\
\hline
\end{tabular}

a. The catculated detection sensitivitios refer to the loo mg Cf facility; values are interference free. 
. 
APPENDIX A: Data Reduction Tables

$-109-$ 
Table A-1. TRANSCRIBE Guthut

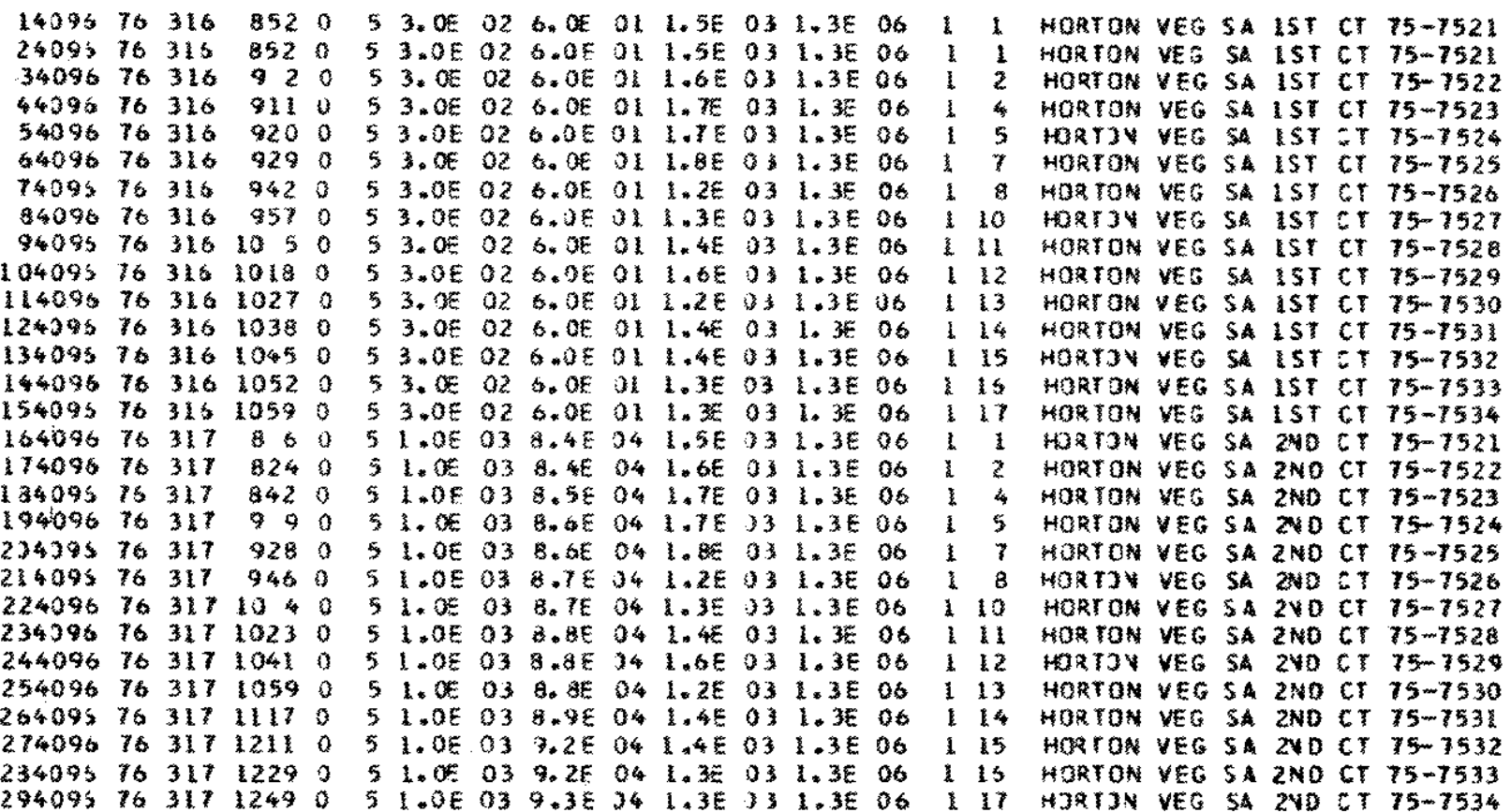

15\% E. . $20=$ $25 \mathrm{PEC} \times \mathrm{NO}=$ 3SPEC. NO * 4 SP EC -NOW: SSPEC.NOW $65 P$ EC. $40 *$ 750 EC.NO CSPEC. WO SSPEC A IOSPEC.NOE IISPEC. 12SPEC.NO\% 1.SPEC.NOF 13SPEC. $\mathrm{WO}=$ $145 P E C$. NOE 15SPEC. $10 \%$ 16 SPER if SPEC *:NO 10SPEC * CSPEC Ma ZOSPEC.NNO 21 PEC, $\mathrm{Na=}$ $225 P E C . N O$ 23 SPEC . WOF 24 SPEC $N O=$ $255 \mathrm{PEC}$. ND= 2SSPEC.NO 27 SPEC. NO= 285 PEC ND= 295 PEC. NO* 


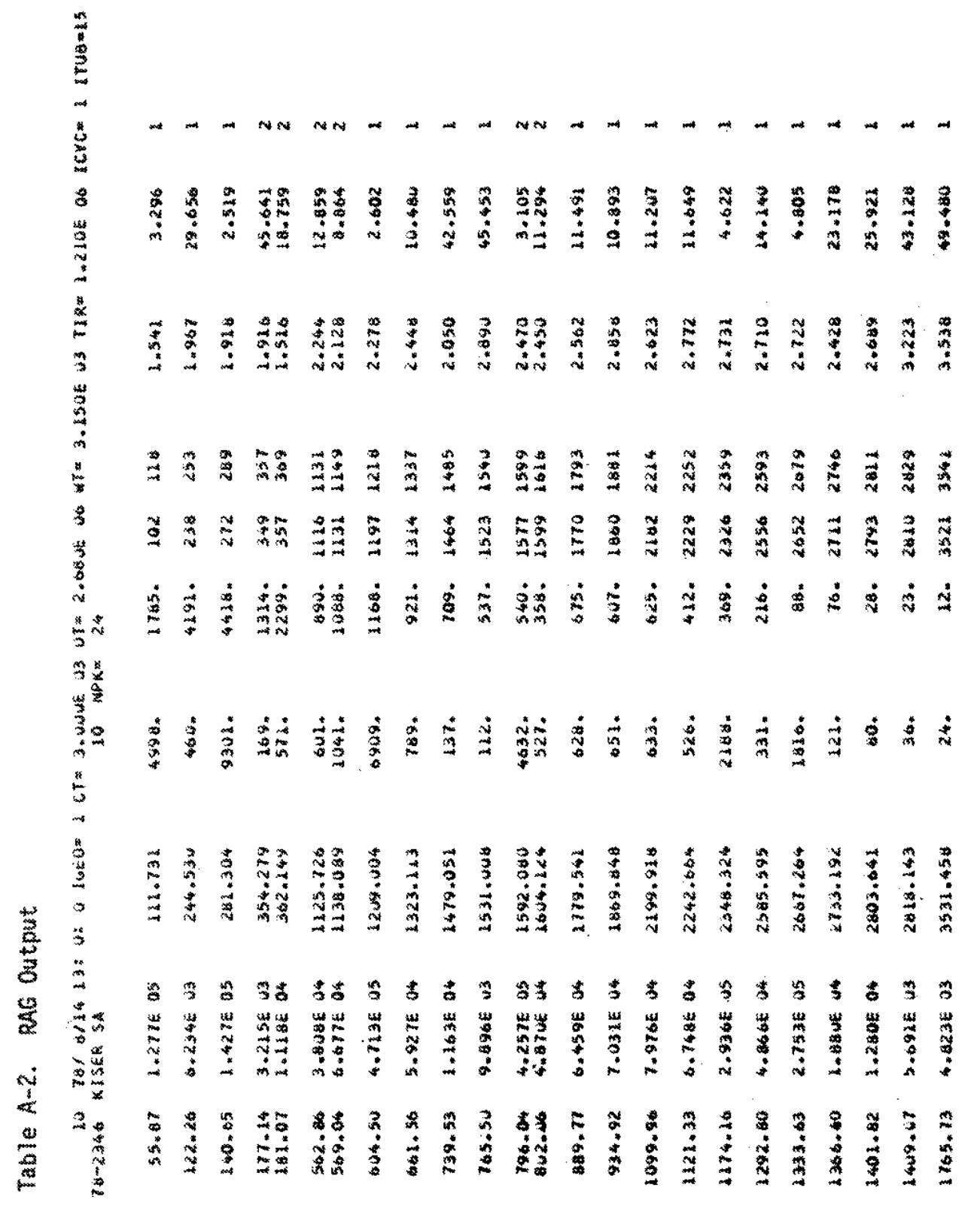


Table A-3. GAMDAT File

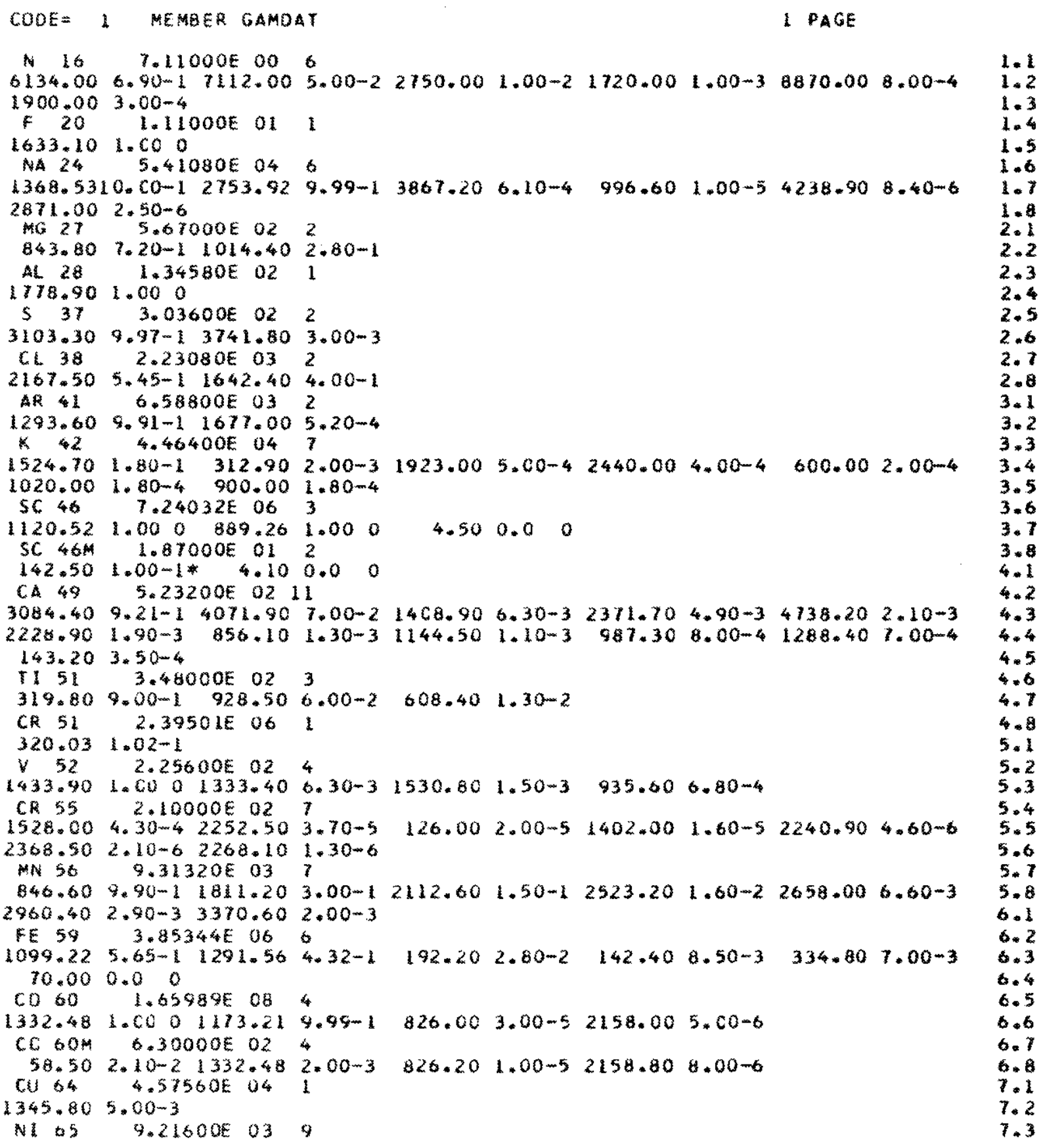


Table A-3. Continued

COOE 1 HMER GAMCAT

2 PAGE

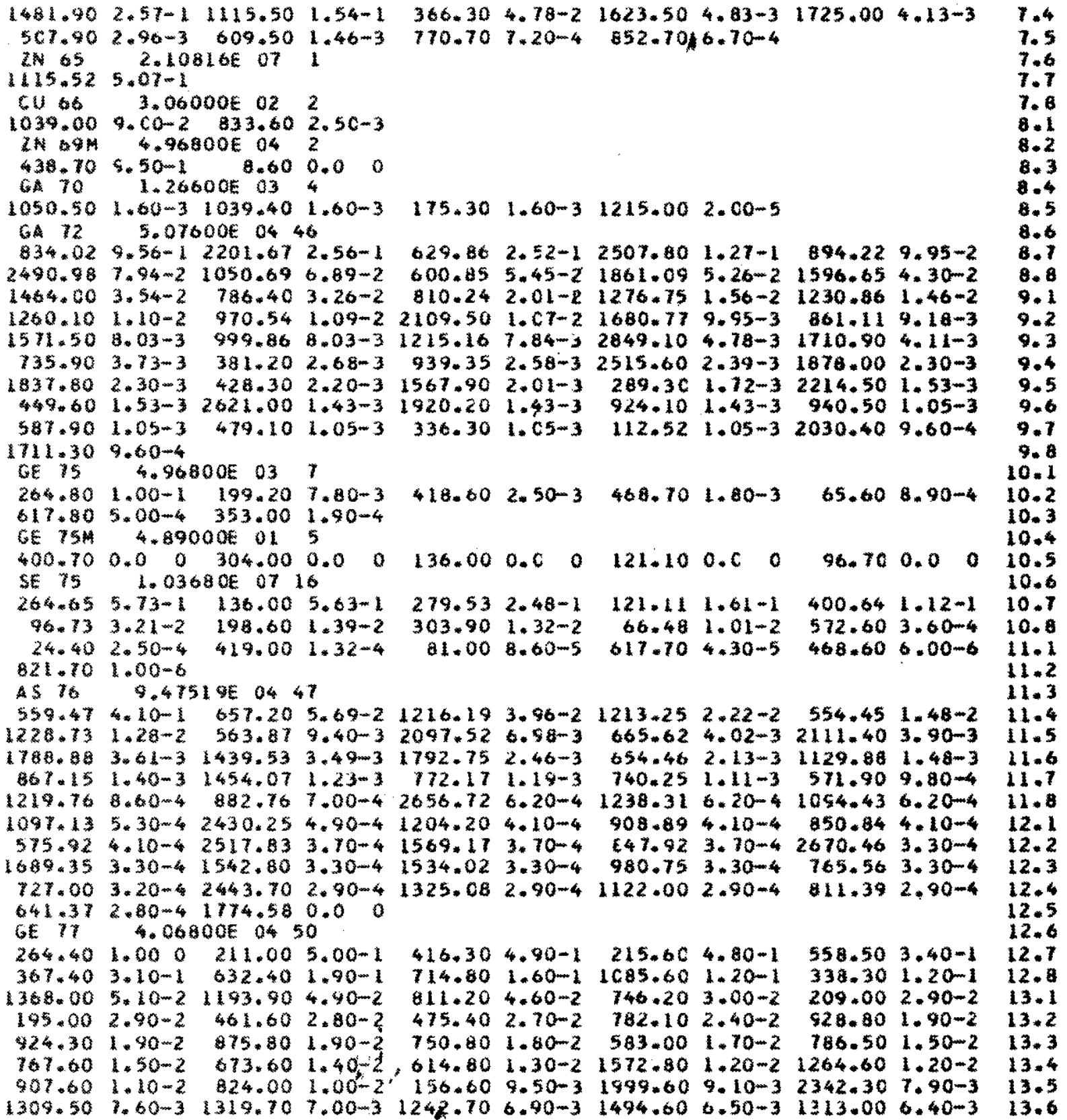


Table A-3. Contrinued

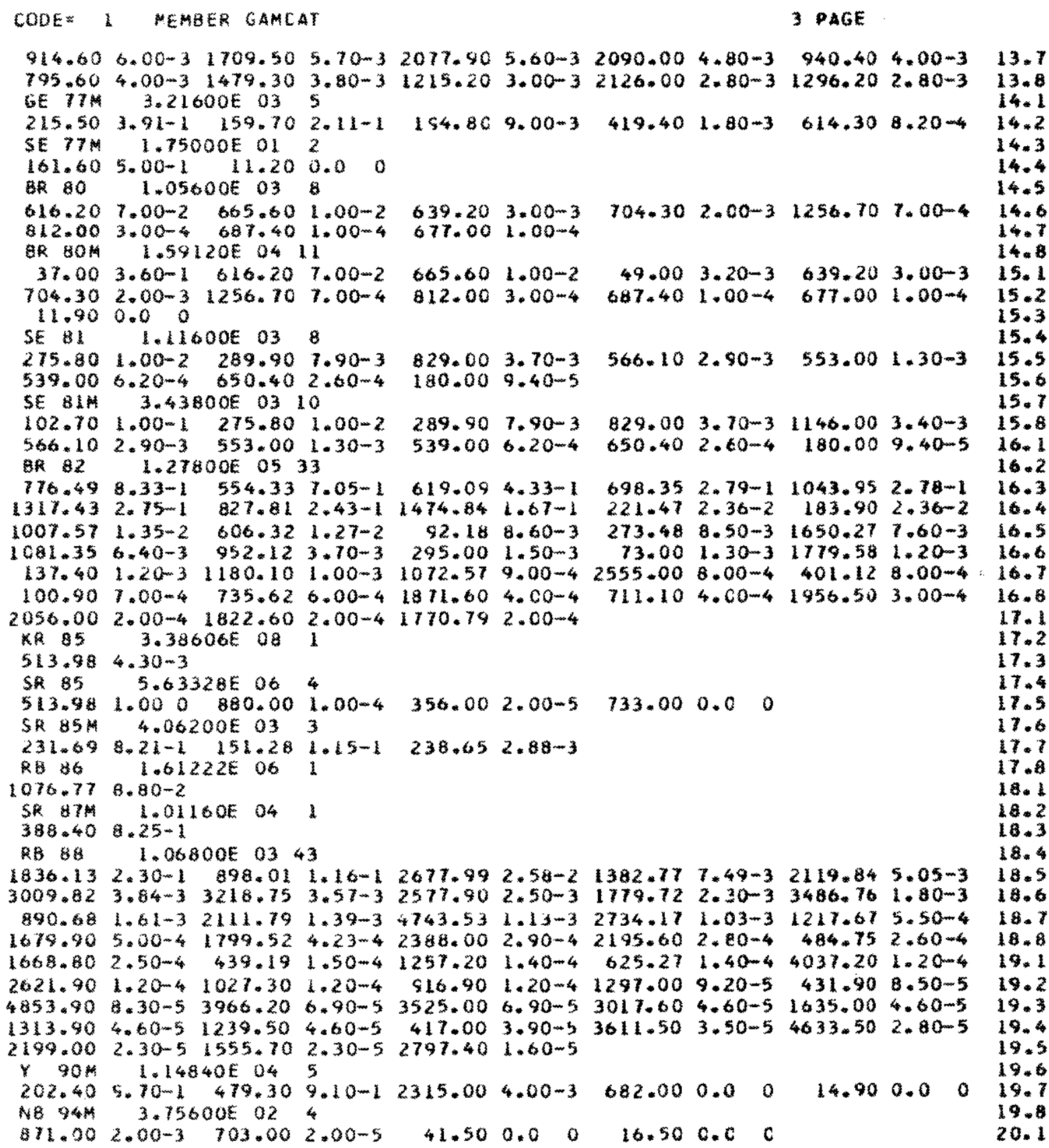


Table A-3. Continued

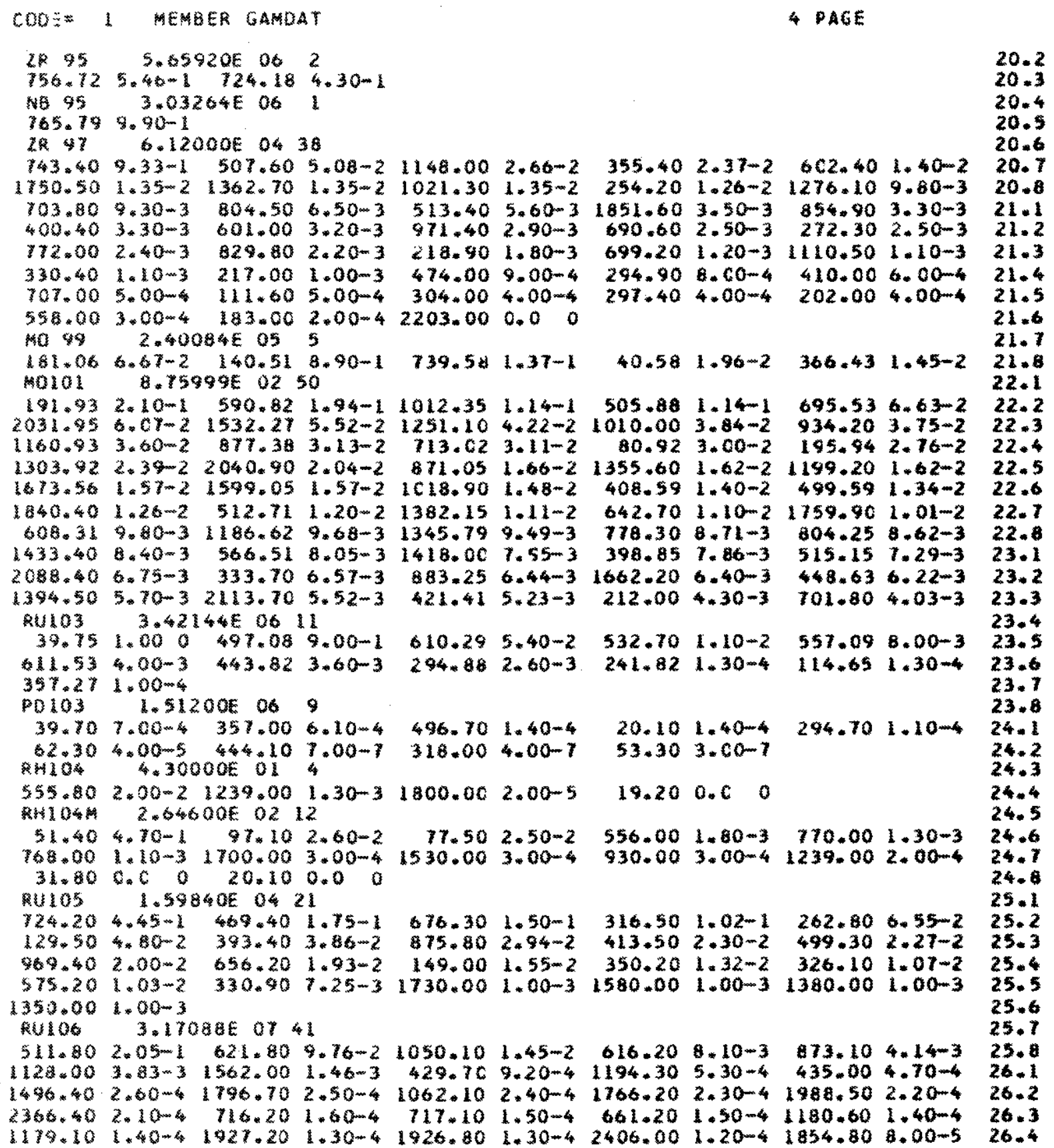


Table Aw3. Continued

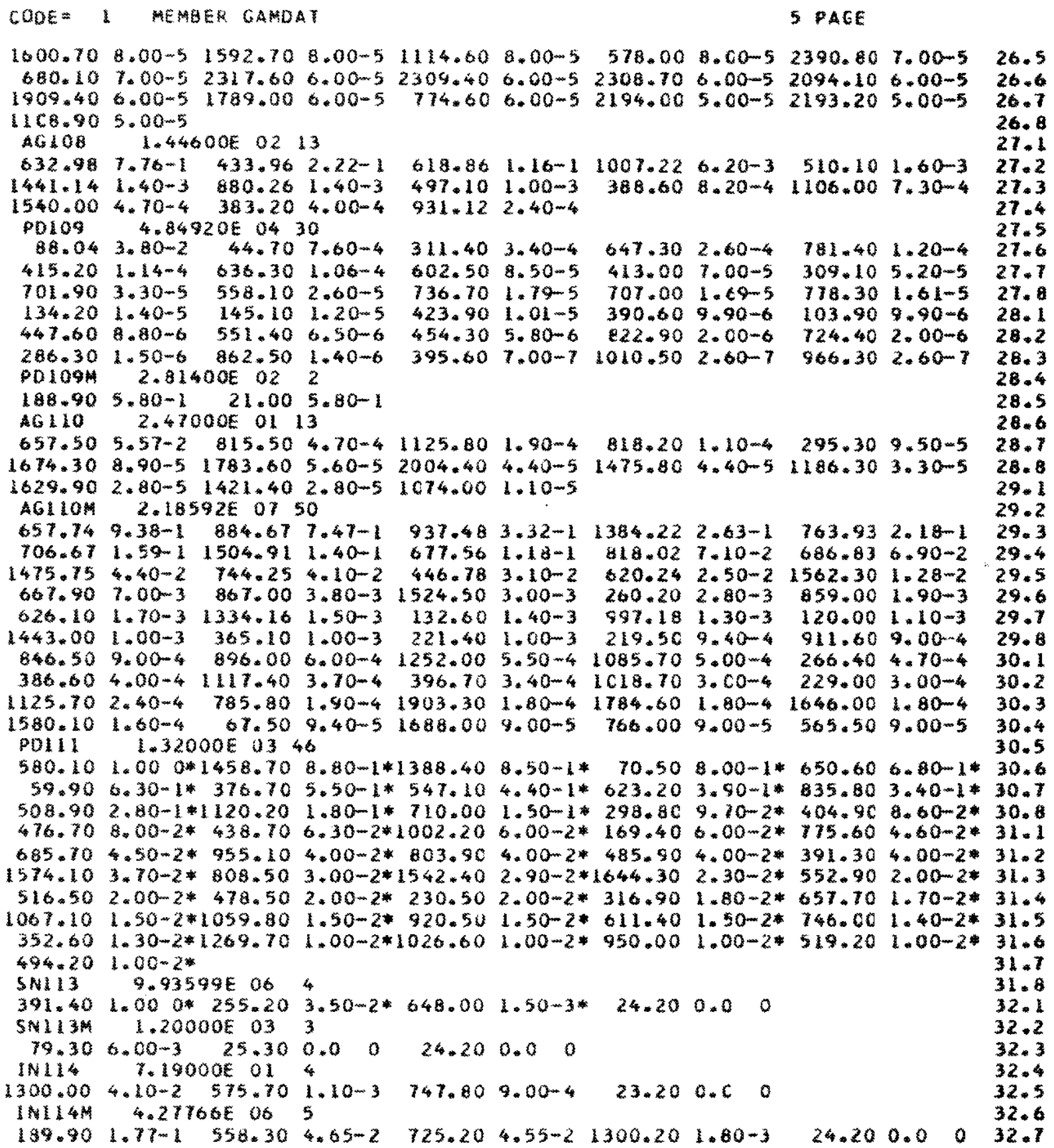


Takse A 3. Continued

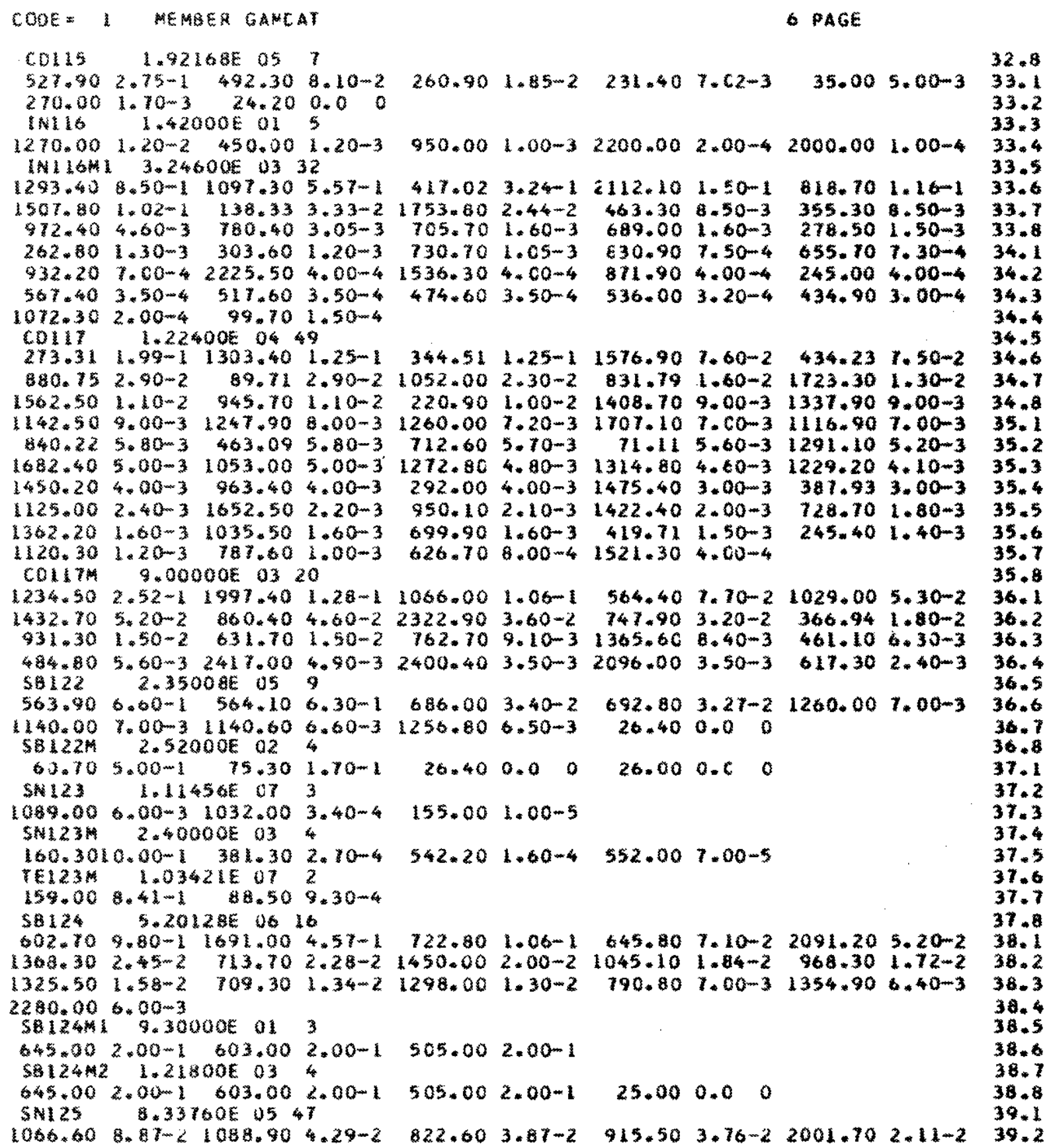


Table A-3. Continued

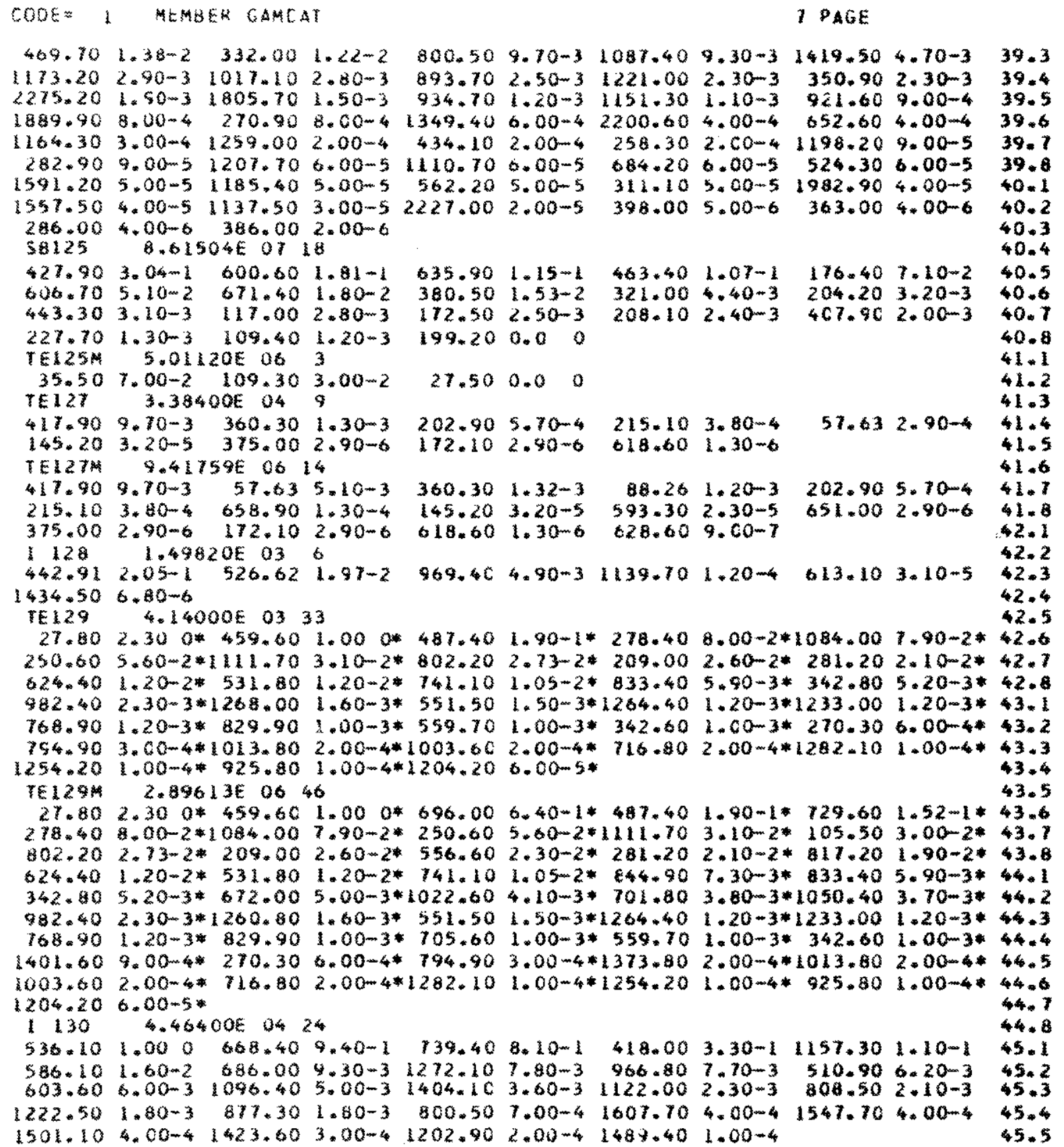


Sable $4-3$. Continued

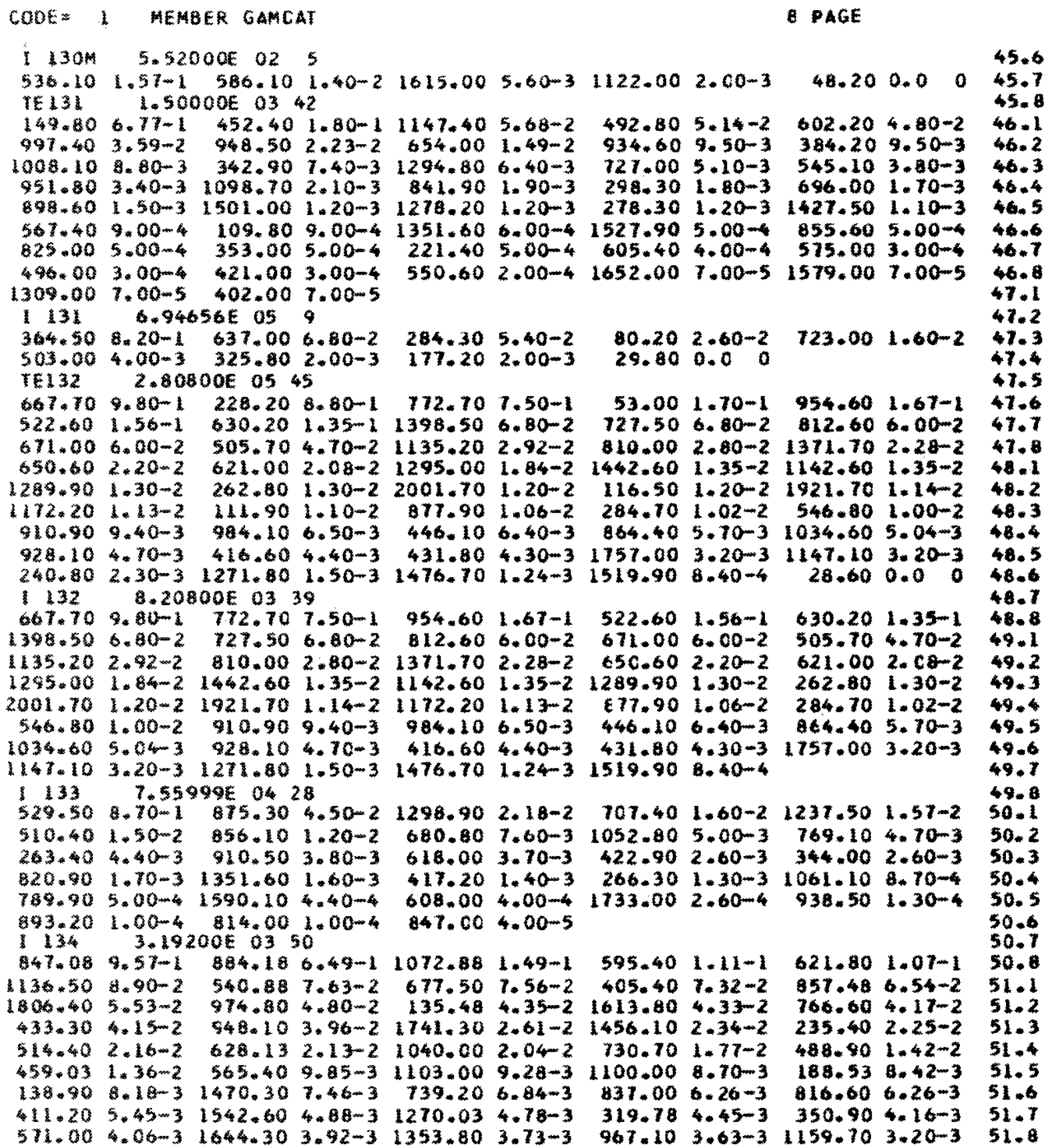


Table $A-3$. Continued

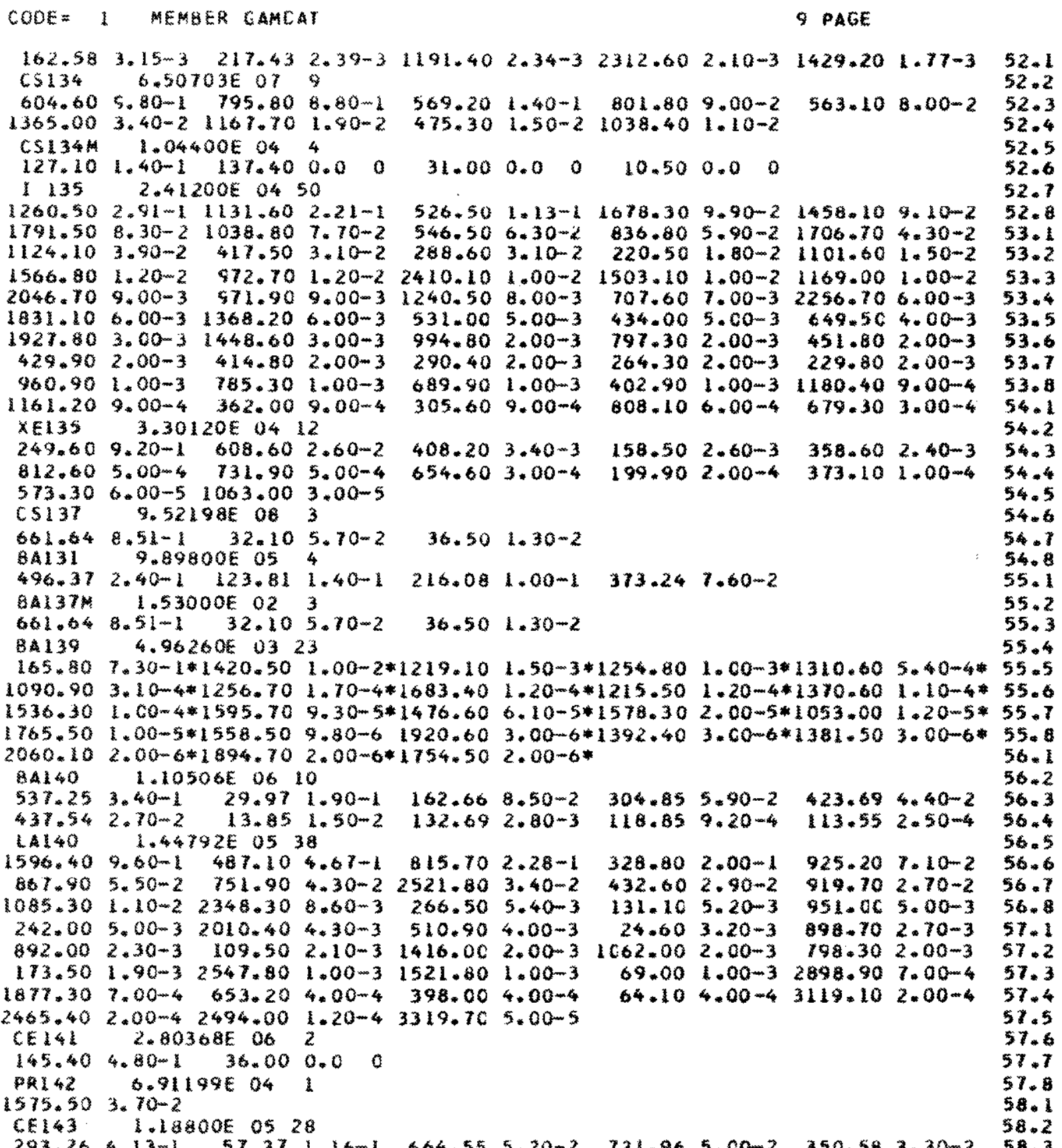


Table A-3, Continued

COCE I AERER GAMDAT

10 PAGE

$231.56 \quad 2.00-2 \quad 490.361 .90-2 \quad 880.39 \quad 9.10-3 \quad 1102.98 \quad 3.60-3 \quad 587.28 \quad 2.40-3$ $433.02 \quad 1.30-3 \quad 139.679 .70-4 \quad 1002.976 .60-4 \quad 447.216 .60-4 \quad 1060.523 .40-4$ $497.913 .30 \mathrm{~m} .437 .813 .10 \mathrm{~m} \quad 399.492 .90-4$ $556.862 .50-431.132 .10-41031.471 .70-4$ $991.101 .20-4 \quad 1047.049 .00-5 \quad 1339.92 \quad 3.70-5$ C.144 $2.45549 E$ o7 15

$03.53 \quad .08-1 \quad 00.121 .54 m 2$

$1.09 .20 \quad 2.90-3 \quad 33.57 \quad 1.50-3$

$\$ 13.802 .30-5 \quad 863.901 .80-5$

NO147 9.466715 os 22

$91.031 .49-1 \quad 531.409 .00-2$

$680.70 \quad 5.60-3 \quad 398.60 \quad 5.50-3$

$197.001 .30-3 \quad 489.609 .00-4$

$589.80 \quad 3.00-4 \quad 680.202 .00-4$

$170.002 .00-162.001 .00-4$

NOL49 $6.48000 E$ O3 40

$211.30 \quad 2.30-1 \quad 114.30 \quad 1.60-1$

$540.60 \quad 0.60 \mathrm{~m} 2 \quad 26 \% .605 .20 \mathrm{~m} 2$

$208.102 .50-2 \quad 74.302 .20-2$

$97.301 .30-2 \quad 58.901 .30-2$

$208.105 .90 \mathrm{~m} \quad 366.605 .70-3$

$294.005 .00 \mathrm{~m} \quad 311.104 .40-3$

$250.103 .30-3 \quad 384.702 .90-3$

$17 \% .80 \quad 1.40-3 \quad 126.60 \quad 1.00-3$

NOL5! 7.44000 E 0238

$110.00 \quad 2.22-1 \quad 1180.90 \quad 1.00-1$

$736.20 \quad .00-2 \quad 423.603 .60-2$

$724.201 .90-2 \quad 678.001 .50-2$

$90.001 .10-2 \quad 402.309 .60-3$

$565.207 .40-3 \quad 541.106 .50-3$

$81.80 \quad 3.30-3 \quad 239.50 \quad 3.00-3$

$149.50 \quad 2.20-3 \quad 206.10 \quad 2.10-3$

$29.101 .50 \mathrm{~m} \quad 1297.601 .30 \mathrm{~m}$

EU152 $4.16551 E$ oa 48

$170.40-1 \quad 344.31 \quad 2.45-1 \quad 1408.02 \quad 1.90-1$

$411.132 .00 \% 2 \quad 1099.73 \quad 1.70-2 \quad 1299.20 \quad 1.60-2$

$367.00 \quad .00-3 \quad 1005.15 \quad 6.00-3 \quad 1457.645 .00-3$

$678.61 \% .00 \mathrm{~m} \quad 586.344 .00-3 \quad 488.72 \quad 4.00-3$

$719.343 .00-3 \quad 1529.12 \quad 2.00-3$

$164.206 .00-3 \quad 963.361 .00-3$

$566.641 .00-3 \quad 503.501 .00-3$

$712.319 .00 \mathrm{~m} \quad 789.908 .00-4$

$251.627 .00-4 \quad 930.586 .00-4$

$\begin{array}{rr}656.40 & 1.50-2 \\ 53.91 & 9.00-4\end{array}$ $809.93 \quad 2.50-4 \quad 8 C 6.46 \quad 2.50-4$ $791.091 .70-41324.631 .20-4$

$270.109 .20-2$ $155.905 .20-2$ $198.90 \quad 1.20-2$ $262.405 .20-3$ $230.30 \cdot 4 \cdot 30-3$ $117.101 .00-3$

$255.707 .60-2$ $797.50 \quad 3.20-2 \quad 1122.603 .60-2$ $85.101 .40-2 \quad 739.201 .20-2$ $69.008 .70-3 \quad 914.20 \quad 8.20-3$ $658.604 .50-3 \quad 324.603 .30-3$ $238.70 \quad 3.00-3 \quad 183.10 \quad 2.50-3$ $199.702 .00-3$

$40.935 .00 \mathrm{~m}$ $99.953 .80-41388.006 .20-5$ $625.00 \quad 5.00-6 \quad 2655.00 \quad 4.00-7$

$440.308 .30-3$

$78.00 \quad 2.00-3$ $299.70 \quad 5.00-4$ $260.00 \quad 2.00-4$

$275.705 .70-3$ $595.701 .80-3$ $154.005 .00-4$ $232.002 .00-4$

$654.40 \quad 8.40-2$ $326.40 \quad 4.00-2$ $443.501 .30 \mathrm{~m} 2$ $556.40 \quad 1.00-2$ $275.205 .10-3$ $213.80 \quad 3.50-3$ $122.30 \quad 2.00 \mathrm{~m}$ $38.700 .0 \quad 0$

$423.508 .10-2$ $240.20 \quad 3.40-2$ $349.301 .30-2$ $245.80 \quad 8.90-3$ $192.00 \quad 5.10 \mathrm{~m} 3$ $301.40 \quad 3.30-3$ $630.201 .90-3$ $30.000 .0 \quad 0$

$175.10+.20-2$ $170.702 .30-2$ $300.601 \cdot 10-2$ $755.60 \quad 7.40-3$ $102.90 \quad 3.30 \mathrm{~m} 3$

$58.302 .40-3$ $197.201 .80-3$

$564.011 .32-11112.041 .24-1$ $967.33 \quad 3.80-2 \quad 443.98 \quad 2.90-2$ $1212.941 .30-2 \quad 688.68 \quad 8.00-3$ $564.08 \quad 5 . \mathrm{com}^{3} \quad 919.314 .00-3$ $295.97 \quad 4.00-3 \quad 810.42 \quad 3.00-3$ $1108.902 .00-3 \quad 926.232 .00-3$ $841.531 .00-3 \quad 674.681 .00-3 \quad 656.521 .00-3$ $416.06 \quad 1.00-3 \quad 329.41 \quad 1.00-3 \quad 1292.75 \quad 9.00-4$

$901.2 \mathrm{C} \quad 7.00-4 \quad 324.877 .00-4 \quad 271.05 \quad 7.00-4$ $520.30 \quad 5.00-4$ CU152A1 $3.34800 \mathrm{E}$ O4 48

$121.72 .20-1 \quad 34.312 .10-11400.021 .70-11112.041 .10-1$ $778.87 .00-1085.83 \quad 8.00-2 \quad 244.66 \quad 6.00-2 \quad 867.33 \quad 3.00-2$ $411.13 \quad 2.00-2 \quad 1299.201 .00-2 \quad 1212.94 \quad 1.00-2 \quad 1089.73 \quad 1.00-2$ $680.60 .00-3 \quad 1005.15 \quad 5.00 \mathrm{~mm} \quad 1457.64 \quad 4.00-3$ $564.064 .00-3 \quad 520.304 .00-3 \quad 919.31 \quad 3.00-3$ $295.97 \quad 3.00-3 \quad 1528.12 \quad 2.00-3$

$926.23 \quad 2.00-3$

$676.614 .00 \mathrm{~m}-3$

$719.343 .00-3$

$964.011 .10-1$ $443.98 \quad 2.00-2$ $367.807 .00-3$ $586.34 .4 .00-3$ $488.723 .00-3$ $810.42 \quad 2.00-3 \quad 1249.911 .00-3$

56.4

58.5

58.6

50.7

58.8

59.1

59.2

59.3

59.4

59.5

59.6

59.7

59.8

60.1

60.2

60.3

60.4

60.5

60.6

60.7

60.8

61.1

61.2

$61 \cdot 3$

61.4

61.5

61.6

61.7

61.8

62.1

62.2

62.3

62.4

62.5

62.6

62.7 62.8 63.1 63.2 63.3 6.3 .4 63.5 63.6 63.7 63.8 64.1 64.2 $64-3$ 64.4 64.5 $64 \cdot 6$ 
Table A-3. Comprnued

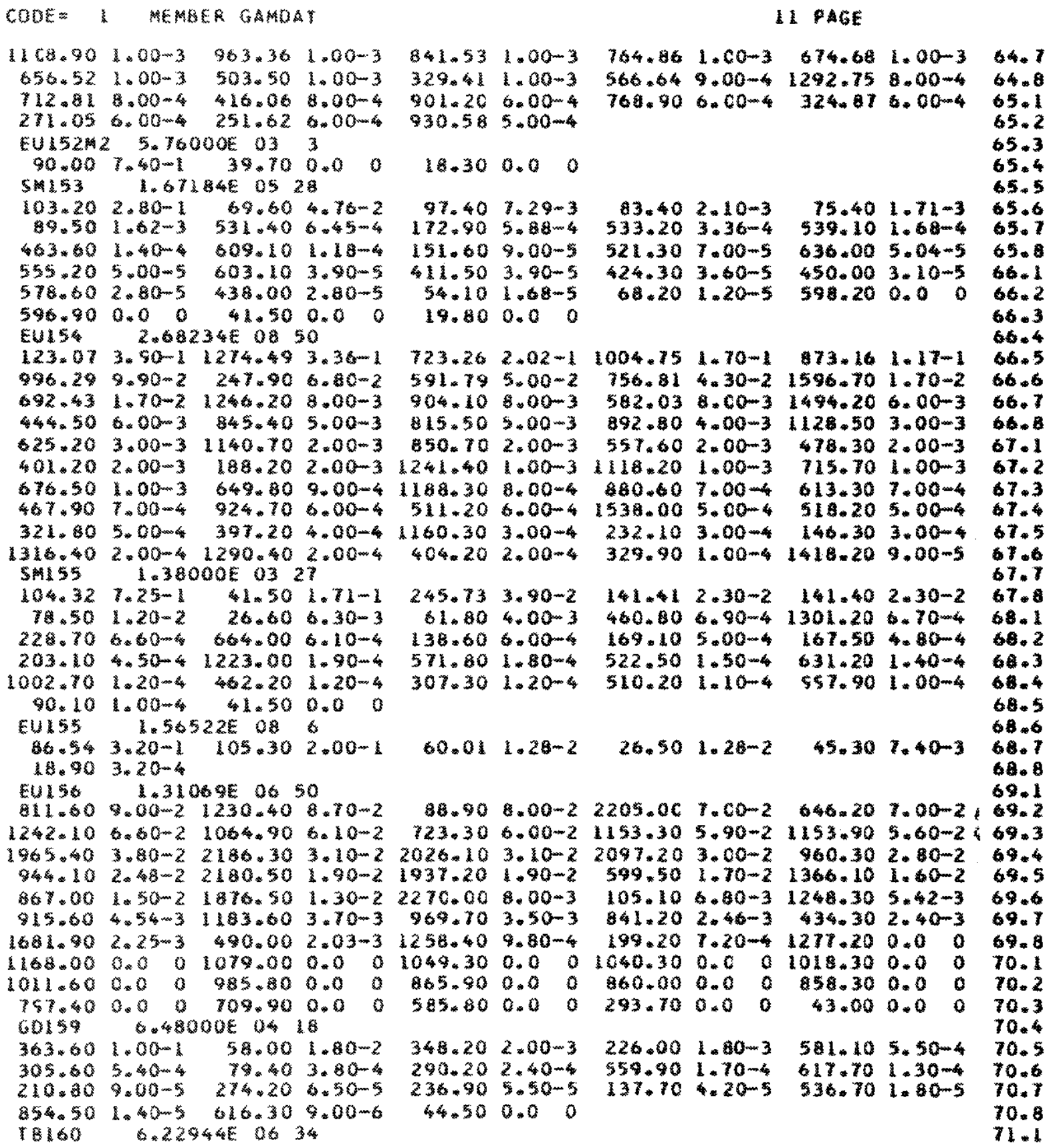


Table A-3. Continued

COD勧 I I MEMER GAMOAT

12. PAGE

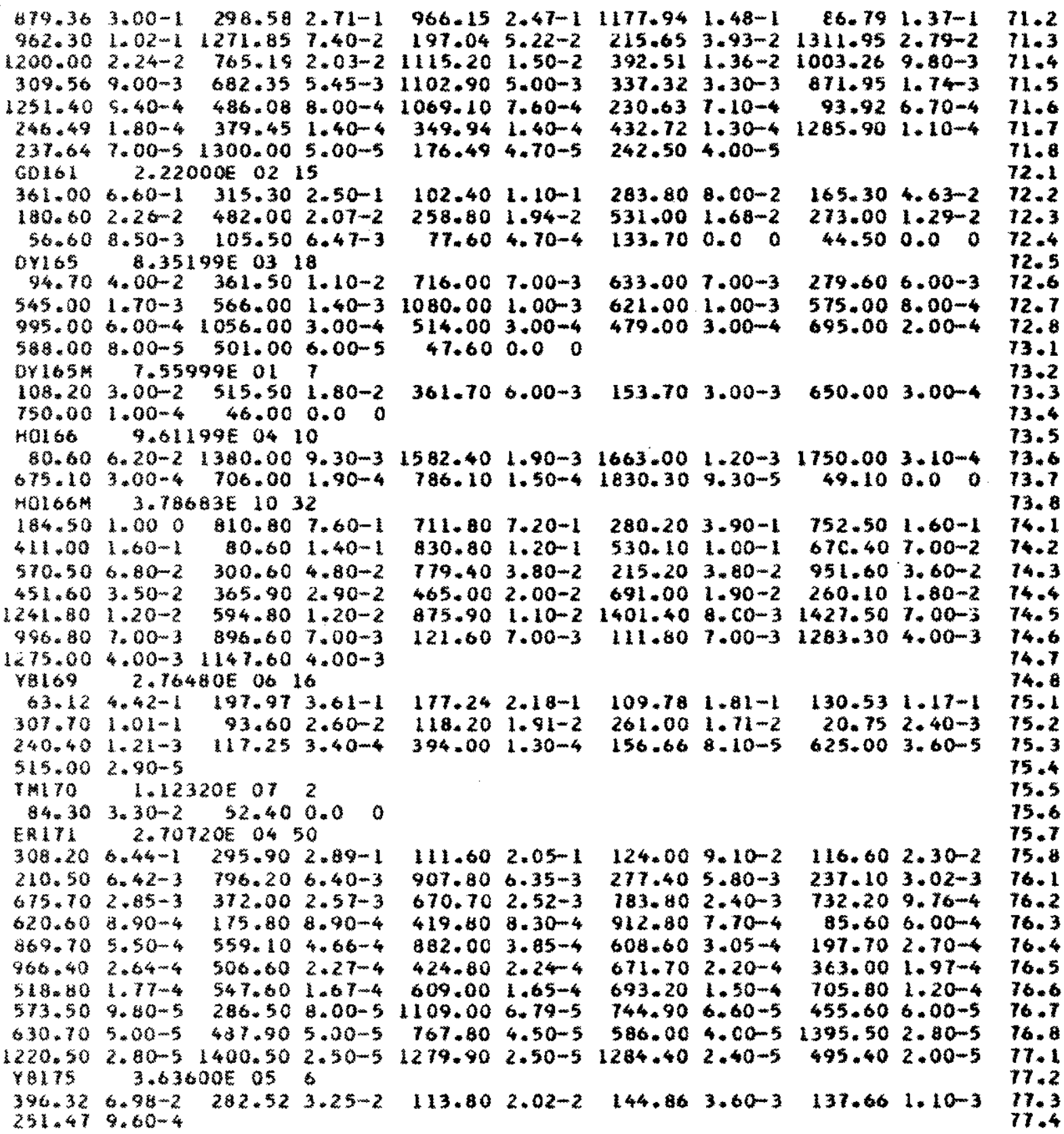




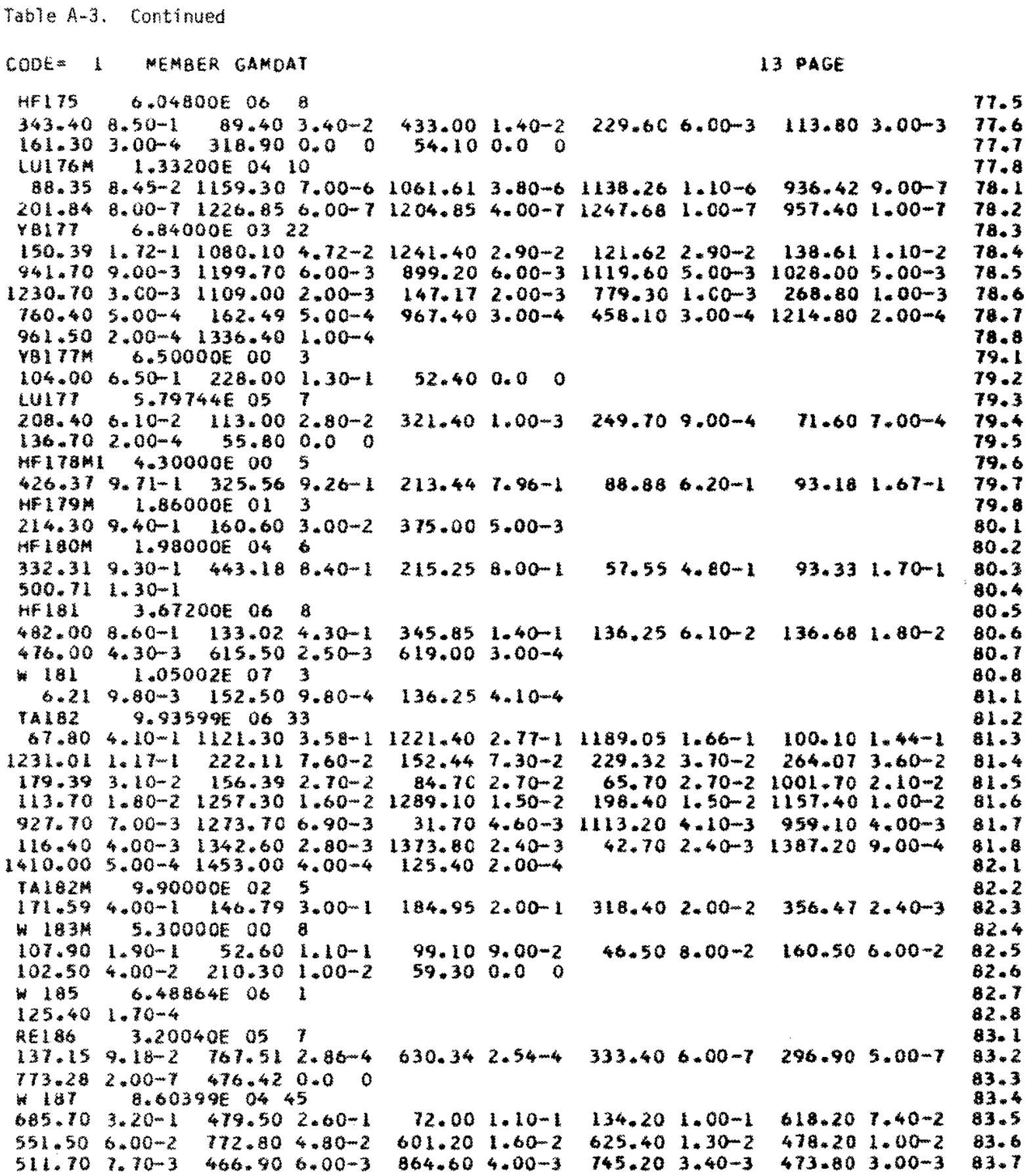


Table Aw3. Continuad

CODE\# I MEMBER GAMCAT

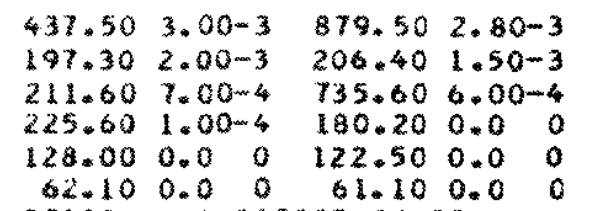

QE188 $6.01200 \mathrm{E} 0435$

$155.001 .000-1633.009 .00-3$

$1610.00 \quad 7.00 \mathrm{~m} 41132.806 .0004$

$195 \% .00 \quad .00 \mathrm{~m} 41786.001 .00-41457.001 .00-4$

$967.001 .00-481.001 .00-4$

$1191.00 \quad 8.00-5 \quad 93.00 \quad 8.00-5$

125. $.00 \quad 4.00 \mathrm{~m} 5 \quad 1230.00 \quad 4.00 \mathrm{~m}$

RE $198 \%$ 1.12200E 036

$6.603 .00-1 \quad 106.002 .10-1$

1.100 .00

$05191 \quad 1.33056 \mathrm{E} 004$

$129.401 .000 * 47.051 .50 \mathrm{~m} * 82.431 .00-3 * 41.850 .00$

OS191M $4.69080 \mathrm{E}$ O4

74.380 .00

IR192 6. 39533E 0622

$316.508 .31-1$ 468.06 $4.76-1$

$612.455 .18-2 \quad 588.574 .44=2$

$416.466 .60-3 \quad 201.314 .96-3$

$136.351 .33-3 \quad 1061.604 .80-4$

$1090.401 .30-5 \quad 1378.50 \quad 1.00-5$

$1 \mathrm{R} 192 \mathrm{A1} 8.51999 \mathrm{E}$ o1 4

$58.00 \quad 3.92-4 \quad 316.501 .01 m$

$0 \$ 193 \quad 1.13400$ os 50

$64.90 \quad 6.32-2 \quad 138.894 .27-2$

$557.361 .30-2 \quad 73.58 \quad 1.30-2$

$106.80 .40-3 \quad 75.635 .140-3$

$251.62 \quad 2.17-3 \quad 181.811 .94-3$

$268.79 .4 .2-3 \quad 96.829 .90-4$

$234.50 .10-154.743 .00-4$

$420.301 .66-4 \quad 524.981 .60-4$

$48.11 .1000435 .709 .90-5$

$41.355 .50-5$ 413.904.70-5

$65.12 \quad 2.90-5 \quad 333.302 .80-5$

In $194 \quad 6.983995 \quad 0443$

$320.50 \quad 1.30-1 \quad 293.55 \quad 2.80-2$

$930.875 .70-3 \quad 300.713 .50-3$

$589.391 .50-31622.406 .90-4$

$482.835 .90-41218.905 .80-4$

$308.452 .98-1$ $205.793 .36-2$

$489.043 .96-3$

$176.98 \quad 1.00 \mathrm{~m} 4$

$295.952 .91-1$ $484.57 \quad 3.17-2$

$684.522 .74+3$

$110.096 .60 \mathrm{~m}$

$295.952 .15-5 \quad 612.45 \quad 3.50 m 6$

$460.493 .95-2$

$321.56 \quad 1.26-2$

$559.26+.86-3$

$298.831 .86-3$

$532.028 .30-4$

$874.361 .90-4$

$712.101 .54-4$

$440.959 .20-5$

$197.40 \quad 4.70-5$

$201.50 \quad 2.80-5$

$045.321 .13-2 \quad 1150.866 .00-3$ $622.05 \quad 3.10-3 \quad 1183.63 \quad 2.90-3 \quad 1469.22 \quad 1.80-3$ $593.726 .80-4 \quad 509.706 .50-4 \quad 890.306 .40=4$ $1175.425 .70-4 \quad 364.97 \quad 5.00-4 \quad 1293.904 .60-4$ $699.00 \quad 3.60-41512=40 \quad 3.40-4$

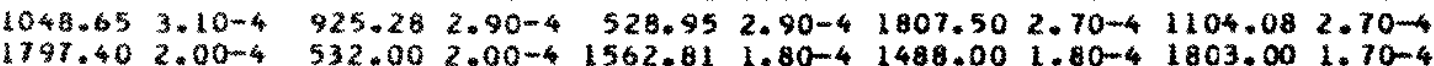

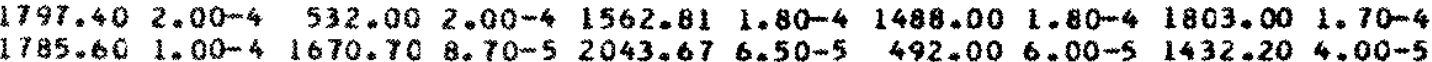
$2114.203 .00 m 51924.332 .90-5 \quad 1832.002 .60-5$

prissM $3.47328 E 0510$
$604.408 .07-2$ $374.48 \quad 7.39-3$ $263.26 \quad 2.29-3$ $280.033 .30-5$

$\$ 30.106 .00-3$

14 PAGE

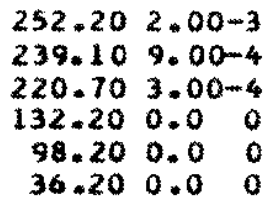

63.8

84.1

64.2

84.3

04.4

84.5

84.6

84.7

84.6

85.1

85.2

85.3

85.4

0.5.5

85.6

85. 7

85.8

a. 1

86.2

86. 3

86. 4

86. 5

86.6

86. 7

86. 8

a7. 1

87. 2

87.3

27.4

87.5

67.6

87.7

97.8

8. 1

ad. 2

88. 3

88.4

88. 5

88.6

BB. 1

88.8

89. 1

89.?

69.3

89.4

69.5

69.6

89.7

99.8

90.1

90.2 
Table A-3. Continued

COOE I MEMBER GAMDAT

I5 PAGE

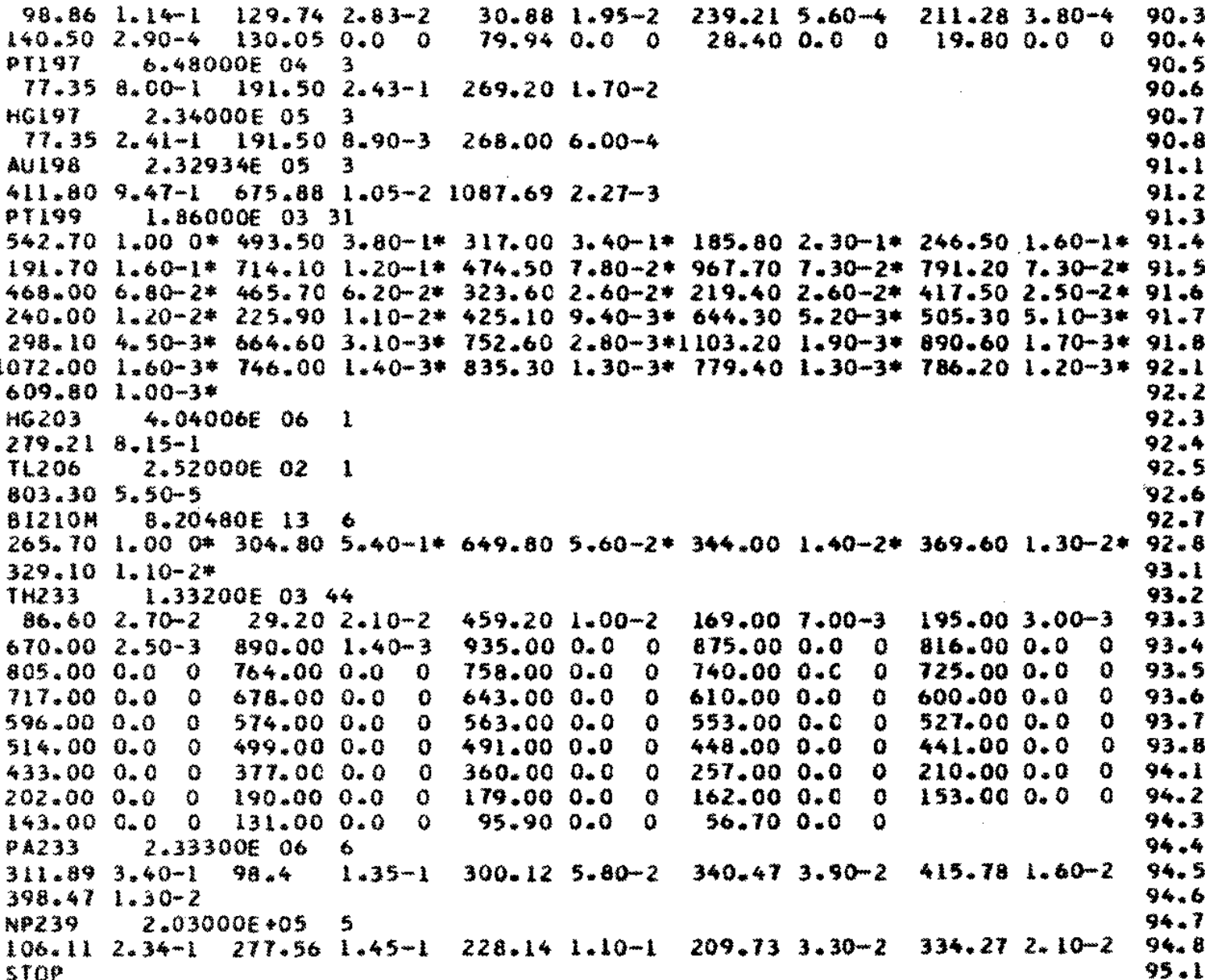


Table A-4. Fux File

CODE I MEMBE FUUKF

1 PAGE

$003.480 E-036.20 E-03$ g4 RING 1 100MO $252 \mathrm{CF}$ SOURCE $3.696 E-059.837 E-05$ L.937E-04 $2.956 E-04 \quad 3.925 E-04 \quad 4.762 E-044.475 E-04$ $4.44 \mathrm{gE}-04 \mathrm{4} .120 E-043.737 E-043.823 E-C 4$ 3.101E-04 2.329E-04 2.781E-04 $2.301 \mathrm{E} m 04 \quad 1.990 \mathrm{E}-04 \quad 1.777 \mathrm{E}-04 \quad 1.605 \mathrm{E}-04 \quad 1.459 \mathrm{E}-04 \quad 1.323 \mathrm{E}-042.477 \mathrm{E}-04$

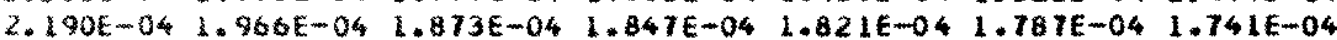
$1.700 E-041.670 E-041.638 E-04 \quad 1.605 E-04 \quad 7.753 E-05 \quad 7.700 E-05 \quad 7.619 E-05$ $7.537 \mathrm{E}-057.455 \mathrm{E}-05 \quad 7.373 \mathrm{E}-05 \quad 7.291 \mathrm{E}-05 \quad 7.209 \mathrm{E}-05$ 7.127E-05 7.046E-05 $0.968 E \sim C 5$ 6. 886E-05 6. 806E-05 6.727E-C5 6.649E-05 6.571E-05 6.445E-05 $6.405 E-05$ 6.398E-05 6.110E-05 7.325E-05 1.420E-05 S.689E-05 5.721E-05 $5.646 E-05 \quad 5.530 E-05 \quad 5.640 E-05 \quad 6.464 E-05 \quad 7.930 E-05 \quad 1.231 E-04 \quad 1.861 E-04$ $2.660 E-04 \quad 3.521 E-04 \quad 4.761 E-04 \quad 5.852 E-04 \quad 6.734 E-047.282 E-047.434 E-04$ $0.027 E-048.371 E-048.413 E-04 \quad 8.121 E-04 \quad 7.500 E-04 \quad 6.592 E-045.474 E-04$ $4.25 I E-043.043 E-04 \quad 1.963 E-04 \quad 1.099 E-044.968 E-05$ 1.548E-05 $2.000 E-06$ $101.370 E-031.990 E-03$ 84 RING 2 LOOMG $252 \mathrm{CF}$ SOURCE

$3.696 \mathrm{E}-05 \quad 9.837 \mathrm{E}-05 \quad 1.937 \mathrm{E}-04 \quad 2.956 \mathrm{E}-04 \quad 3.925 \mathrm{E}-04 \quad 4.762 \mathrm{E}-04 \quad 4.475 E-04$ $4.448 E-04 \quad 4.120 E-04 \quad 3.737 E-04 \quad 3.823 E-C 4 \quad 3.101 E-04 \quad 2.329 E-042.781 E-04$ $2.301 E-04 \quad 1.990 E M 04 \quad 1.777 E-04 \quad 1.605 E-04 \quad 1.459 E-04 \quad 1.323 E-04 \quad 2.477 E-04$ $2.190 E-04 \quad 1.966 E-04 \quad 1.873 E-04 \quad 1.847 E-04 \quad 1.821 E-04$ i.787E-04 $1.741 E-04$ 1.700E $-04 \quad 1.070 E-04 \quad 1.638 E-04 \quad 1.605 E-047.753 E-05 \quad 7.700 E-05 \quad 7.619 E-05$ $7.337 E-05 \quad 7.455 \mathrm{E}-05 \quad 7.373 E-05 \quad 7.291 \mathrm{E}-05 \quad 7.2 C S E-05 \quad 7.127 \mathrm{E}-05 \quad 7 . C 46 E-05$

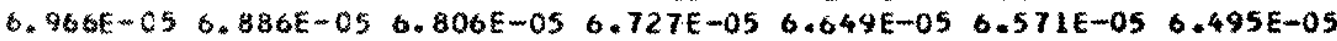
$6.405 E-03$. $398 E-056.110 E-05 \quad 7.325 E-C 5$ 1.420E-05 $5.699 E-05 \quad 5.721 E-05$ $5.046 E-C 5 \quad 5.530 E-05 \quad 5.640 E=05$ 6.464E-05 7.930E-05 $\quad$ L.23LE-04 $1.861 E-04$ 2. $00 E-043.521 E-044.761 E-045.852 E=04 \quad 6.734 E-04 \quad 7.2 B 2 E-04 \quad 7.434 E-04$ $8.027 E-0.8 .371 E-048.413 E-04 \quad 8.121 E-04 \quad 7.5 C C E-046.592 E-045.474 E-04$ $4.25 I E-C 43.043 E-0.41 .963 E-04 \quad 1.099 E-04 \quad 4.968 E-05 \quad 1.548 E-05 \quad 2.000 E-06$ sषy

1.1

1. 2

1.3

1.4

1.5

1.6

1. 7

1. $y$

2.1

2.2

2.3

2. 4

2.5

2.6

2.7

2.8

3.1

3.2

3.3

3.4

3.5

3.6

3.7

3.8

4.1

$4 \cdot 2$

$4 \cdot 3$ 
Table An5. Cross Section file

COOE 1 MEMBER SIGMAF

1 PAge

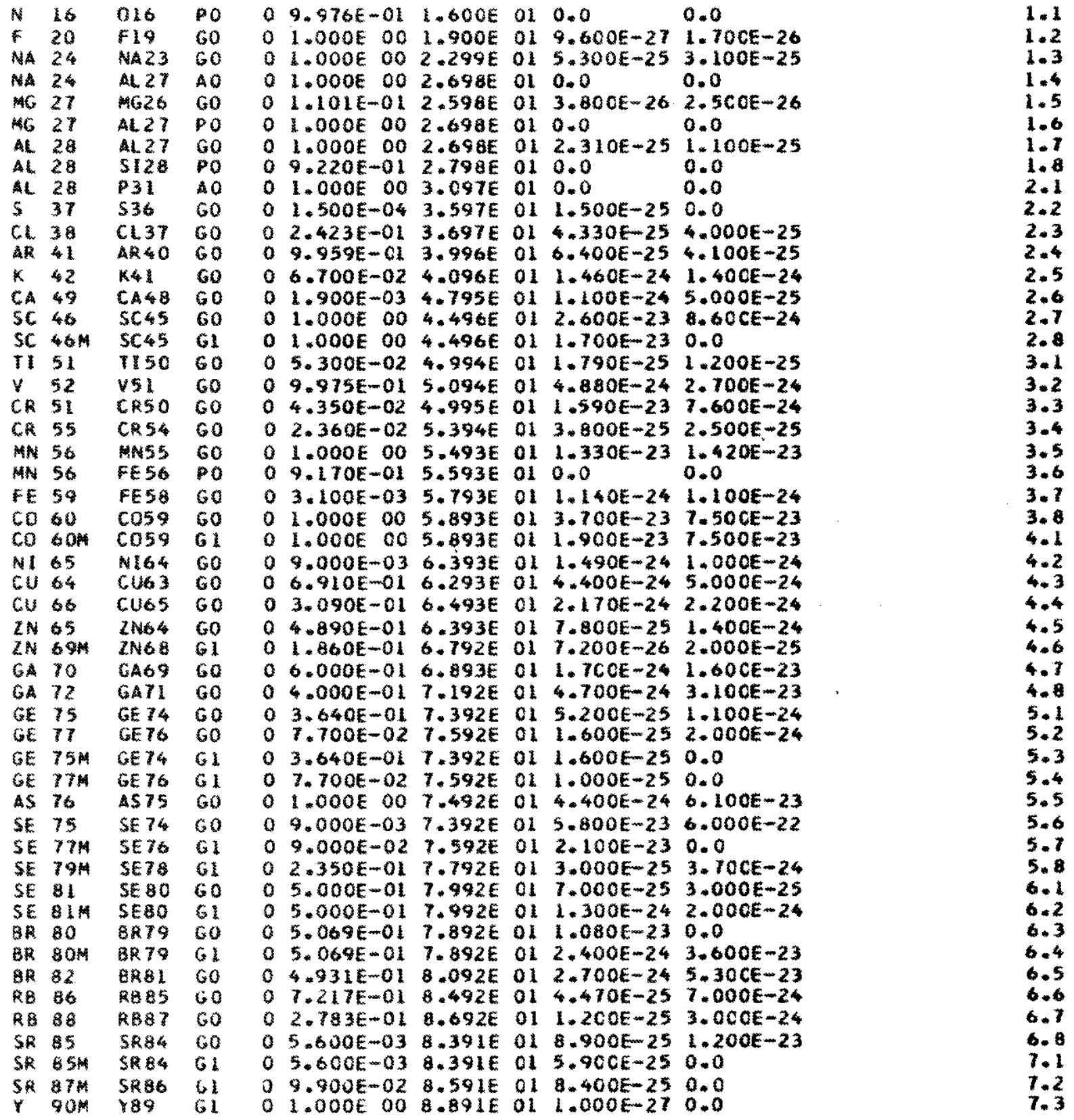


Table A.5. Continued

GOOE 1 HEMBLE SIGMAF 2 PAGE

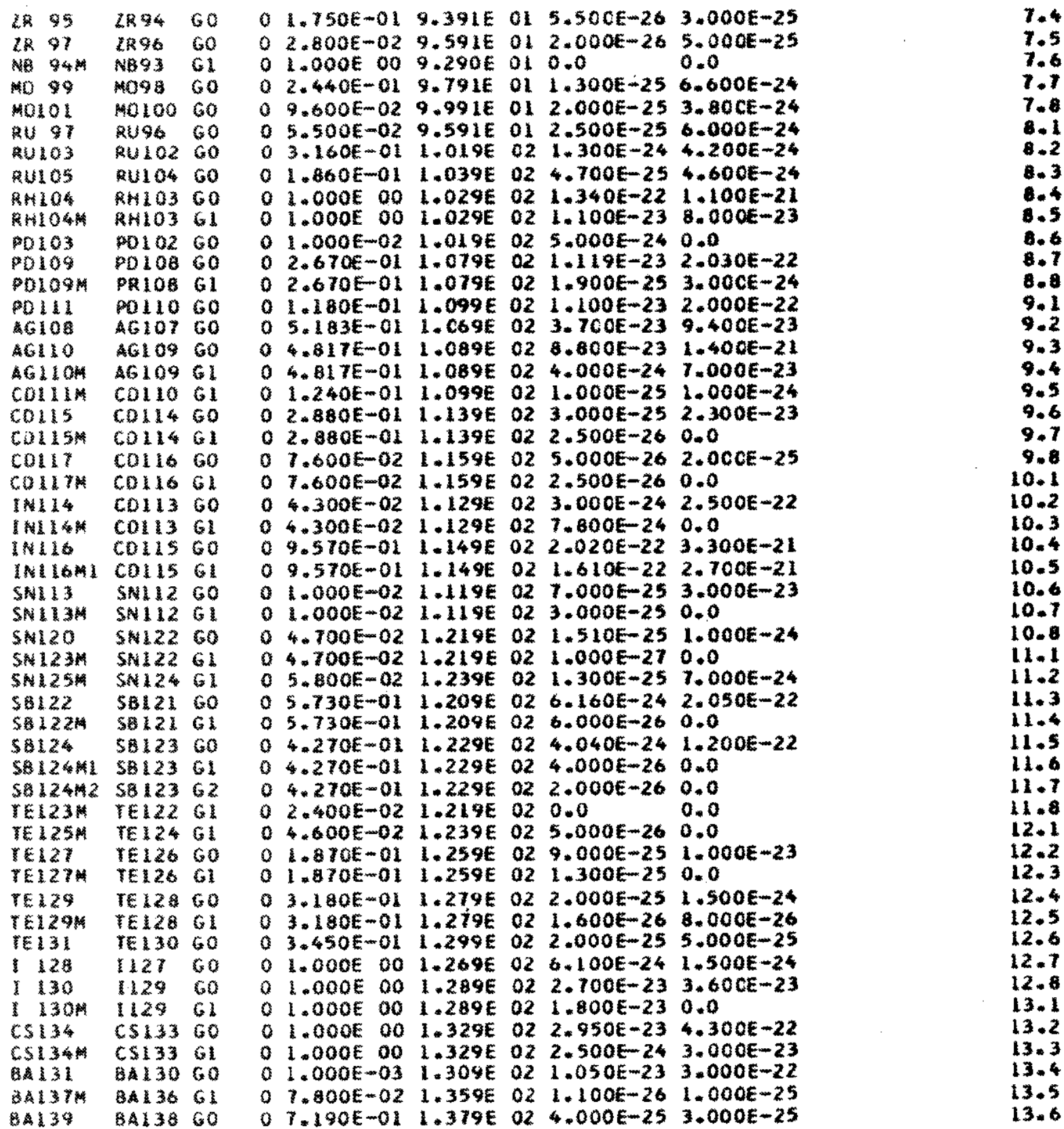


Table A.5. Continued

COOE 1 MEMBER SLGMAF 3 PAGE

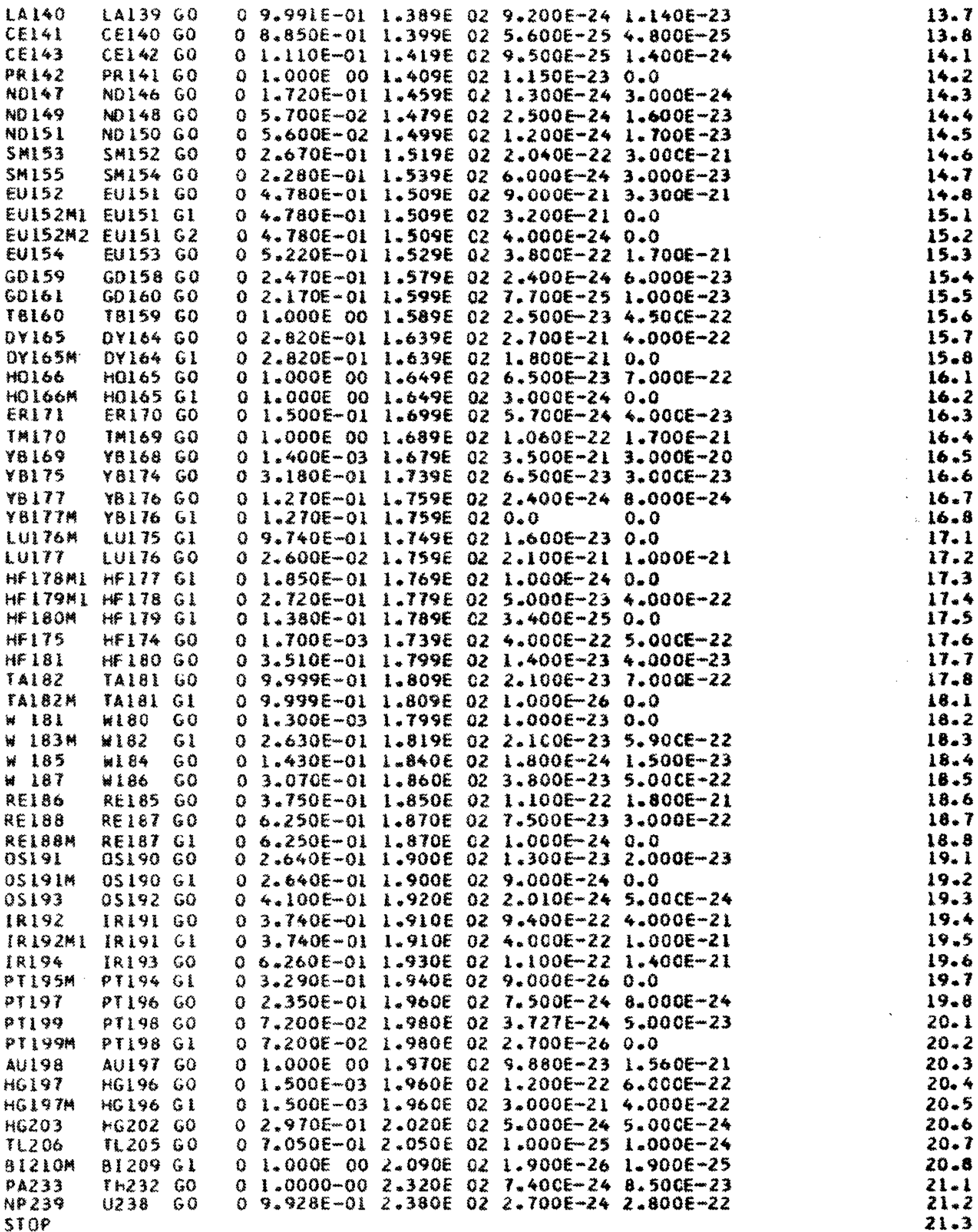


Table A-6. EFFCAL Data File

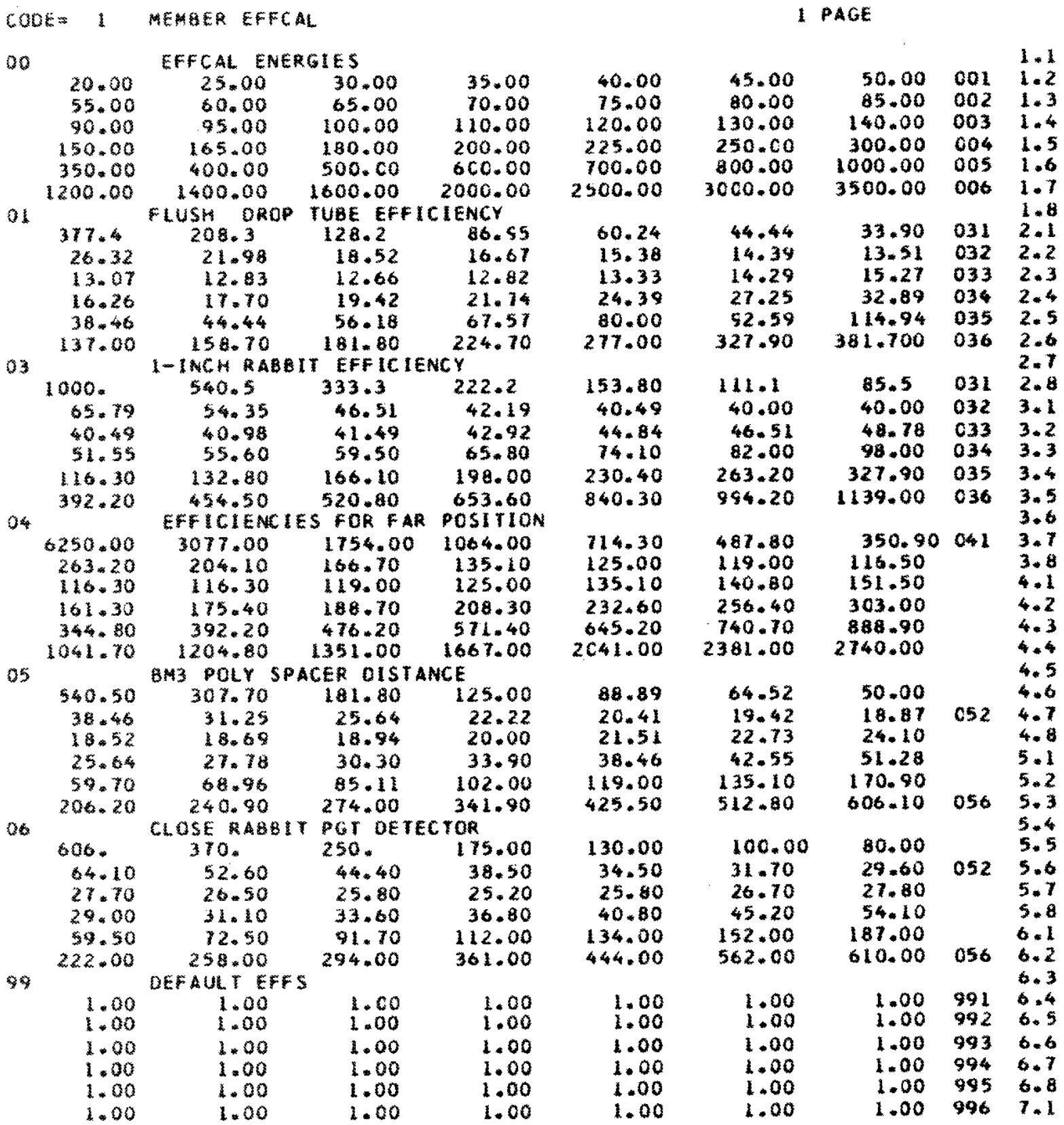


Table A-7. SIFteg output

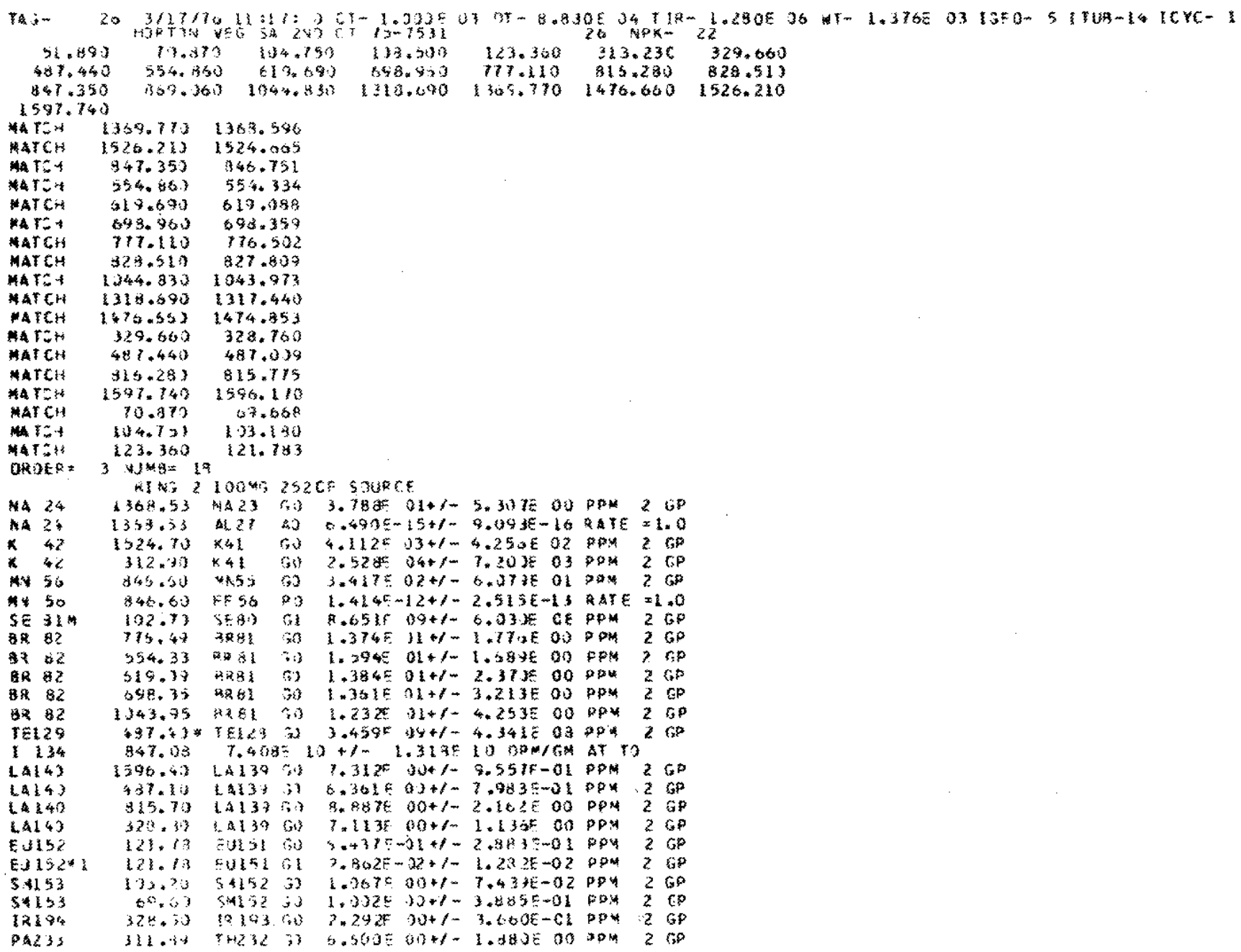


Table A-7. Continued

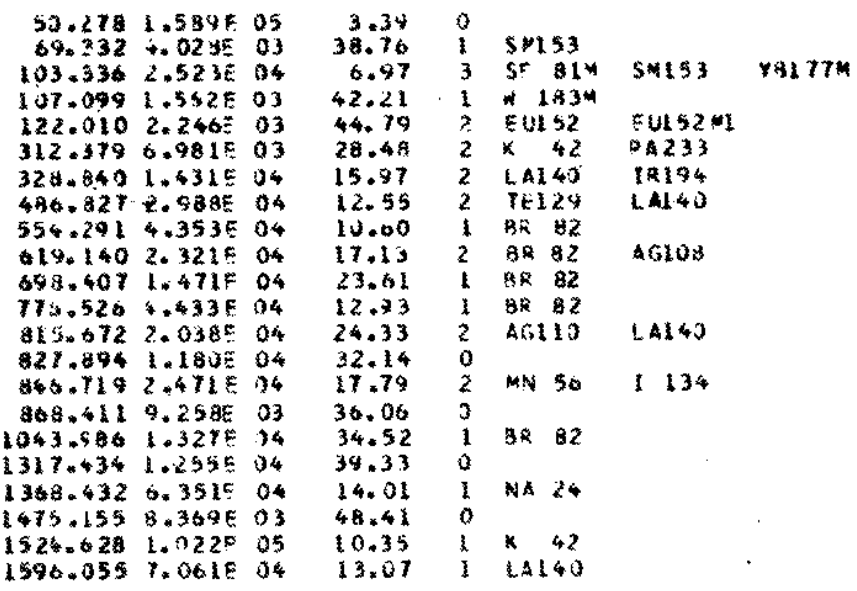


The gold wires used in the flux mapping experiments in the 17 -mg ${ }^{252} \mathrm{Cf}$ activation facility were $20 \mathrm{mil}$ in diameter and $1 / 2$ inch length; each weighed about $50 \mathrm{mg}$. Both bare wires (surm rounded completely by $\mathrm{H}_{2} \mathrm{O}$ and polyethylene) and wires within cylindrical cadmium pillboxes $(30$ mil-thick) were activated at seven different distances from the ${ }^{252} \mathrm{Cf}$ source. Because of the thickness of the wires, a correction factor for both thermal and epithermal (resonance) flux depression was requixed.

The flux depression factor is defined here as the measured specific activity of the wire relative to the specific activity of a wire of infinitely sma1l diameter. In calculating this factox, the wire of radius $R$ was assumed to be activated in the same mannex as a foil of thickness $R$. Thermal flux depression factors for these experiments were calculated for a thick $\mathrm{l} / \mathrm{v}$ detector in a Maxwellian spectrum. Resonance flux depression factors were calculated for both cadmium-covered $1 / \mathrm{V}$ detector foil and for a thick detector foil with Dopp1er-broadened resonance in an isotropic $1 / \mathrm{E}$ flux.

\section{THERMAL FLUX DEPRESSION}

The themal flux depression factor was calculated according to the method of Baumann. For a slab $1 / \mathrm{V}$ detector such as gold in an isotropic Maxwellian flux, the thermal flux depression factor, $F$, is given by

$$
F=\frac{1-2 \mathrm{~K}_{3}\left(\mathrm{~K} Y_{0}\right)}{2 \mathrm{~K} Y_{0}}
$$

$Y_{0}$ is the product of the atom density of the foil per unit area and the microscopic absorption cross section per atom. $Y_{0}$ thus expresses the foil thickness in units of absorption mean free paths evaluated at the most-probable velocity of the incident flux. The effective foil thickness ${ }^{29}$ is $\mathrm{KY}_{\mathrm{O}}$ and allows the Maxwellian average flux depression value to be expressed in terms of equivalent monoenergetic cross sections which would give identical flux depression values. The $E n(x)$ mathematical functions are defined in Reference 20 . For the particular conditions in this experiment, 
$Y_{o}=(0.0254 \mathrm{~cm})\left(19.32 \mathrm{~g} / \mathrm{cm}^{3}\right) \frac{6.022 \times 10^{23}}{196.97 \mathrm{~g}}\left(98.8 \mathrm{~cm}^{2}\right)=0.148$

and, from Reference 19

$K=1.045$ so that $E=0.379$ at $\left(K Y_{0}\right)=0.155$

Solving for the thermal flux depression factor,

$$
F=\frac{1-2(0.379}{2(0.155)}=0.781
$$

\section{RESONANCE FLUX DEPRESSION}

The cadmium cutoff energy, $\mathrm{E}_{\mathrm{C}}$, an activated gold cadmium 30-mil-thick wier inside a cylindxical pillbox is calculated from Reference 20 for $2 / 3$ beam and $1 / 3$ isotropic flux to be

$$
\begin{aligned}
& E_{\mathrm{c}}=\frac{2}{3} E_{\mathrm{c}}(\text { beam })+1 / 3 E_{\mathrm{C}}(150)= \\
& 2 / 3(0.475)+1 / 2(0.625)=0.52 \mathrm{eV}
\end{aligned}
$$

The gold absoxption cross section in the resonance region may be considered to be $1 / V$ upon which large resonances are superimposed. Therefore, $R I$ total $=R_{1 / V}+R_{\text {res }}$ *

This cutoff is actually not sharp, and the cadmium itself shields some of the epithermal resonances of the gold cross section. A correction factor given by Martin ${ }^{20}$ for this effect is about $1 \%$.

Calculation of the resonance flux depression factor $F$ includes depression factors for the $1 / \mathrm{V}$ portion $\mathrm{F} 1 / \mathrm{V}$ of the epi thermal cross section and for 48 separate resonances, Fres. The epithermal activation of gold is dominated by the large resonance at $4.90 \mathrm{ev}$. The method of Baumann ${ }^{39}$ was used in these calculations. for the case of thick resonance detector foils in an $1 / \mathrm{E}$ isotopic flux, the effect of Doppler broadening is included by the paraneter

$$
\theta=\frac{4 E_{m} E_{O}}{A \Gamma^{2}}
$$

where

$$
\begin{aligned}
& \mathrm{E}_{\mathrm{n}}=\text { the temperature of the absorber (in electron volts), } \\
& \mathrm{E}_{\mathrm{O}}=\text { the resonance energy, } \\
& \mathrm{F}=\text { the total resonance width, and }
\end{aligned}
$$



$A=$ the ratio of the mass of the absorber atom to that of the neutron.

The changes in resonance flux depression factors $F$ with foil thickness $Y_{0}$ in absorption mean free paths at the peak of the resonance have been reported for different values of $\theta$. The total resonance integral is the sum of $1 / v$ portion, $R 1 / v$ plus the contributions of each individual resonance ERIres. The resonance integral for each resonance is found from the peak absorption cross section onax and from reported resonance paraneters. ${ }^{21}$

$$
R_{\text {res }}=\frac{\pi \sigma_{\max } \Gamma_{Y}}{2 \mathrm{E}_{\mathrm{O}}}
$$

where

$$
\sigma_{\max }=\frac{2.6036 \times 10^{6}}{E_{0}} \frac{\Gamma_{Y} \Gamma_{Y}}{\Gamma^{1}} g
$$

The average epithermal flux depression factor $\vec{F}$ for the gold wire was found to be 0.1446 from

$$
\tilde{F}=\frac{(\mathrm{RI})_{i} \mathrm{Fi}_{\text {res }}+\mathrm{RI}_{1 / v} \mathrm{~F}_{1 / v}}{(\text { all resonances })(\mathrm{RI} \text { total })}
$$

Individual resonance integral and flux depression contributions to the total resonance integral and to the average flux depression factors are sumnarized in Table 2 .

The $1 / \mathrm{V}$ flux depression factor was calculated for a $1 / \mathrm{V}$ detector in an isotropic $1 /$ E flux from

$$
F^{N / N}=\frac{1-2 E_{3}\left(K Y_{O} / 2\right)}{K Y_{O}}=0.95
$$

Because, $Y_{0}=0.0325$,

then $K=0.956(2 / 3$ beam $+1 / 3$ isotropic $)$

and $K X_{0}=0.0311$

Interpolating from Table $1^{22}$ gives $E_{3}=0.4852$

The $1 / \mathrm{V}$ portion of the resonance integral is given by

$$
R I_{1 / v}=\int_{0.525 \mathrm{ev}}^{10 \text { Mev }} \sigma_{2200} \frac{\sqrt{\mathrm{E}_{2200}}}{\mathrm{E}} \frac{\mathrm{dE}}{\mathrm{E}}=43 \text { barns }
$$




\section{REFERENCES}

1. R. Hofstader. "Alkall Halide Seintillation Counters." Phys. Rev. 74, 100 (1948).

2. D. V. Freck and $J$, Wakefield. "Gamma-Ray Spectrum obtained with a Lithium-Drifted Junction in Germanium." Nature 193, 669 (1962).

3. W. L. Lyon. Anat. Chen. 45, 386A (1973).

4. W. W. Exgle. A Oneminensional Disorete Ordinates Transport Code with Anisotopio Soattering. USAEC Report K-1693, Union Carbide Nuclear Division, Oak Ridge, TN (1967).

5. M. K. Drake. Data Foxmats and Procedures for the ENDE Neutron Crose Section Library, ENDF-102, Vol. 1, USAEC Report BNL-50274, Brookhaven National Laboratory, Upton, NY (1970).

6. W. W. Bowman and K. W. Mackurdo. "Radjoactive Decay Gamma Ordered by Enexgy and Nuclide." Atomic and Nuctear Data mables 73 (No. 2-3) (1974).

7. Chort of the Nuelides, General Electric Co., Schnectady, NY $(1972)$.

8. G. Rudstram and F. Lund. "Delayed Neutron Activities Produced in Fission: Mass Range 79 98." Phys. Rev. C13, $321(1976)$.

9. G. Ruacham, S. Shalev, and O. Johnson. "Delayed Neutron Emission from Separated Fission products." Mucz. Instrom. Methods 720, 33 (1974).

10. M. Asghar, J. Crancon, J. Gautheron, and C. Ristori. "Delayed Neutron Emission Probabilities of $92,{ }^{3} \mathrm{Kr}, 92,93 \mathrm{Rb}$,

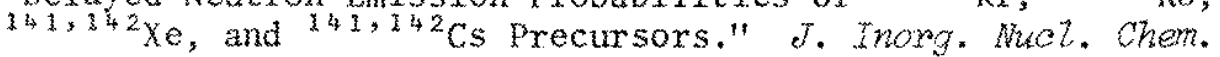
$37,1563(1975)$.

11. G. Fudstran and S. Shalev. "Energy Spectra of Delayed Neutrons from Separated Fission Products." Whe . Phys. Aa35, $397(1974)$.

12. G. R. Keepin. Physics of Motear Kinetios, p. 82, 86, 90, 146. Addison-Wesley, Reading MA (1965). 
13. E. J. Onega, P. W. Forbes, A. K. Furr, and A. Robeson. "The Measurement of Short-lived Delayed Photoneutrons from Fission-Fragment Gamma Rays." Trans. Am. Mucl. Soc. 12, 289 (1969); see also NucZ. Soi. Eng. 32, 49 (1968).

14. W. W. Graham, III, D. S. Harmer, and C. E. Cohern. "Accurate Delayed-Neutron Parameter Measurements in a HeavymWater Reactor." Ancl. Soi. Eng. 38, 33 (1969).

15. J. P. Church. "Evaluation of Published Delayed-Neutron Parameters for Uranium-235 and Uranium-235 Heavy Water Systems." Wuct. Sei. Eng. 43, 229 (1971).

16. W. W. Bowman. "Rapid Analysis of Germanium Spectra." Nuc2. Instmun. Methods 96, 135 (1971).

17. Savamah Fiver Laboratory Quarterly Report. Hydrogeochemical and Stream Sediment Reconnaissance - Eastem United States National Uranizm Resource Evaluation Program. Report DPST -76-138-3, Savannah River Laboratory, E. T. du Pont de Nemours \& Co., Aiken, SC (1976).

18. N. p. Baumann. Resonance Integrals and Self Shielding Factors for Detector Foils. USAEC Report DP-817, Savannah River Laboratory, E. I. du Pont de Nemours \& Co., Aiken, SC (1963).

19. N. P. Baumann and M. B. Stroud. "Self Shielding of Detector Foils in Reactor Fluxes." Mucleonies 23 (8), 98 (1965).

20. D. H. Martin. "Correction Factors for Cd-CoveredmFoil Measurements." Wucleonios 13 (3), 52 (1955).

21. Neutron Cross Sections, Vol. I, Resonance Parameters. USAEC Report BNL-325, Third Edition, Brookhaven National Laboratory, Upton, NY (1973). 